ESCUELA TÉCNICA SUPERIOR DE INGENIERÍA AGRONÓMICA, ALIMENTARIA Y DE BIOSISTEMAS

\title{
VIRULENCE CHARACTERIZATION OF AVIAN ENTEROCOCCUS FAECALIS FIELD ISOLATES AND GENETIC APPROACH TO SELECT MORE RESISTANT LAYING HENS
}

TESIS DOCTORAL

Ana Estefanía Blanco García

Ingeniero Agrónomo 

UNIVERSIDAD POLITÉCNICA DE MADRID

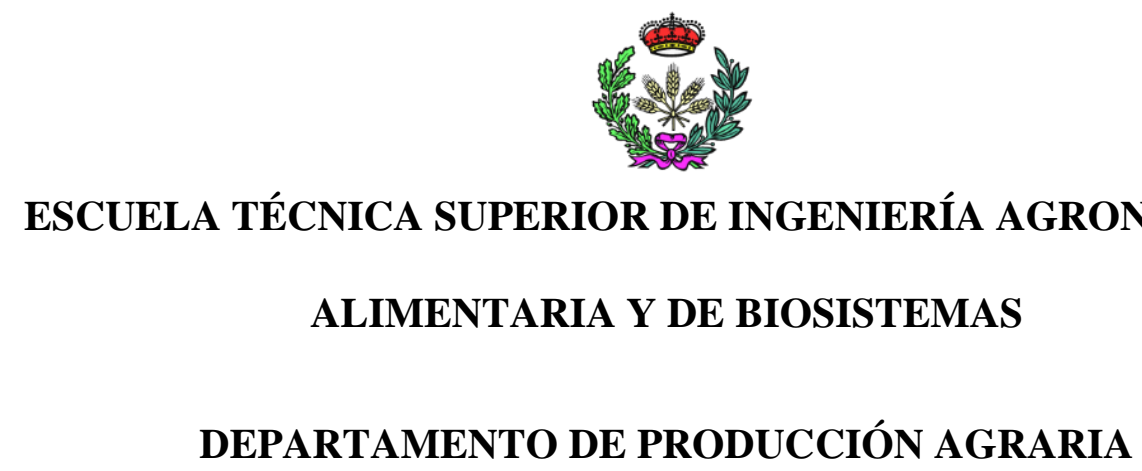

TESIS DOCTORAL

\title{
VIRULENCE CHARACTERIZATION OF AVIAN ENTEROCOCCUS FAECALIS FIELD ISOLATES AND GENETIC APPROACH TO SELECT MORE RESISTANT LAYING HENS
}

\author{
Ana Estefanía Blanco García \\ Ingeniero Agrónomo \\ Director de Tesis \\ Director de Tesis \\ D. Carlos Buxadé Carbó \\ D. Rudolf Preisinger \\ Prof. Dr. Dr. Ingeniero Agrónomo \\ Prof. Dr. Ingeniero Agrónomo
}


"The scientific man does not aim at an immediate result.

He does not expect that his advanced ideas will be readily taken up.

His work is like that of the planter-for the future.

His duty is to lay the foundation for those who are to come, and point the way"

Nikola Tesla

A mi familia 


\section{ACKNOWLEDGEMENTS}

This dissertation would not have been possible without the guidance and the support of several persons. It is a pleasure to convey my gratitude to them all in my humble acknowledgment.

First and foremost, I offer my utmost gratitude to my supervisors for believing in my capabilities and their advice, guidance and unconditional support. Carlos, thanks for your friendship and for motivating me to reach the goals that I set for my life and all you have taught me. Prof. Preisinger, thanks for the election of the interesting topics of this dissertation, your good advice and for letting me present the dissertation results at national and international seminars and conferences.

I thank Dr. Sharifi for your valuable contributions in the statistical analysis. Your experience and knowledge have contributed to the success of this work. Dr. Cavero and Dr. Icken, thank you so much for your tireless support and suggestions, as well as your patience and understanding through difficult times.

I want to acknowledge my dear colleagues, Dr. Schmutz, Dr. Voß, Dr. Barz und Dr. Mazaehri for your kind attention, your constructive comments as well as for your always friendly and positive attitude during discussions.

The most important experience during my $\mathrm{PhD}$ has probably been my stay in the Lohmann Tierzucht GmbH "family". The great working environment you breathe and your interest in the progress of my dissertation have been a great motivation to provide the best of me. Thanks to you all.

I thank also the company Lohmann Tiertucht $\mathrm{GmbH}$ for the financial and technology support.

Finally, I want to thank my boyfriend Alberto and my friends for being a constant source of encouragement. Particular thanks to my family for your unconditional support to achieve the objectives in my life.

I would like to thank everybody who in one way or another contributed to the success of this dissertation. 
ACKNOWLEDGEMENTS.............................................................................................................. V

TABLE OF CONTENTS ...................................................................................................... VII

INDEX OF TABLES AND FIGURES ................................................................................XIII

ABBREVIATION LIST ........................................................................................................... XVII

SUMMARY...............................................................................................................................XIX

RESUMEN (Spanish summary) ................................................................................................ XXV

\section{CHAPTER 1.}

GENERAL INTRODUCTION AND OBJECTIVES........................................................ - 31 -

1.1. LITERATURE REVIEW .............................................................................. 31 -

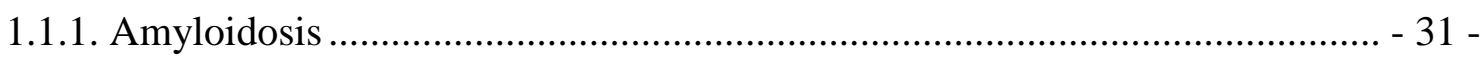

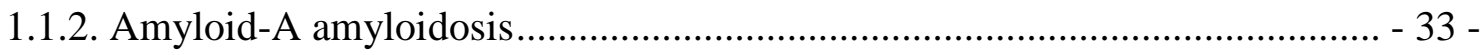

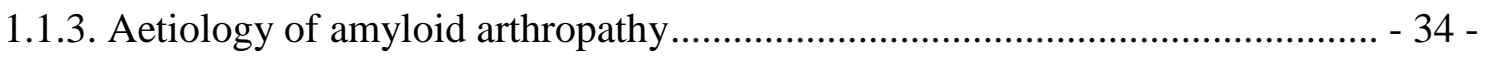

1.1.3.1. Enterococcus faecalis bacterium.................................................... -35 -

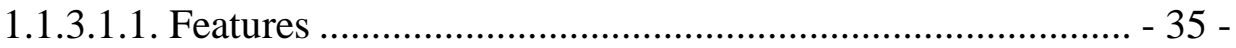

1.1.3.1.2. Diseases in chickens ........................................................ - 35 -

1.1.3.1.3. Transmission of E. faecalis ............................................. - 38 -

1.1.4. Pathogenesis of amyloid arthropathy …................................................. -40 -

1.1.5. Pathology of amyloid arthropathy ……...................................................... -42 -

1.1.5.1. Breed susceptibility ................................................................. 46 -

1.1.6. Approaches for a possible treatment........................................................ 48 -

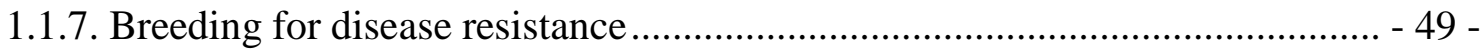




\section{CHAPTER 2.}

GENERIC METHODOLOGY TO EVALUATE THE PATHOGENICITY OF AVIAN ENTEROCOCCUS FAECALIS STRAINS (EXPERIMENT 1)................................. - 55 -

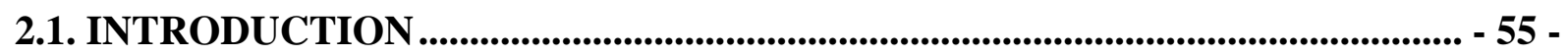

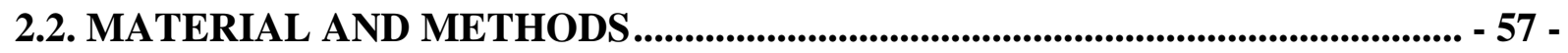

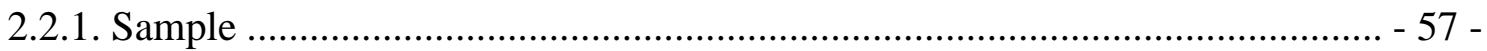

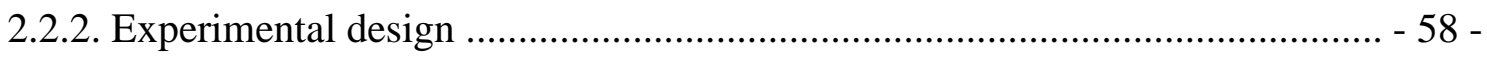

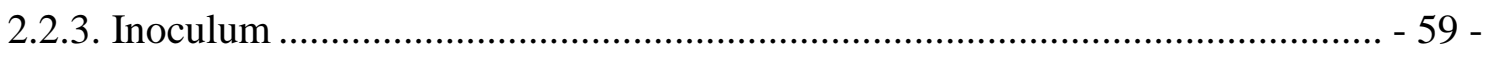

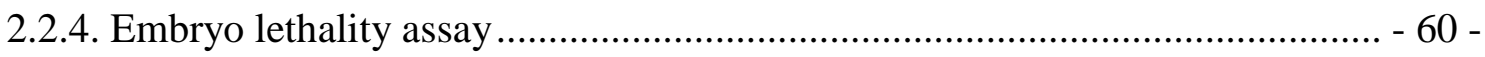

2.2.5. Macroscopic lesions and re-isolation...................................................... 60 -

2.2.6. Statistical analysis ............................................................................. 61 -

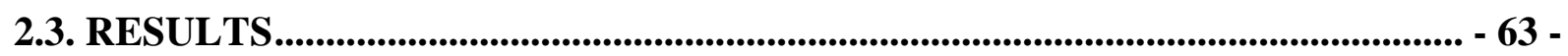

2.3.1. Embryo lethality assay .................................................................... 63 -

2.3.2. Median lethal dose …........................................................................................ 64 -

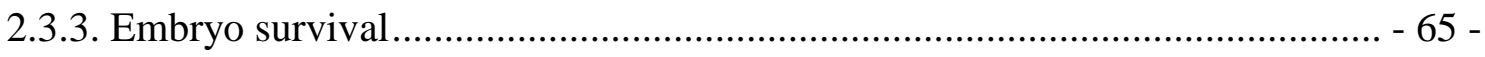

2.3.4. Macroscopic lesions.............................................................................. 66 -

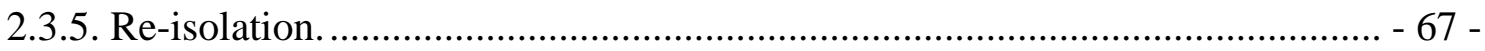

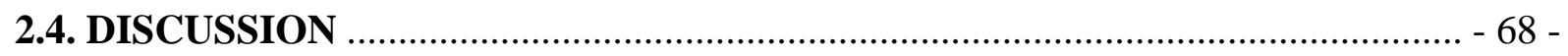




\section{CHAPTER 3.}

VIRULENCE CHARACTERIZATION OF AVIAN ENTEROCOCCUS FAECALIS FIELD ISOLATES BY CHICKEN EMBRYO LETHALITY ASSAY AND ERIC-PCR

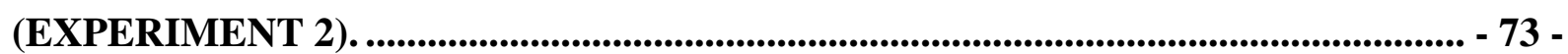

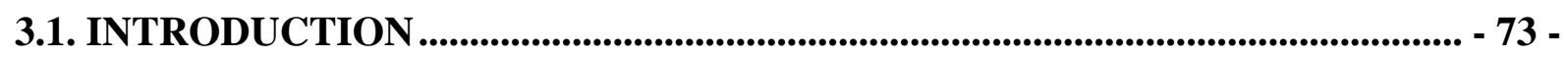

3.2. MATERIAL AND METHODS .......................................................................... - 74 -

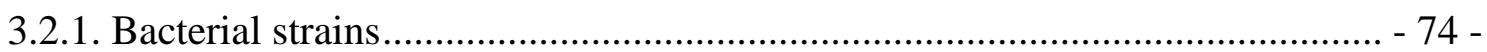

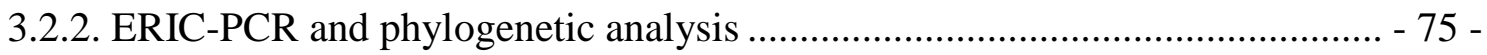

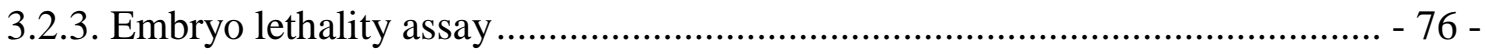

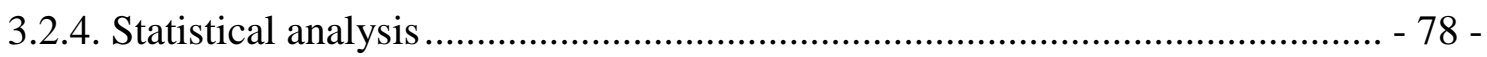

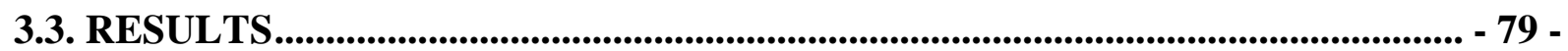

3.3.1. ERIC-PCR method and phylogenetic analysis .......................................... - 79 -

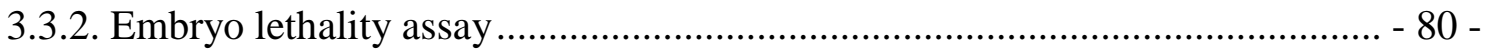

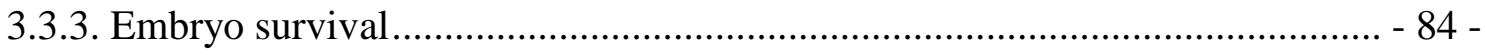

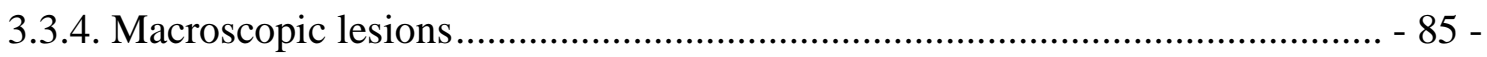

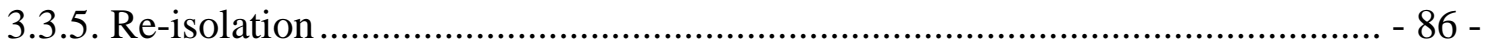

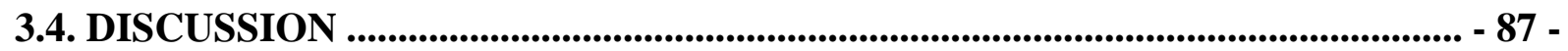

\section{CHAPTER 4.}

GENETIC APPROACH TO SELECT MORE RESISTANT LAYING HENS FOR ENTEROCOCCUS FAECALIS INFECTION (EXPERIMENT 3)................................ - 93 -

4.1. INTRODUCTION ........................................................................................................... - 93 -

4.2. MATERIAL AND METHODS............................................................................................. - 95 -

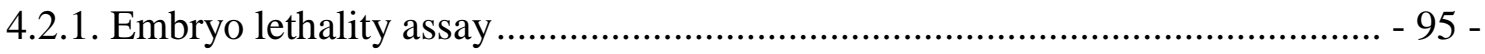

4.2.2. Preliminary study .............................................................................. -96 -

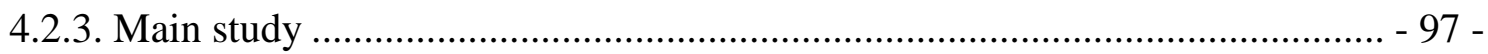


4.2.4. Traits of economic importance - 97 -

4.2.5. Statistical analysis $-98-$

4.2.5.1. Preliminary study $-98-$

4.2.5.2. Main study $-99-$

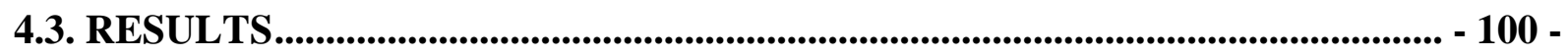

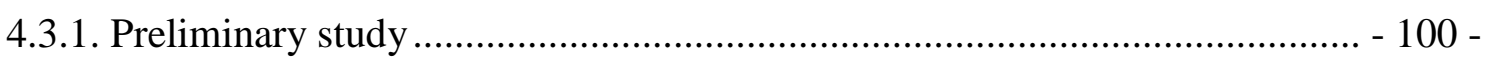

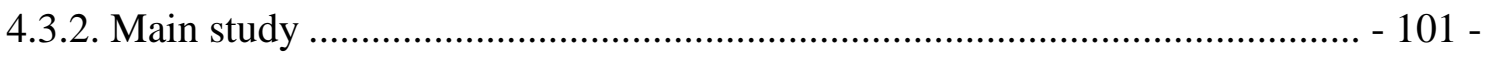

4.3.2.1. Embryo lethality assay ................................................................. - 101 -

4.3.2.2. Descriptive statistics.................................................................. - 104 -

4.3.2.2. Heritabilities and genetic correlations........................................... - 105 -

4.4. DISCUSSION ............................................................................................................. - 108 -

\section{CHAPTER 5.}

GENERAL DISCUSSION AND FINAL CONCLUSIONS. ................................... - 111 -

5.1. GENERAL DISCUSSION................................................................................................ - 111 -

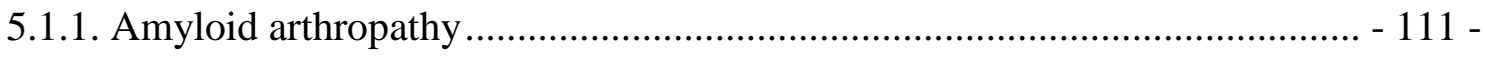

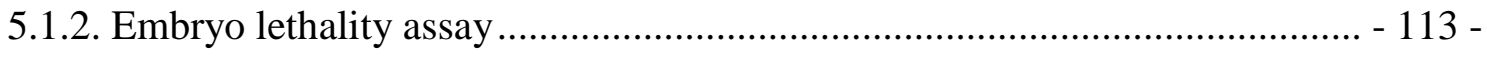

5.1.3. Virulence characterization of avian E. faecalis field strains........................ - 117 -

5.1.4. Genetic variation in susceptibility to E. faecalis infection ............................ - 120 -

5.1.5. Genetic selection against susceptibility to E. faecalis infection .................... - 121 - 


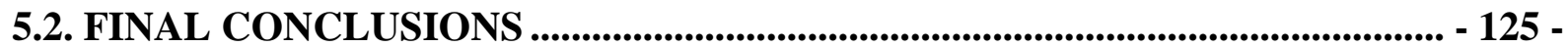

5.3. SUGGESTIONS FOR FURTHER RESEARCHES .................................................. - 127 -

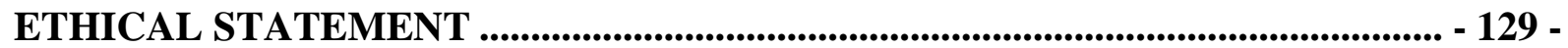

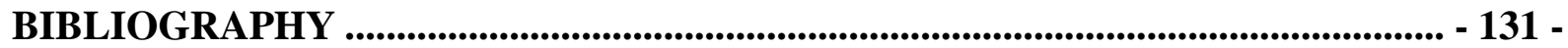




\section{INDEX OF TABLES AND FIGURES}

CHAPTER 1. - 31 -

Table 1.1. Amyloid fibril proteins and their precursors in animals $-32-$

Figure 1.1. Speculative illustration of pathogenesis of amyloid arthropathy. $-41-$

Figure 1.2. Inner view of a femoral-tibial joint of a spontaneous case of AA $-43-$

\section{CHAPTER 2.}

Table 2.1. Characteristics of the ELAs I-IV carried out in order to evaluate the $E$. faecalis strain K923/96. $-58-$

Table 2.2. Percentage of chicken embryo mortality with increasing infectious dose of the E. faecalis strain K923/96 following inoculation of $0.2 \mathrm{ml}$ into the AC. $-64-$

Figure 2.1. Probit analysis on infectious dose of E. faecalis strain K923/96. $-65-$

Figure 2.2. Survival curves of 10-day-old chicken embryos inoculated into the AC with different infectious doses of the E. faecalis strain K923/96. $-66-$

Figure 2.3. Macroscopic lesions of white laying hen embryos infected with different infectious doses of the E. faecalis strain K923/96. $-67-$

\section{CHAPTER 3}

Figure 3.1. Inoculum verification through the incubation of $0.1 \mathrm{ml}$ of inoculum per dose of the E. faecalis strain $2140-5$ on Columbia sheep blood agar plates. $-77-$

Figure 3.2. Phylogenetic tree of 1 E. hirae and 67 E. faecalis strains based on the aligned nucleotide sequences after ERIC-PCR. $-82-$

Figure 3.3. Virulence classification of 68 E. faecalis strains, one E. hirae strain (strain 580) and a negative control group (Neg. Co) sorted by the EMR that produce in 10-day-old chicken embryos inoculated into the $\mathrm{AC}$ with the represented number of $\mathrm{CFU}$. -83 - 
Figure 3.4. Chicken EMR produced by the E. faecalis strain K923/96 used as positive control in 10 individual ELAs when 10-day-old embryos were inoculated into the AC with the represented number of CFU. $-84-$

Figure 3.5. Survival curves of 10-day-old chicken embryos inoculated into the AC with $5 \mathrm{CFU} / \mathrm{ml}$ of three groups of different Enterococcus spp. strains classified by its virulence degree. $-85-$

Figure 3.6. Macroscopic lesions of white laying hen embryos infected with different $E$. faecalis strain with different virulence degree. $-86-$

CHAPTER 4. - 93 -

Table 4.1. Accumulated embryo mortality in six individual ELAs during the preliminary study. $-96-$

Table 4.2. Characteristics of the ELAs VII-IX carried out in the main study. $-97-$

Figure 4.1. Average EMR of 10-day-old embryos from 466 families during three ELAs when they were inoculated into the AC with $2.5 \mathrm{CFU} / \mathrm{ml}$ of the E. faecalis strain K923/96...$102-$

Figure 4.2. Macroscopic lesions of brown embryos infected with the E. faecalis strain K923/96 -102 -

Figure 4.3. Survival curves of 10-days old chicken embryos inoculated into the AC with the E. faecalis strain K923/96 in three ELAs. $-103-$

Table 4.3. Means, SD, as well as minimum (Min) and maximum (Max) values for the embryonic survivability and traits of economic importance. $-104-$

Table 4.4. Estimation of heritability and repeatability for embryonic survivability using univariate repeatability animal model with logit and probit link functions. $-105-$

Table 4.5. Genetic correlations between the embryonic survivability and the analysed traits. - 106 - 
Figure 4.4. Breeding values for embryonic survivability plotted against breeding values

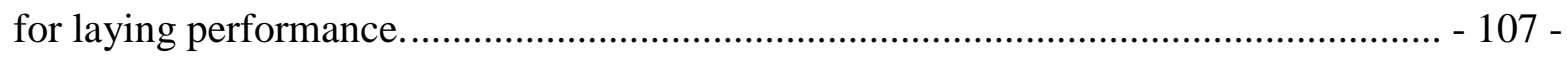




\section{ABBREVIATION LIST}

\begin{tabular}{|c|c|c|c|}
\hline AA & Amyloid arthropathy & $\mathbf{K}_{\text {dyn }}$ & Dynamic stiffness \\
\hline $\mathbf{A C}$ & Allantoic cavity & LSMEANS & Least squares means \\
\hline AEF & Amyloid enhancing factor & \multirow[t]{2}{*}{ MALDI-TOF } & Matrix-assisted linear \\
\hline $\operatorname{apoSAA}$ & $\begin{array}{l}\text { Serum Amyloid A } \\
\text { apolipoprotein }\end{array}$ & & $\begin{array}{l}\text { desorption/ionization time- } \\
\text { of-flight }\end{array}$ \\
\hline BS & Breaking strength & MLST. & Multilocus sequence typing \\
\hline BW & Body weight & MS & Mass spectrometry \\
\hline CFU & Colony-forming units & PBS & Phosphate-buffered saline \\
\hline $\mathbf{L D}_{\mathbf{5 0}}$ & Median lethal dose & PFGE & $\begin{array}{l}\text { Pulsed-field gel } \\
\text { electrophoresis }\end{array}$ \\
\hline ELA & Embryo lethality assay & PG's & Proteoglycans \\
\hline EMR & Embryo mortality rate & p.i. & Post-inoculation \\
\hline ERIC-PCR & $\begin{array}{l}\text { Enterobacterial Repetitive } \\
\text { Intergenic Consensus } \\
\text { Polymerase Chain Reaction }\end{array}$ & RED & $\begin{array}{l}\text { Restriction endonuclease } \\
\text { digestion }\end{array}$ \\
\hline $\mathbf{E W}$ & Egg weight & RT-PCR & $\begin{array}{l}\text { Real-time polymerase chain } \\
\text { reaction }\end{array}$ \\
\hline GAGs & Glycosaminoglycans & SAA & Serum Amyloid A \\
\hline $\mathbf{h}^{2}$ & Heritability & SAP & Serum Amyloid P \\
\hline HDL & High-density lipoprotein & SPF & Specific pathogen-free \\
\hline IAPP & Islet Amyloid Polypeptide & ST & Sequence type \\
\hline IL & Interleukin & TTR & Transthyretin \\
\hline
\end{tabular}




\section{SUMMARY}

In the last twenty years, major progress in the understanding of systemic amyloid-A amyloidosis, also known as amyloid arthropathy (AA) in chickens, has been gained. However, several topics related to this disease remain unclear, such as the higher susceptibility of brown layers compared to white layers, the biochemical mechanism of the pathogenesis and the transmission route as well as a possible effective treatment to prevent or cure the disease.

AA is the only type of amyloidosis that has been associated with chronic infections induced by Enterococcus $(\boldsymbol{E}$.) faecalis strains and, therefore, the treatment of this disease has focused to date on the prevention and/or treatment of this infection. Given the intrinsic and acquired resistance of $E$. faecalis to several antimicrobials and the new regulations to reduce the antibiotic use in animal production, its treatment becomes more complicated. Additionally, little is known about the risk from field avian E. faecalis strains and it is currently difficult to estimate its virulence degree. Consequently, control measures against $E$. faecalis infection such as biosecurity, hygiene, responsible use of antibiotics, development of effective vaccines or the breeding and genetic selection are essential. Therefore, in the present dissertation different avian E. faecalis field strains were characterized and the possibility to select more resistant laying hens against E. faecalis infection through the Embryo Lethality Assay (ELA) was investigated. The ELA is proposed as an alternative model to replace the adult avian challenge assays.

To date, adult avian challenge assay is the most used animal model in order to determine the degree of virulence of isolated fungi and bacteria, as well as in the selection for disease resistance. However, this model is currently limited by the exposure to pathogens on a large scale, its technical complexity, the cost associated and for ethical reasons. Therefore, the 
aim of the Experiment 1 was to develop a generic methodology of the ELA as a diagnostic model to establish the pathogenicity of E. faecalis strains in embryos of White Leghorn layers. Of particular interest was to determine the virulence of the avian E. faecalis strain K923/96 and assess its median lethal dose $\left(\mathbf{L D}_{\mathbf{5 0}}\right)$ in order to use it as reference strain in further analyses. The ELA was repeated four times. $0.2 \mathrm{ml}$ of different infectious doses of the cited strain (from 2.5 to 2500 colony-forming units (CFU) per ml) were inoculated into the allantoic cavity (AC) of 10-day-old embryos. The embryo mortality rate (EMR) was determined by daily candling of the eggs over a period of seven days and based on this information the $\mathrm{LD}_{50}$ was calculated. The infectious dose showed a significant effect on the EMR. The EMR with the doses of 2.5, 5, 25, 250 and $2500 \mathrm{CFU} / \mathrm{ml}$ was $43 \%, 45 \%, 63 \%$, $90 \%$ and $93 \%$, respectively. The estimated dose at $\mathrm{LD}_{50}$ was $6.6 \mathrm{CFU} / \mathrm{ml}$. The highest EMR was recorded after three and four days post-inoculation (p.i.) in all doses. In summary, the methodology proposed in this experiment can be used as reference in further researches on $E$. faecalis virulence taking into account that the EMR produced in the ELA depends on the dose; the higher the infectious dose, the greater the EMR and the lower the embryo survival time.

In order to characterize the virulence of different avian E. faecalis field strains and thus corroborate the ELA capacity for distinguishing E. faecalis strains, 68 avian E. faecalis strains through the ELA were characterized in the Experiment 2. Of particular interest was to characterize the genetic diversity of these strains by Enterobacterial Repetitive Intergenic Consensus Polymerase Chain Reaction (ERIC-PCR) under the hypothesis that strains with similar DNA banding patterns might be similar also in its infective ability. The ELA was performed ten times with subsets of 7-8 E. faecalis strains on a sample of 9987 eggs, including two control groups (positive and negative). An estimated 3-24 CFU were inoculated into the AC of 10-day-old embryos of White Leghorn layer hens. The EMR was determined 
by means of candling the eggs over a period of seven days. The ELA was able to distinguish the virulence of the E. faecalis strains. Twenty-six strains were considered as avirulent strains with an EMR of below 40\%. Five strains were highly virulent with an EMR above 80\%, and the remaining 37 strains were classified as strains of moderate virulence, causing an EMR between $40 \%$ and $80 \%$. The highest EMR occurred three and four days p.i. From the fourth day p.i., almost no embryonic mortality was observed. Therefore, the ELA could be optimized by reducing experiment duration to four days p.i. ERIC-PCR did not cluster the strains according to its virulence, although ERIC banding patterns revealed a considerable genetic diversity. In conclusion, the ELA can be considered a reliable and useful tool to predict the virulence of avian E. faecalis strains. The results obtained in this experiment can be used as a basis for future researches on the E. faecalis virulence, and high pathogenic isolates tested might be good candidates for the production of vaccines.

The aim of the Experiment 3 was to investigate the possibility to select more resistant laying hens against $E$. faecalis infection through the ELA, which is proposed as an alternative model to replace the adult avian challenge assays. A preliminary study was first carried out under the hypothesis that chicken embryos of brown layers would be more susceptible compared with embryos of white layers when they are infected with the same E. faecalis strain and infectious dose since white layers are less susceptible to AA than brown layers. To this end, the ELA was performed six times in the preliminary study. $0.2 \mathrm{ml}$ of two infectious doses of the avian E. faecalis strain K923/96 (2.5 and $5 \mathrm{CFU} /$ per $\mathrm{ml}$ ) were inoculated into the AC of 10-day-old embryos of brown layers. The EMR was determined by daily candling of the eggs over a period of four days. The infectious dose showed a significant effect on the EMR. The average EMR estimated for the doses of 2.5 and $5 \mathrm{CFU} / \mathrm{ml}$ was $69 \%$ and $83 \%$, respectively. They differed significantly from each other. On the basis of these results, 7563 embryos of 10-day-old from 500 families of brown layers (from one to eight embryos per 
family) were inoculated into the AC with only one infectious dose of $2.5 \mathrm{CFU} / \mathrm{ml}$ of the avian E. faecalis strain K923/96 in three more ELAs. The EMR was determined by daily candling of the eggs over a period of four days. Genetic parameters of embryonic survivability to $E$. faecalis infection were estimated to judge the possibility to apply the value of genetic selection. Furthermore, the genetic correlation between embryonic survivability and some traits of economic interest such as laying performance, egg weight $(\mathbf{E W})$, body weight $(\mathbf{B W})$, breaking strength $(\mathbf{B S})$ and dynamic stiffness $\left(\mathbf{K}_{\mathbf{d y n}}\right)$ was calculated. The average EMR estimated of these three ELAs was 50\% and the highest EMR occurred three and four days p.i. as expected. The estimated heritability for embryonic survivability to the infection by $E$. faecalis was $\mathrm{h}^{2}=0.17-0.20$ indicating that the selection of more resistant laying hens to $E$. faecalis infection is feasible. However, a high genetic negative correlation was estimated between embryonic survivability and laying performance at the peak of lay $\left(r_{g}=-0.69\right)$ and at the end of the production $\left(r_{\mathrm{g}}=-0.55\right)$, as well as with BS $\left(r_{\mathrm{g}}=-0.48\right.$ to -0.30$)$, which is undesirable from a breeding point of view. A positive correlation was found between EW and the embryonic survivability $\left(\mathrm{r}_{\mathrm{g}}=+0.16\right)$ and no genetic correlation with $\mathrm{BW}$ and $\mathrm{K}_{\mathrm{dyn}}$ was found. Therefore, although it was demonstrated that it is possible to breed for E. faecalis resistance, the improvement of other important traits will be penalized.

On the basis of the results obtained in the present dissertation it can be concluded that the ELA is a reliable and useful tool to characterize the virulence of avian E. faecalis strains as well as to select more resistant laying hens against $E$. faecalis infection, which can be use as alternative model to replace the adult avian challenge assays. Virulence characterization of avian E. faecalis field isolates allows us to know the risk that the strains represent and provide valuable information, which can be important for the selection of isolates for the production of vaccines. Regarding to the possibility to select more resistant laying hens against $E$. faecalis infection, the estimated heritability for embryonic survivability to the infection of $E$. 
faecalis indicates that it is feasible. However, the undesirable correlations between the embryonic survivability and some analysed traits show the need to take into account all traits and their genetic correlations to achieve a balanced genetic progress.

A new perspective for the implementation of genetic selection for E. faecalis susceptibility in laying hens is offered in the present dissertation. Practical implementation of selection against susceptibility to $E$. faecalis infection will require that breeding company is convinced that AA is of significant economic importance, which depends on disease incidence, production costs and losses associated with sick and/or dead birds, in addition to welfare and food safety concerns of consumers. 


\section{RESUMEN (Spanish summary)}

En los últimos 20 años ha habido un importante avance en la comprensión de la amiloidosis sistémica A-amiloide, también conocida en las aves como artropatía amiloide (AA). Sin embargo, algunas cuestiones relacionadas con esta enfermedad permanecen sin resolver, tales como la mayor susceptibilidad de las estirpes semipesadas (marrones) en comparación con las estirpes ligeras (rubias), el mecanismo bioquímico de la patogénesis y las vías de transmisión, así como un posible tratamiento eficaz para prevenir o curar la enfermedad.

La AA es el único tipo de amiloidosis asociado con infecciones crónicas inducidas por cepas de Enterococus $(\boldsymbol{E}$.) faecalis y por lo tanto el tratamiento de esta enfermedad se ha enfocado hasta la fecha en la prevención y/o tratamiento de dicha infección. Dada la resistencia intrínseca y adquirida de E. faecalis hacia los antimicrobianos y las nuevas regulaciones para la reducción del uso de antibióticos en la producción animal, su tratamiento es cada vez más limitado. Además, se desconoce el riesgo que suponen las cepas de campo y actualmente es difícil estimar el grado de virulencia de éstas. En consecuencia, las medidas de control de la infección por E. faecalis, tales como la bioseguridad, la higiene, el uso responsable de antibióticos, el desarrollo de vacunas efectivas o la selección genética para aumentar la resistencia a la infección por E. faecalis, son imprescindibles. Por lo tanto, en la presente tesis se caracterizaron diferentes cepas aviares de E. faecalis y se evaluó la posibilidad de seleccionar gallinas ponedoras más resistentes a la infección de E. faecalis mediante el Ensayo de Letalidad Embrionaria (ELA), el cual se propone como un modelo alternativo para reemplazar los ensayos de desafío con aves adultas.

La prueba de desafío en aves adultas es el modelo animal más utilizado hasta la fecha para determinar el grado de virulencia de hongos y bacterias, así como para la selección 
genética de aves más resistentes a enfermedades. Sin embargo, este modelo está actualemente limitado por la exposición a gran escala de las aves a patógenos, su complejidad, los costes que supone y por razones éticas. Por lo tanto, el objetivo del Experimento 1 fue desarrollar una metodología genérica del ELA como modelo diagnóstico para caracterizar la virulencia de cepas de E. faecalis en embriones de gallinas ponedoras ligeras Leghorn. De particular interés fue determinar la virulencia de la cepa aviar de E. faecalis K923/96 y estimar su dosis letal media $\left(\mathbf{L D}_{\mathbf{5 0}}\right)$ para utilizarla como cepa de referencia en estudios posteriores. Se realizaron un total de cuatro ELAs. Se inocularon 0,2 $\mathrm{ml}$ de cinco dosis infecciosas (de 2,5 a 2500 unidades formadoras de colonias $(\mathbf{C F U}) / \mathrm{ml}$ ) de la citada cepa en la cavidad alantoidea (AC) de embriones de 10 días de edad. Durante siete días se registró diariamente la tasa de mortalidad embrionaria (EMR) mediante ovoscopía y, en base a esta información, se calculó la $\mathrm{LD}_{50}$. La dosis infecciosa mostró un efecto significativo sobre la EMR. La EMR con las dosis $2,5,5,25,250$ y $2500 \mathrm{CFU} / \mathrm{ml}$ fue $43 \%, 45 \%, 63 \%, 90 \%$ y $93 \%$ respectivamente. Se estimó una $\mathrm{LD}_{50}$ de $6,6 \mathrm{CFU} / \mathrm{ml}$. La mayor EMR se produjo tres y cuatro días postinoculación (p.i.) con todas las dosis. En resumen, la metodología propuesta en este estudio puede utilizarse como referencia en estudios futuros sobre la virulencia de cepas de $E$. faecalis, aunque se debe tener en cuenta que la EMR producida en un ELA depende de la dosis; cuanto mayor es la dosis de infección, mayor es la EMR y menor el tiempo de supervivencia de los embriones.

Con el objetivo de caracterizar la virulencia de diferentes cepas aviares de campo de $E$. faecalis, y así poder corroborar la capacidad del ELA para distinguir diferentes cepas, en el Experimento 2 se caracterizaron 68 cepas aviares de E. faecalis mediante el ELA. De particular interés fue caracterizar la diversidad genética de estas cepas mediante la Amplificación de Secuencias Intergénicas de Consenso Repetitivas de Enterobacterias (ERIC-PCR) bajo la hipótesis de que las cepas con patrones de bandas de ADN similares 
pueden ser similares también en su capacidad de producir infección. Se llevaron a cabo un total de 10 ELAs con subgrupos de 7-8 cepas y dos grupos control (positivo y negativo). Se inocularon de 3 a $24 \mathrm{CFU}$ en la AC de embriones de 10 días de edad de gallinas ponedoras ligeras Leghorn. Durante siete días se registró diariamente la EMR mediante ovoscopía. El ELA fue capaz de diferenciar las cepas de E. faecalis con respecto a la EMR que produjeron. Se clasificaron 26 cepas de E. faecalis como avirulentas con una EMR inferior al 40\%. Cinco cepas fueron altamente virulentas con una EMR por encima del 80\%, y las 37 cepas restantes presentaron moderada virulencia con una EMR entre 40\% y 80\%. La mayor EMR se registró tres y cuatro días p.i. A partir del cuarto día apenas se obsevó mortalidad embrionaria, por lo que el ELA podría ser optimizado reduciendo el tiempo de observación a cuatro días. La ERIC-PCR no agrupó las cepas de acuerdo a su virulencia, aunque los patrones de bandas revelaron una considerable diversidad genética. En base a los resultados obtenidos, se puede concluir que el ELA es una herramienta fiable y útil para predecir la virulencia de cepas aviares de E. faecalis. Los resultados obtenidos en este experimento pueden utilizarse como base para futuras investigaciones sobre la virulencia de E. faecalis, y las cepas de alta patogenicidad halladas podrían ser buenas candidatas para la producción de vacunas.

El objetivo del Experimento 3 fue investigar la posibilidad de seleccionar aves más resistentes a la infección por E. faecalis mediante el ELA, el cual se propone como un modelo alternativo para reemplazar el ensayo con aves adultas. Se llevó a cabo un estudio preliminar bajo la hipótesis de que los embriones de gallinas ponedoras semipesadas podrían ser más susceptibles que los embriones de gallinas ponedoras ligeras cuando se infectan con la misma cepa de E. faecalis y la misma dosis, ya que las gallinas ponedoras ligeras son menos susceptibles a la AA que las gallinas ponedoras semipesadas. Durante el estudio preliminar se llevaron a cabo seis ELAs. Se inocularon $0,2 \mathrm{ml}$ de dos dosis infecciosas $(2,5$ y $5 \mathrm{CFU} / \mathrm{ml}) \mathrm{de}$ la cepa de E. faecalis K923/96 en la AC de embriones de 10 días de edad de gallinas 
ponedoras semipesadas. Durante cuatro días se registró diariamente la EMR mediante ovoscopía. La dosis infecciosa mostró un efecto significativo sobre la EMR. La EMR media con las dosis de $2,5 \mathrm{UCF} / \mathrm{ml}$ y $5 \mathrm{CFU} / \mathrm{ml}$ fue $69 \%$ y $83 \%$ respectivamente, y fueron significativamente diferentes. En base a estos resultados, se infectaron 7563 embriones de 10 días de edad de 500 familias de gallinas ponedoras semipesadas (de uno a ocho embriones por familia) con una única dosis infecciosa de 2,5 CFU/ml de la cepa de E. faecalis K923/96 en tres ELAs adicionales. Durante cuatro días se registró diariamente la EMR mediante ovoscopía. Se estimaron los parámetros genéticos de la supervivencia embrionaria a la infección por E. faecalis para juzgar el valor de la selección genética, y se investigó la relación entre la supervivencia embrionaria y algunos parámetros de interés económico tales como el rendimiento de producción, el peso del huevo $(\mathbf{E W})$, el peso corporal $(\mathbf{B W})$, la resistencia a la rotura $(\mathbf{B S})$ y la rigidez dinámica $\left(\mathbf{K}_{\mathbf{d y n}}\right)$. La EMR media de estos tres ELAs fue $50 \%$ y la mayor mortalidad se produjo los días tres y cuatro p.i., como era de esperar. La heredabilidad estimada para la supervivencia embrionaria a la infección por E. faecalis fue $\mathrm{h}^{2}=0,17-0,20$ indicando que la selección de gallinas ponedoras más resistentes a la infección por E. faecalis es factible. Sin embargo, se estimó una alta correlación genética entre la supervivencia embrionaria y el rendimiento de producción en el pico de puesta $\left(\mathrm{r}_{\mathrm{g}}=-\right.$ $0,69)$ y al final de la producción $\left(r_{g}=-0,55\right)$, así como con BS (de $r_{g}=-0,48$ a -0,30), lo cual es indeseable desde el punto de vista de la selección genética. Se encontró una correlación positiva entre EW y la supervivencia embrionaria $\left(\mathrm{r}_{\mathrm{g}}=+0,16\right)$ y no se observó correlación genética con BW y $\mathrm{K}_{\mathrm{dyn}}$. Por lo tanto, aunque se ha demostrado que es posible seleccionar aves más resistentes a la infección por E. faecalis, esto podría penalizar la mejora de otros parámetros importantes.

En base a los resultados obtenidos en la presente tesis se puede concluir que el ELA es una herramienta útil y fiable para la caracterización de la virulencia de cepas aviares de $E$. 
faecalis así como para la selección de gallinas ponedoras más resistentes a la infección por $E$. faecalis, el cual puede utilizarse como modelo alternativo para sustituir los ensayos de desafío con aves adultas. La caracterización de la virulencia de las cepas aviares de E. faecalis aisladas en brotes de campo nos permite conocer el riesgo que éstas suponen y proporciona información valiosa para futuras investigaciones epidemiológicas. Además, esta información puede ser importante en la selección de aislados para la producción de vacunas. En cuanto a la posibilidad de seleccionar gallinas ponedoras más resistentes a la infección por E. faecalis, la heredabilidad estimada para la supervivencia embrionaria a la infección por E. faecalis indica que es factible. No obstante, las correlaciones indeseables entre la capacidad de supervivencia embrionaria y algunos de los parámetros analizados muestran la necesidad de tener en cuenta todos los parámetros y sus correlaciones genétias para lograr un progreso genético equilibrado.

La presente tesis ofrece una nueva perspectiva para la implementación de la selección genética para la susceptibilidad de E. faecalis en gallinas ponedoras. La implementación práctica de la selección contra la susceptibilidad a la infección por E. faecalis requerirá que la empresa de genética se convenza de que la AA tiene una importancia económica significativa, la cual depende de la incidencia de la enfermedad, los costes de producción y las pérdidas asociadas a los animales enfermos además de las preocupaciones sobre el bienestar de los animales y la seguridad alimentaria de los consumidores. 


\section{CHAPTER 1.}

\section{GENERAL INTRODUCTION AND OBJECTIVES.}

\subsection{LITERATURE REVIEW}

\subsubsection{Amyloidosis}

Amyloidosis is a general term that refers to diseases associated with the deposition of amyloid fibril protein, mainly in the extracellular spaces of organs and tissues of animals and humans. These amyloid fibril proteins are the main component of the amyloid and are deposited as insoluble fibrils due to the sequential changes in protein folding under certain conditions.

Amyloidosis can be classified based on the tissue distribution of amyloid deposits (local or systemic amyloidosis), the absence or presence of pre-existing disease (primary or secondary amyloidosis) and the chemical type of amyloid fibril protein. To date, there are 31 amyloid fibril proteins characterised in humans (Sipe et al. 2014), which differ in primary amino acid sequence (Landman et al., 1998a). Ten of these 31 fibrils proteins have also been described in domestic and wild cage animals (Sipe et al. 2014) (Table 1.1.).

Due to the great number of recognised amyloid types, the pathogenesis of amyloidosis is extremely variable and, therefore, research has focused on fibrillogenesis (Landman et al., 1998a). Amyloid fibril formation begins with abnormal folding of an amyloidogenic 
precursor protein. Depending on the precursor protein, the misfolding can result from an inadequate proteolytic cleavage (e.g., Islet Amyloid Polypeptide (IAPP)), an amino acid substitution (e.g., transthyretin (TTR)) or an excessive production of serum concentrations in response to acute phase (e.g., Serum Amyloid A (SAA)) (Dember, 2005). According to Woldemeskel (2012), all resulting fibrils are arranged in a characteristic B-pleated sheet fibrillar structure and they are morphologically indistinguishable, despite the great diversity in structure and function of amyloidogenic protein precursors.

Table 1.1. Amyloid fibril proteins and their precursors in animals. ${ }^{1}$

\begin{tabular}{lll}
\hline Fibril protein & Precursor protein & Occurrence \\
\hline AA & (Apo) Serum Amyloid A (S) & Chicken, duck, turkey, cat, etc. \\
AL & Inmunoglobulin Light Chain (S, L) & Cat, horse \\
AApoAI & Apolipoprotein AI (S) & Dog \\
AApoAII & Apolipoprotein AII (S) & Mouse \\
ATTR & Transthyretin (S) & Monkey \\
AFib & Fibrinogen Aa (S) & Stone martens \\
Aß & Aß precursor protein (L) & Dog, sheep, bear, ape \\
AIAPP & Islet Amyloid Polypeptide (L) & Apes, cat, racoon, cougar \\
AIns & Insulin (L) & Degu \\
ACas & A-S2C Casein (L) & Cow \\
\hline
\end{tabular}

${ }^{1}$ Modified from (Sipe et al., 2014). S: systemic; L: local.

Besides the fibril protein that defines the type of amyloidosis, all types of amyloid deposits contain several common components such as, proteoglycans (PG's), serum amyloid P (SAP) and glycosaminoglycans (GAGs). The latter is a promoter of fibrillogenesis (Dember, 2006). 


\subsubsection{Amyloid-A amyloidosis}

Amyloid-A amyloidosis (also referred to as systemic amyloid according to the distribution of amyloid deposition and secondary amyloidosis by the presence of pre-existing disease) occurs as a consequence of chronic inflammatory or infectious conditions. This leads to a dramatic increase in the levels of serum amyloid A (SAA) to fight the inflammation (Westermark, 2005). It should be noted that SAA is an acute phase protein synthesised by the liver (Gruys et al., 2005).

According to Landman et al. (1998a) amyloid fibrils are formed from SAA prior to Cterminal proteolytic cleavage and transformation into mature amyloid-A fibrils, which are produced at a different site from the sites of deposition. Among the chronic infections and inflammatory diseases that lead to the development of amyloid-A amyloidosis in humans are tuberculosis, rheumatoid arthritis and leprosy (Dember, 2005).

In chickens, amyloid-A amyloidosis is known as amyloid arthropathy (AA), which was first described by Landman et al. (1994) as a complication of bacteraemia derived chronic (poly) arthritis. AA is characterised by amyloid-A depositions in the joints (mainly in knee and hock joints and with a higher incidence in the left leg) (Steentjes et al., 2002 and Bautista et al., 2009). Landman et al. (1994) observed that the first signs of AA in chickens occur mainly during rearing period from five to six weeks of age onwards. Lame birds have difficulties accessing food and water, and consequently can become dehydrated and die. Therefore, AA compromises the welfare of chickens and has a significant economic impact since the disease affects about 20-30\% of all European flocks (Landman et al., 1998a). Interestingly, it occurs mainly associated with chronic infections induced by arthropathic and amyloidogenic Enterococcus (E.) faecalis strains (Landman et al., 1997), which has only been described in association with this disease in chickens and not in humans or other species so 
far (Landman et al., 1999a). This form of amyloidosis is the only amyloid type found in chickens so far (Landman et al., 1998a).

\subsubsection{Aetiology of amyloid arthropathy}

There are various bacteria, which may induce AA. Landman et al. (1998b) observed that brown layers inoculated intravenously with doses between $10^{2}$ and $10^{8} \mathrm{CFU}$ of $E$. faecalis, Staphylococcus (S.) aureus, Escherichia (E.) coli and Salmonella (S.) Enteritidis showed joint amyloidosis. However, the most severe joint amyloidosis was observed in layers infected with E. faecalis. Landman \& Feberwee (2001) observed that brown layers developed joint amyloidosis after intra-articular inoculation of Mycoplasma synoviae. However, E. faecalis is the bacterium which has been isolated mostly in amyloidogenic joints of field cases of AA in brown layers (Landman et al., 1994) and which has been showed to produce a large amount of amyloid deposits when inoculated (Landman, 1999).

According to the results of the analysis of routine post-mortem conducted by Landman et al. (1998b) in field cases, 12.9\% (249/1930) of the necropsied brown layers during 1996 and 1997 suffered from AA. E. faecalis were isolated in $76.6 \%$ of the affected birds. S. aureus and E. coli were only isolated in $8.3 \%$ and $5 \%$ of the affected brown layers respectively. In the case of the broiler breeders, only $2.9 \%$ (53/1815) suffered from AA in the same period of time. S. aureus, E. faecalis and E. coli were isolated in $73.4 \%, 25 \%$ and $1.5 \%$ of the affected birds, respectively. Steentjes et al. (2002) examined 30 birds from five affected broiler breeder flocks by unilateral (left side) lameness. They found $83 \%(25 / 30)$ amyloid-positive hock joint of broiler parent stock. E. faecalis was isolated in 77\% (23/30) from the hock joints of the affected birds, and $S$. aureus was isolated from the joint in only one affected bird $(1 / 30)$. 
Additionally, E. faecalis is a trigger of the acute phase response in chickens and, therefore, is considered to be a causative agent of AA (Landman et al., 1994). For this reason, it has been deemed important to underline the main features of E. faecalis and its role in AA, as well as its possible routes of transmission in the following sections.

\subsubsection{Enterococcus faecalis bacterium}

\section{$\underline{1.1 .3 .1 .1 . ~ F e a t u r e s ~}$}

Enterococci are Gram-positive bacteria, which can appear as single cocci, arranged in pairs or form short-chains. They are mainly catalase negative, facultative anaerobic, nonspore forming and non-motile. They are able to grow in $6.5 \% \mathrm{NaCl}$, can hydrolysed esculin and tolerate $40 \%$ bile salts (Fisher \& Philips, 2009).

E. faecalis is able to survive a wide range of conditions in nature. The bacterium can grow at a temperature range of 10 to $45^{\circ} \mathrm{C}$ and in environments with $\mathrm{pH}$ of $4.5-9.9$. E. faecalis colonies are characterised by its round form, smooth and grey colour. They have a diameter of approximately $2 \mathrm{~mm}$ eventually surrounded by an alpha-haemolysis on Columbia sheep blood agar. E. faecalis constitutes a part of the endogenous intestinal microflora of birds and humans. The bacterium is considered the third leading cause of nosocomial bacteraemia in patients with underlying conditions (Gregersen et al., 2010). Fisher \& Philips (2009) and Gregersen et al. (2010) reported that E. faecalis and Enteroccocus (E.) faecium are the species most frequently isolated from the microbial intestinal flora of one-day-old chicks.

\subsection{Diseases in chickens}

E. faecalis has been associated with high numbers of poultry diseases. However, very little is known about the epidemiology and pathogenesis of E. faecalis infections in animal species (Gregersen et al., 2010). The bacterium has been isolated from pulmonary 
hypertension syndrome in broilers (Tankson et al., 2001), septicaemia and endocarditis in a broiler parent flock (Chadfield et al., 2004). According to Gregersen et al. (2010), E. faecalis were isolated in $5.4 \%(167 / 3100)$ of the necropsied broiler breeders affected by different lesion types such as arthritis, amyloidosis, valvular endicarditis, salpingitis, peritonitis and septicaemia. Landman et al. (1998b) and Steentjes et al. (2002) observed by Pulsed-Field Gel Electrophoresis (PFGE) that several E. faecalis strains associated with AA from different origins showed similar Restriction Endonuclease Digestion (RED) patterns. Therefore, Landman et al. (1998b) suggested a wide distribution of a single virulent clone of E. faecalis causing amyloid-A amyloidosis in chickens. Petersen et al. (2009) observed the same tendency through Multilocus Sequence Typing (MLST). With this technology, they showed the specific association between amyloid-A amyloidosis in poultry and the Sequence Type (ST) 82 of E. faecalis, which has been related with this disease worldwide (Petersen et al., 2007). Later, Petersen et al. (2010) developed a Real-Time Polymerase Chain Reaction (RTPCR) method for the rapid and specific detection of the MLST 82 of E. faecalis, based on a so-called kinetic PCR approach.

According to the database from the Multi Locus Sequence Typing website (http://www.mlst.net), ST36, ST59, ST82, ST170, ST171, ST172 and ST174 have been associated with amyloid-A amyloidosis, and ST34, ST82, ST174 and ST177 have been associated with first week mortality in layers (Olsen et al., 2012b). Additionally, Gregersen et al. (2010) observed that ST32, ST176, ST177 and ST249 have the capacity of inducing AA in broiler breeders, and ST16, ST82, ST174 and ST249 have the capacity of inducing septicaemia and/or salpingitis. Of all these STs, ST82, ST174 and ST177 constitute more than $80 \%$ of the mortality related with broiler breeders (Gregersen et al., 2010). It should be noted that of all the STs cited above, only ST16, ST34, ST36, ST59 and ST82 have, until now, been identified in both poultry and humans (http://www. mlst.net). Therefore, Freitas et al. (2009) 
suggested that isolated strains in animals and humans might have the same origin which could be spread through the food chain. Furthermore, Hayes et al. (2003) argued that poultry meat in particular, might be a route of transmission of E. faecalis to humans. In regards to its zoonotic potential, E. faecalis is a serious challenge due to its antimicrobial resistance and is therefore gaining great attention.

E. faecalis possess the ability to acquire antimicrobial resistance and virulence factors which are not exclusively associated with a disease (Olsen et al., 2012a). E. faecalis have a natural intrinsic resistance towards several antimicrobials such as chloramphenicol, clindamycin, erythromycin, tetracycline, high-level aminoglycosides, beta-lactam antibiotics and vancomycin (McBride et al., 2007). Many virulence genes related with enterococcal infections have been identified: aggregation substance (asal or agg), endocarditis antigen (efaA), cytolisine (cylA), gelatinase ( $g e l E)$, collagen-binding protein (ace), hyaluronidase (hyl) and extracellular surface proteins (esp). The research done by Ciftci \& Diker (2009) showed that the virulence genes gelE, cylA and asal (or agg) could have an effect on the pathogenesis of AA. The chickens inoculated (intraarticular and intravenous inoculations) with gelE negative strains did not show any pathological signs, whereas $65.2 \%$ of gelE positive strains caused AA. Additionally, the chickens inoculated with asal (or agg) or cylA strains (both negative and positive strains) showed AA. In a study done by Olsen et al. (2012a), the virulence genes ace, efaA and gelE were present in all isolates obtained from poultry and humans. However, these virulence genes cannot be the only cause for the pathogenicity of $E$. faecalis in poultry since these genes were also present in all commensal isolates. The esp gene was the only gene not detected among any poultry isolates. Additionally, Olsen et al. (2012a) did not observe any difference on the virulence profile among isolates from clinical birds and cloacal isolates from healthy birds. Furthermore, these authors did not find major differences 
in the virulence gene profile from E. faecalis isolates of human and poultry which would confirm the possible zoonotic potential of this bacterium.

\subsection{Transmission of E. faecalis}

Several experimental investigations to demonstrate the possible routes of transmission of E. faecalis in chickens have been reported in the literature (Landman et al., 1999a; 1999b; 2000; 2001 and 2003; Fertner et al., 2011 and Olsen et al., 2012c).

Landman et al. (1999b) found that the same E. faecalis strain which infected the parent stock was also present in an analysed offspring population. But the reproductive organs from the infected birds were not affected. Therefore, they concluded that vertical transmission is possible. Landman et al. (1999a and 1999b) discarded the theory that E. faecalis is spread by the transovarial route because yolk sac infections of chicken embryos with E. faecalis resulted in a massive mortality within a few days of incubation. However, after inoculation of egg albumen with low doses of E. faecalis, some chicks were successfully hatched. This suggests that an infection via the oviduct is a possible way of vertical transmission (Landman et al., 1999a and 1999b).

Landman et al. (2000) observed that some hatchery air samples (up to $10^{3} \mathrm{CFU} / \mathrm{l}$ air), Marek's disease vaccine suspensions (up to $10^{6} \mathrm{CFU} / \mathrm{ml}$ vaccine suspension) and injection needles (9500 to $61000 \mathrm{CFU} /$ needle) of two hatcheries were contaminated with an arthropathic and amyloidogenic E. faecalis strain during processing and vaccination of the newly hatched layer chickens. Besides, three isolates showed a similar RED pattern to $E$. faecalis 6085.94 (amyloidogenic E. faecalis strain used as control) and the other 17 isolates were close or unrelated to control E. faecalis strain. Although the authors could not explain 
the high concentration of E. faecalis found in Marek vaccine suspensions, they suggested that this could be a possible iatrogenic infection route in chickens.

Fertner et al. (2011) carried out studies on the transmission of E. faecalis among chickens during a hatch in two hatchers. They sampled a cloacal swab from each single chicken and assumed that an immediate massive growth of E. faecalis in pure culture (at $0 \mathrm{~h}$ ), would be an indicator for vertical transmission. Not immediate but massive growth within the next $24 \mathrm{~h}$ indicated either a horizontal or vertical transmission due to the interaction of the chicks in the hatchery, as well as from infected or contaminated eggs. Fertner et al. (2011) observed the same tendency for ST82 and ST249. A massive increase of the bacterial growth from 0 to $24 \mathrm{~h}$ in brown layers suggests horizontal transmission - orally and cloacally by means of the 'drinking' route between chicks. In white layers, only the ST177 was isolated at $0 \mathrm{~h}$ and no later than $24 \mathrm{~h}$. However, other STs like ST82 and ST249 were isolated only after 24 h suggesting the horizontal transmission of these STs.

In accordance with the results of Fertner et al. (2011), Olsen et al. (2012c) observed an increment of the growth of E. faecalis in broiler chickens during the hatch. E. faecalis colonised $1 \%$ of all the chickens at the beginning of the hatch and after $24 \mathrm{~h}$ was detected in $70 \%$ of them. This suggests a vertical and horizontal transmission. Besides, all of the STs of E. faecalis that were isolated at the time of hatch were also present after $24 \mathrm{~h}$. The authors therefore suggest that the intestine of broiler chickens is a possible route for the horizontal transmission of E. faecalis from the hatchery to the farm.

On the basis of the information obtained, both vertical and horizontal transmissions of E. faecalis seem possible through different transmission routes. Moreover, Landman et al. (2000) suggested that AA could be an iatrogenic infection in chickens after intramuscular 
inoculation of Marek vaccine suspensions contaminated with arthropathic and amyloidogenic E. faecalis strains.

\subsubsection{Pathogenesis of amyloid arthropathy}

AA is associated with chronic inflammation and infection, which appears to be induced by E. faecalis strains in chickens (Westermark, 2005). The acute phase response is a complex systemic early-defence mechanism activated to fight the inflammation or infection. Pro-inflammatory cytokines play an important role in initiating the acute phase response (Sevimli et al. 2008). The increase in the levels of interleukin (IL) -1 and IL-6 during an infection is induced by the synoviocytes (type B cells) and macrophages (type A cells) as a local response, as shown in Figure 1.1. Although there is very little literature on the role of cytokines in AA, Sevimli et al. (2008) reported that IL-1 appears to have an important role in the amyloid pathogenesis due to its positive association with high SAA levels in blood and the severity of AA. However, the role of IL-6 is still unclear.

SAA is mainly synthesised by the liver during the acute phase response. However, the extrahepatic production of SAA has been reported in different human tissues such as ovary, brain or kidney (Upragarin et al., 2005). Ovelgönne et al. (2001) reported that SAA is synthesised in the synoviocytes and in the vessel walls of the synovium in chickens affected by AA while the healthy chickens did not express SAA mRNA in the synoviocytes. According to Kisilevsky \& Manley (2012), SAA is gaining more attention not only because it is the precursor protein of amyloid-A amyloidosis, but also as its plasma concentration may increase 1000-fold during the acute phase response, its influence on high-density lipoprotein (HDL) structure and function, and on HDL's role in reverse cholesterol transport. However, the physiological role for SAA still remains contradictory among the different proposals of the current literature. 


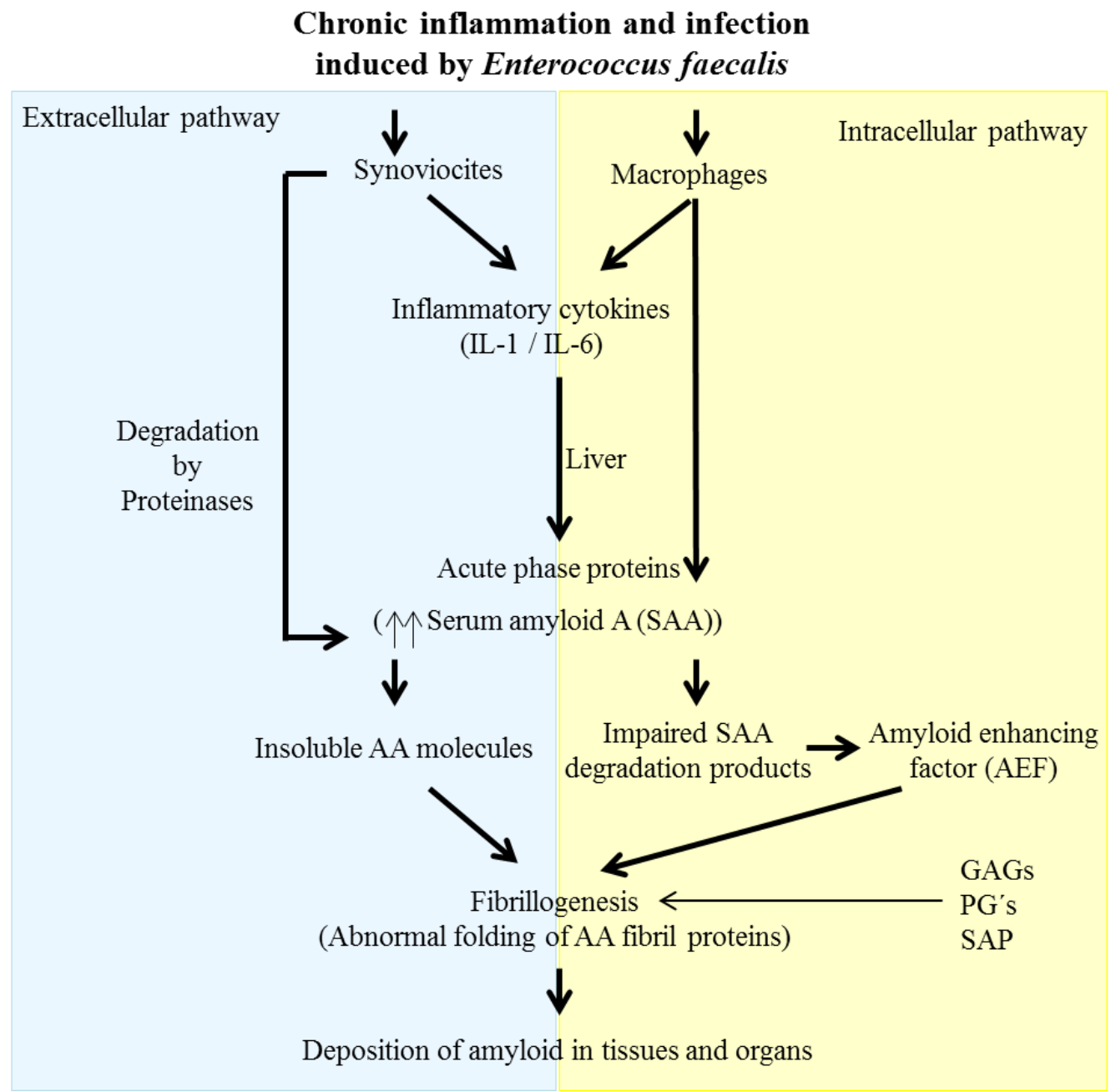

Figure 1.1. Speculative illustration of pathogenesis of amyloid arthropathy.

According to Upragarin et al. (2005) and Abbas (2005), SAA can be degraded by intra- and extracellular pathways (Figure 1.1.). Through the intracellular pathway, SAA degradation products may act as a source of the amyloid-A fibril precursor (Upragarin et al., 2005), that is to say, like an amyloid enhancing factor (AEF). According to Landman et al. (1998a), AEF is considered to be a material with high content of B-pleated sheets that acts as nest or template for the generation and growth of amyloid-A fibrils. Through the extracellular pathway, SAA is degraded by proteinases (Upragarin et al., 2005) and a possible defect in the 
cells of monocyte origin that degrade SAA could generate insoluble amyloid-A molecules rather than soluble amyloid-A molecules (Abbas, 2005).

According to Upragarin et al. (2005), a persistent acute phase response will provide an elevated precursor protein SAA necessary for SAA and amyloid-A fibril formation. However, an elevated production of SAA by itself is not sufficient for the deposition of amyloid since it is common to inflammatory states that do not necessarily lead to amyloid-A amyloidosis (Abbas, 2005). Furthermore, other factors are involved in the development of amyloid-A amyloidosis since the amyloid formation does not occur in all individuals in the same way (Upragarin et al., 2005). Thus, factors such as the isoform or proteolytic cleavage site of SAA (amyloid fibrils are transformed from SAA prior to C-terminal proteolytic cleavage), the SAP and GAGs are thought to contribute to amyloid pathogenesis (Landman, 1999).

\subsubsection{Pathology of amyloid arthropathy}

The published literature of Landman et al. (1994 and 1998b), Peperkamp et al. (1997), Ovelgönne et al. (2001), Petersen et al. (2008) and Bautista et al. (2009) describes field cases of avian amyloidosis and agrees that the gross features of AA are characterised by deposits of orange-coloured amyloid materials in the joints (mainly in knee joints and with a higher incidence in the left knees) and a turbid orange-yellow amyloid material in the synovial fluid, as shown in Figure 1.2.

Landman et al. (1994) observed the first signs of AA in field cases in brown layer breeds between 5 and 6 weeks of age. Affected chickens were smaller than healthy ones. The chickens had ruffled feathers and chirped like younger chickens, showing reduced weight gain, uni- and bilateral swelling of tibio-metatarsal and femorotibial joints, mainly on the left side. Petersen et al. (2008) observed erosion of the articular cartilage as well as in bone tissue 
in commercial layers between 24 and 37 weeks of age. Bautista et al. (2009) reported that 5\% of the commercial layers showed lameness and inflammation of the knee joints after 17 weeks of age, though no significant mortality was observed.

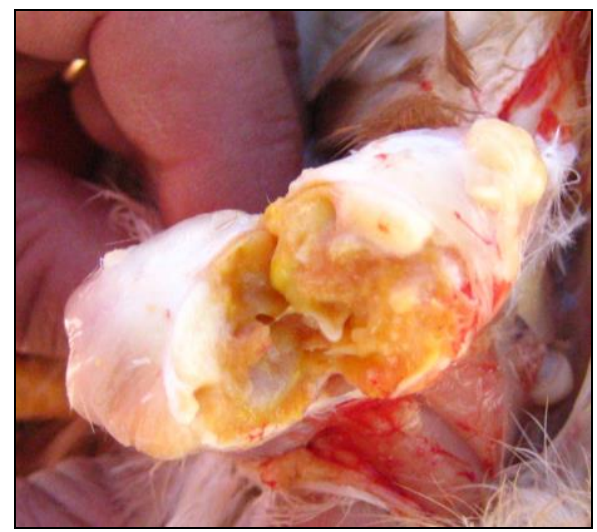

Figure 1.2. Inner view of a femoral-tibial joint of a spontaneous case of AA. (Image courtesy of Ibertec, 2012).

Additionally, AA is often accompanied by hepatomegaly and renomegaly, and sometimes by hydropericardium and ascites. The most affected organs are the liver, spleen and kidneys. At necropsy, deposits of amyloid can be seen in the liver, located in Disse's space, in the kidney, located in the interstitium of cortex and medulla, and in the spleen, located in the white pulp. The liver usually shows a pale brownish hue and the spleen appears pale (Bautista et al., 2009). Amyloid deposits occasionally appear in the heart, and can be found in the digestive tract, in the proventriculus, and the small intestine, located in the duodenal or jejunal section, the pancreas, being the least affected organ (Peperkamp et al., 1997). Rarely brain, lungs and skin are affected (Landman et al., 1998a).

Regarding the reproductive system, Landman et al. (1999b) observed that four out of six 27-week-old brown layer breeds with arthritis, which were inoculated intravenously with 
$10^{9} \mathrm{CFU}$ of E. faecalis, had productive ovaries and remained in production (from 50 to $100 \%$ ) although with oscillations. Landman et al. (2001) examined 18 brown layer breeds that displayed lameness. At necropsy, it was observed that ten of them suffered from AA, of which seven had active reproductive organs (70\%) and only one bird stopped laying eggs (10\%). This means a diminished number of eggs in affected birds and, therefore, an important financial loss for the poultry industry.

Field cases of AA in broiler parent stocks have also been reported by Landman et al. (1998b), Ovelgönne et al. (2001) and Steentjes et al. (2002), and the signs were very similar to those previously described in layers.

Peperkamp et al. (1997) observed that amyloid deposition is more severe in field amyloid cases than in experimentally infected birds. There are several reports about experimentally infected birds with E. faecalis and the many possible ways of infection. However, pathogenesis and clinical manifestations of induced avian amyloidosis follow a similar pattern to field cases of AA. Landman et al. (1999b) studied the induction of AA in embryonated eggs; neither the dipped embryonated eggs nor the inoculation of the air chamber with E. faecalis resulted in AA. However, yolk sac inoculation produced a high EMR within two days while egg albumen inoculation hardly produced any embryonic deaths. In one-day-old chick the intramuscular inoculation of $10^{6} \mathrm{CFU}$ of E. faecalis caused arthritis $(60 \%)$ and articular amyloidosis $(40 \%)$ whereas oral inoculation was ineffective (Landman, 1999). Additionally, according to Landman et al. (1997; 1998b; 1999a and 1999b), six-weekold brown layer chickens developed AA after intravenous, intra-articular and intraperitoneal inoculations of $10^{8}$ or $10^{9} \mathrm{CFU}$ of E. faecalis. Landman et al. (1999a) found that intratracheal, oral or intramuscular inoculations were ineffective. Landman et al. (2003) reported in a later study that both intra-tracheal and intramuscular inoculations (in musculus 
gastrocnemius and musculus pectoralis) induce lameness and arthritis. The joint lesions with the inoculations in the $m$. gastrocnemius were more severe than in the $m$. pectoralis. Besides, they reported that the exposure to aerosolized E. faecalis produced bacteraemia.

In general, inoculations with high doses of E. faecalis could develop AA and show the typical clinical and pathological lesions according to Landman (1999), and according to Ciftci \& Diker (2009) E. faecalis has a predilection for joints of chickens regardless of the inoculation route. Nevertheless, it is to be noted that although AA is characterised by the deposition of amyloid, there are experimentally inoculated chicken cases where these depositions have not been observed. Ovelgönne et al. (2001) observed amyloid deposits in the joints of all infected brown layers at six weeks of age. However, at necropsy (i.e. at 13 weeks of age), the amyloid deposits were not observed in all infected white layers although their joints were bacteriologically positive. According to the study of Landman et al. (2003), the experimentally inoculated chickens at one day of age did not show any amyloid deposits at necropsy (at ten weeks of age). These authors reported that outbred brown layer chickens were used. These have an immune system with a genetically determined diversity (Hawken $e t$ al., 1998) which might serve as a possible explanation for this fact. Consequently, the acute phase reaction necessary to amyloid deposition might not occur in the same way in all birds.

An extensive diagnosis is therefore necessary to confirm amyloid deposits and rule out similar extracellular deposits such as collagen and fibrin (Woldemeskel, 2012). Congo red stain is the most commonly used tool for the identification of amyloid (Picken, 2007). Green birefringence under polarised light is used with amyloid orange deposits (Snyder, 2007), as well as immunohistochemistry (antibody against apoliprotein AI) and biochemical characterisation which helps to identify the specific constituents composing the amyloid deposits (Picken, 2007). Histopathologic identification of amyloid deposits is required to 
assess the amyloid type (Woldemeskel, 2012). Serology and bacteriology of blood samples and/or of affected joints are complementary proofs to amyloid diagnosis which have been used in research conducted, for instance, by Landman et al. (2003) and Sevimli et al. (2005), to name a few.

\subsubsection{Breed susceptibility}

The incidence of AA has been reported in field cases in brown layer breeds (Peperkamp et al., 1997 and Bautista et al., 2009) and occasionally in broiler breeder flocks (Gregersen et al., 2010). AA has never been reported in broiler chicks in field cases probably because they are slaughtered at an early age of seven weeks. Interestingly, AA has never been reported in field cases in white layer breeds and they are more resistant to induced AA than brown layers (Ovelgönne et al., 2001). Therefore, differences in susceptibility to AA between brown and white layers have been investigated in many cases (Zekarias et al., 2000 and Ovelgönne et al., 2001). However, it still remains puzzling.

Zekarias et al. (2000) observed that the defence reaction that recognises an invading bacterium and produces antibodies specific against that antigen appears to be different between breeds, i.e. brown and white layers had a different immune reaction when they were infected with an amyloidogenic E. faecalis strain. Therefore, the greater susceptibility to the disease of brown layers as compared to white layers may be associated with the immunological response pattern.

Zekarias et al. (2000) detected more $\mathrm{CD}^{+} \mathrm{T}$ cells present in the synovial membrane and peripheral blood of affected joints from white layer breeds resistant to AA induced by $E$. faecalis than on the susceptible brown layer breeds. Likewise, chickens resistant to Salmonella infection showed more $\mathrm{CD}^{+} \mathrm{T}$ cell according to Berndt \& Methner (2001). 
However, chicken strains susceptible to coccidiosis showed more $\mathrm{CD} 8^{+} \mathrm{T}$ cells than resistant lines (Lillehoj, 1994). Therefore, the amount of T cells appears unrelated to the resistance to disease (Zekarias et al., 2002).

Zekarias et al. (2000) observed that white layers showed a cell-mediated response characterised by $\mathrm{T}$ cell proliferation and macrophage activity whilst brown layers showed a high humoral antibody response due to the large number of plasma cells present in its arthritic synovial membrane. Besides, Sevimli et al. (2005) reported that the most affected brown layers by AA presented the highest numbers of macrophages and heterophil. Therefore, they concluded that the rate of macrophages and heterophil migration into the tissue may be associated with the severity of AA.

Additionally, Ovelgönne et al. (2001) reported that the differences in susceptibility to AA among individuals could have a genetic basis but it cannot be explained by the SAA genes. These authors reported that although there are minor differences located in the untranslated regions of both mRNAs, the amino acid sequences of SAA of both chicken breeds are identical with 4 exons and 3 introns. Therefore, they concluded that the promoters of the brown and white layers must house the functional differences between the SAA genes. It should be noted that only one SAA gene has been identified in the chicken genome while SAA is encoded by four different genes in humans and mice (Upragarin et al., 2005).

Furthermore, Ovelgönne et al. (2001) reported that the fact that the brown layers might have higher blood SAA levels than white layers cannot explain the differences in susceptibility to AA. When the brown and white layers were inoculated intra-articularly with E. faecalis, the amyloid deposits were only observed in the injected joints, whereas the other joints remained free of amyloid. However, local production of SAA in the affected joints might play a role in amyloid depositions. Therefore, they suggested that the synoviocytes of 
brown layers might proliferate more strongly than the synoviocytes of white layers and, therefore, produce larger amounts of extrahepatic SAA that may act as nidus of amyloid fibrils. Quantitative studies of the extrahepatic production of SAA are therefore required to investigate this possibility.

\subsubsection{Approaches for a possible treatment}

AA is an irreversible disease (Landman et al., 1998a), probably due to the fact that amyloid fibrils have low solubility and a relative resistance to proteolytic digestion under physiological conditions. Therefore, the best option would be to treat the underlying inflammatory disease and prevent the occurrence of fibrillogenesis. Substances which facilitate or inhibit the amyloid depositions have been reported by Sevimli et al. $(2005,2008$ and 2013). These authors observed that high doses of vitamin A increased the severity of AA induced by E. faecalis and Freund's adjuvant, while methylprednisolone and pentoxifylline inhibit amyloidosis. Additionally, Shtrasburg et al. (2012) observed the possible role of alkylating agents in the prevention of amyloidogenesis in mice where cyclophosphamide and chlorambucil were the most potent inhibitors.

Therefore, the treatment of AA has focused to date on the prevention of chronic inflammation. However, the recent study conducted by Kanata et al. (2015) concluded that chickens previously exposed to AA may improve with age or even the amyloid deposits may tend to regress when chronic infection disappears.

In regard to chronic infection induced by E. faecalis, measures to prevent E. faecalis colonisation could have a direct impact on animal welfare by reducing the burden of infection thereby lowering environmental stress and, therefore, to reduce the incidence rate of AA. It is therefore necessary to learn more about the different avian E. faecalis field strains. Until 
today, the characterisation of E. faecalis strains has enabled us to relate its STs with the disease, as well as to identify the possible virulence genes involved. Worldwide, it is well known that the ST82 of E. faecalis is associated with AA in poultry. However, it is still not known whether ST82 as well as other STs which were found both in poultry and human, are normal inhabitants of the gastro-intestinal tract or represent a genuine zoonosis. Therefore, it would be interesting to conduct further studies on the different strain of E. faecalis affecting brown layer chickens with emphasis on the specific STs that are associated with AA.

In addition, E. faecalis can be transmitted among birds vertically and horizontally. Investigations to prevent and reduce enterococci contamination in birds and to figure out if the AA actually represents a zoonosis should be developed on a parallel basis. It should be taken into account that E. faecalis have a natural resistance towards antimicrobials and, therefore, the enterococcal infection treatments are increasingly limited. Consequently, efficient control measures against E. faecalis infection are required. Different general strategies could be applied in the fight against $E$. faecalis infection, such as the development of effective vaccines made from proven high pathogenic isolates or breeding for more resistant laying hens against $E$. faecalis infection.

\subsubsection{Breeding for disease resistance}

Estimations from FAO (2003) suggest that the world eggs' production will reach 89.9 million metric tons in 2030, at a growth rate of 1.6 percent per year from 2015 until 2030. It is therefore expected that the egg poultry industry progress steadily. However, infectious diseases are still responsible for high losses in the poultry industry due to mortality, veterinary costs, product contamination and subclinical symptoms. The major tools to combat avian infectious diseases are antibiotics and vaccines. Changes in regulations about the use of antibiotics in animal production and the fact that some vaccines are only partly effective 
underline the need for other approaches to disease control (Warner et al., 1987). Selection for disease resistance could be useful for this purpose.

The development of a disease in an animal occurs after the interaction between the environment and the genotype of the individual. The environment can be controlled under strong hygienic measures and biosecurity. However, the genetic control of the disease resistance is highly complex and is generally controlled by many genes. Estimates of heritability do not indicate which or how many genes are involved in the control of a particular trait (Warner et al., 1987). However, the estimation of the heritability of resistance to a disease shows the additive genetic component and allows predicting the selection response. According to Arthur \& Albers (2003), heritability of resistance to a disease is generally under $10 \%$. Berthelot et al. (1998) estimated heritabilities for resistance to the cecal carrier state of $S$. Enteritidis from $h^{2}=0.08$ to $h^{2}=0.09$. Janss \& Bolder (2000) reported heritability of $\mathrm{h}^{2}=0.12$ for mortality to $S$. Enteritidis. Cavero et al. (2009) reported heritability for resistance to $E$. coli of $\mathrm{h}^{2}=0.17$, and different studies estimated direct heritabilities for ascites syndrome up to $\mathrm{h}^{2}=0.44$ (Ahmadpanah et al., 2017).

Additionally, the estimation of the genetic correlation between disease resistance and other traits of economic significance is very important in order to carry out an indirect selection through a correlated response. Thus, antagonistic correlations might make simultaneous improvement of these both traits difficult. Unfortunately, information on genetic correlations among disease resistance and production traits is scarce. Han \& Smyth (1972) reported that chickens selected for higher growth rate were more susceptible to develop of Marek's disease than chickens selected for slower growth rate. Gavora et al. (1974) observed that more resistant chickens against Marek's disease had lower body weight and their eggs were smaller than susceptible chickens. Chickens selected by Spencer et al. (1979) for high 
egg production showed more resistance to lymphoid leukosis virus. More recently, Greef et al. (1998) and Moghadam et al. (2001) reported the genetic correlation between ascites syndrome and body weight, which is not clear. Greef et al. (1998) reported a negative correlation and, on the contrary, Moghadam et al. (2001) reported a positive correlation between these traits. Cavero et al. (2009) reported positive correlations between resistance to colibacillosis and important production traits. These authors observed that laying hens which are more resistant against $E$. coli infection have a better start of lay and lower feed intake while susceptible laying hens to colibacillosis showed better breaking strength and egg weight, although these differences between resistant and susceptible laying hens were not large. Therefore, they concluded that the improvement of the analysed traits will not be penalized if the selection for $E$. coli resistance is added into a commercial selection program.

Direct selection has made remarkable progress, but it still has some limitations (Jie \& Liu, 2011). Breeding for disease resistance requires that the birds are exposed to pathogens, which cannot be applied to high number of hens because of animal welfare constraints in addition to the associated costs. Usually, mortality is the criterion for disease resistance. However, it can be an obstacle when the infection does not cause death and the infected birds do not present clinical symptoms. Besides, the possible interaction among pathogens should be considered because the economic importance of infectious diseases as a whole is much higher than that of one disease alone. Consequently, breeding for resistance is usually carried out whenever losses were increasing and other means of control seemed ineffective. 
-52 - 


\subsection{OBJECTIVES}

The overall aims of this doctoral thesis were i) to characterize the virulence of different avian E. faecalis field isolates through the Embryo Lethality Assay (ELA) and ii) to investigate the possibility to select more resistant laying hens against E. faecalis infection through the ELA, which is proposed as an alternative model to replace the adult avian challenge assay.

To achieve the main objective, the following specific objectives are addressed:

- Develop a generic methodology to evaluate the pathogenicity of avian E. faecalis strains through the ELA in chicken embryos.

- Assess the median lethal dose $\left(\mathrm{LD}_{50}\right)$ and the virulence of a well-known pathogenic avian E. faecalis strain (K923/96), which can be used as reference strain in further analyses.

- Corroborate the capacity of the ELA for distinguishing E. faecalis strains in chicken embryos.

- Characterize the genetic diversity of different avian E. faecalis strains by ERIC-PCR under the hypothesis that strains with similar DNA banding patterns may be similar also in its infective ability.

- Evaluate the ELA in chicken embryos of brown layers under the hypothesis that these embryos are more susceptible compared with embryos of white layers when they are infected with the same E. faecalis strain and infectious dose.

- Estimate the heritability for embryonic survivability to E. faecalis infection and its relationship with traits of economic interest. 
-54 - 


\section{CHAPTER 2.}

\section{GENERIC METHODOLOGY TO EVALUATE THE \\ PATHOGENICITY OF AVIAN ENTEROCOCCUS FAECALIS STRAINS (EXPERIMENT 1).}

\subsection{INTRODUCTION}

E. faecalis is gaining more attention, not only because it has been associated with several poultry diseases (Gregersen et al., 2010), but also because of its ability to acquire antimicrobial resistance and its capacity to transfer pathogenicity islands, which encode virulence genes (Coburn et al., 2007). Consequently, E. faecalis could acquire the ability to survive in an environment in which antimicrobial agents are heavily used and, therefore, the enterococcal infection treatments are increasingly limited (Hayes et al., 2003). Hence, a better understanding of the virulence mechanisms of the E. faecalis strains is needed to develop preventive measures.

In order to study the role of E. faecalis in the pathogenesis of AA, adult avian challenge assay is the most used animal model. AA has been experimentally induced with $E$. faecalis in one-day-old chickens (Landman, 1999) and in six-week-old brown layer chickens (Landman et al., 1997; 1998b; 1999a and 1999). However, relatively high costs, complexity and ethical considerations limit the application of such challenge tests. Therefore, it seems appropriate to use the chicken ELA, which can provide an alternative tool to study the 
virulence of different strains in a faster, more sensitive, less expensive, more specific and relatively simple form (Wooley et al., 2000; Gibbs et al., 2003; Gibbs \& Wooley, 2003; Oh et al., 2012 and Seo et al., 2013).

Chicken ELA has been proposed to determine the degree of virulence of isolated fungi (Jacobsen et al., 2010), and bacteria such as E. coli (Wooley et al., 2000; Gibbs et al., 2003; Gibbs \& Wooley, 2003; Montgomery et al., 2005 and Oh et al., 2012), Francisella spp. (Nix et al., 2006), Yersinia enterocolítica (Townsend et al., 2008), Campylobacter jejuni (StewartTull et al., 2009), S. aureus (Polakowska et al., 2012), Riemerella anatipestifer (Seo et al., 2013) and Listeria (L.) monocytogenes (Andersson et al., 2015). In the case of Enterococcus spp., Borst et al. (2014) reported that the ELA is able to differentiate between virulent and avirulent Enterococcus (E.) cecorum strains, whose genotype has been closely related to each other through PFGE. Rudolph (2004) reported that different E. faecalis strains produced different degrees of mortality when the embryos were infected in the allantoic cavity (AC) with a single infectious dose $(2500 \mathrm{CFU} / \mathrm{ml})$. Furthermore, they were able to compare and confirmed the results obtained by the ELA with the results obtained by the adult avian challenge assay in a following experiment, where six-week-old chicks were infected with an infectious dose of $10^{10} \mathrm{CFU}$ of two E. faecalis strains tested previously in embryos.

According to the revised literature cited above, it seems necessary to develop a methodology in accordance with the isolate types and the purpose of the inoculation, taking into account that the embryo mortality rate (EMR) produced during an ELA is influenced by several factors such as:

- The source of fertilized eggs and good embryo quality, which are necessary to ensure that the inoculation is the only cause of mortality (Wooley et al., 2000; Gibbs et al., 2003 and Gibbs \& Wooley, 2003). 
- The age of the embryos at the inoculation since strains' virulence appears to differ based on embryonic development (Seo et al., 2013).

- The route of infection, which depends largely on the isolate type and the purpose of the inoculation (Wooley et al., 2000).

- The infectious dose, which appears to be related to the embryo survival time and rate (Nix et al., 2006).

Therefore, the main goal of this research was the evaluation of the ELA as a diagnostic model that could be used to establish the pathogenicity of E. faecalis strains cultured from field samples of AA. Of particular interest was to assess the median lethal dose $\left(\mathrm{LD}_{50}\right)$, which is defined as the dose required to kill half of the embryos at a defined time for a tested population, and the virulence of a well-known pathogenic avian E. faecalis strain (K923/96), which has been previously related with avian amyloidosis (Rudolph, 2004 and Petersen et al., 2009) and which will be used as the reference strain in further analyses.

\subsection{MATERIAL AND METHODS}

\subsubsection{Sample}

A total of 3443 eggs of White Leghorn Layers at an age of 47 - 51 weeks were used for the different ELAs (see Table 2.1. for further details). The tested flocks were free from diseases like Salmonella and Mycoplasma. Only first quality hatching eggs were used, which means soiled eggs as well as eggs with hairline cracks were sorted out. Eggs were stored at 15 ${ }^{\circ} \mathrm{C}$ for a maximum of four days prior to incubation and incubated in an auto-rotating egg incubator at $37.8{ }^{\circ} \mathrm{C}$ and $52-56 \%$ relative humidity. 
Table 2.1. Characteristics of the ELAs I-IV carried out in order to evaluate the E. faecalis strain K923/96.

\begin{tabular}{llllll}
\hline ELA & I & II & III & IV & $\begin{array}{l}\text { Viable count } \\
(\mathrm{CFU} / \mathrm{ml})\end{array}$ \\
\hline No. embryos/control $^{2}$ & 60 & 57 & 108 & 148 & - \\
No. embryos/dose $^{2}$ & 100 & 290 & 300 & 300 & - \\
Infectious dose (CFU/ml) $^{3}$ & & & & & $>1000$ \\
& 2500 & - & - & - & $>250$ \\
& 250 & - & - & - & $85-258$ \\
& 25 & 25 & 25 & 25 & $15-60$ \\
& - & 5 & 5 & 5 & $10-35$ \\
\hline
\end{tabular}

\footnotetext{
${ }^{1}$ Verification of the number of $\mathrm{CFU} / \mathrm{ml}$ contained in each used infectious dose.

${ }^{2}$ Embryos of the control group were inoculated in the AC with $0.2 \mathrm{ml}$ of sterile PBS.

${ }^{3}$ By an inoculation volume of $0.2 \mathrm{ml} / \mathrm{embryo}, 500,50,5,1$ and $0.5 \mathrm{CFU} / \mathrm{embryo}$ were inoculated respectively.
}

\subsubsection{Experimental design}

The overall scope of this research included four ELAs (I to IV) that are illustrated in Table 2.1. White fertilised eggs of a commercial layer programme of Lohmann Tierzucht $\mathrm{GmbH}$ were inoculated via the AC after 10 days of incubation. A single known and wellcharacterized pathogenic avian E. faecalis strain K923/96 (Rudolph, 2004 and Petersen et al., 2009) was used in all these ELAs. Different doses of the E. faecalis strain mentioned above were used in the present research in order to determine the $\mathrm{LD}_{50}$. As shown in Table 2.2., the doses used in the ELA I were reduced in the following ELAs due to the high mortality recorded with the higher doses. In addition to the infected embryos, there was always one control group in each ELA, which was inoculated in the AC with $0.2 \mathrm{ml}$ of sterile phosphatebuffered saline (PBS). 


\subsubsection{Inoculum}

The E. faecalis strain K923/96 isolated from the amyloidogenic joint of a brown layer, which was already used by Rudolph (2004) and Petersen et al. (2009), was used in all ELAs. The preparation of the inoculum was applied in accordance with the following protocol (Rudolph, 2004).

The bacteria, which were preserved in a CRYOBANK ${ }^{\mathrm{TM}}$ tube, were recovered by removing the cryobank tube from the freezer. A sterile forceps was used to roll one bead on a Columbia sheep blood agar plate. The agar plate was incubated aerobically for $24 \mathrm{~h}$ at $37^{\circ} \mathrm{C}$. After incubation, colonies were scraped off and a suspension of $10 \mathrm{ml}$ was prepared in PBS. This suspension was set to the photometer, of a wavelength at $650 \mathrm{~nm}$. To obtain a suspension around $5 \times 10^{7} \mathrm{CFU} / \mathrm{ml}$ (culture I), it was adjusted with an absorbance to approximately 0.164 \pm 0.01 . To adjust the suspension, $100 \mu \mathrm{l}$ of the culture I were given into $10 \mathrm{ml}$ of PBS (culture II). For the culture III another $50 \mu \mathrm{l}$ of the culture II were given into $10 \mathrm{ml}$ of PBS (dilution 1:1 with an infectious dose of $2500 \mathrm{CFU} / \mathrm{ml}$ ). From this dose, different dilutions were obtained: $1 / 10,1 / 100,1 / 500$ and 1/1000 with infectious doses of 250, 25, 5 and $2.5 \mathrm{CFU} / \mathrm{ml}$, respectively (Table 2.1.). By an inoculation volume of $0.2 \mathrm{ml} / \mathrm{embryo}, 500,50,5,1$ and 0.5 CFU/embryo were inoculated respectively. However, Rudolph (2004) reported that the number of counted colonies in the experiments they did may vary between 500 and 5000 $\mathrm{CFU} / \mathrm{ml}$. Therefore, in order to guarantee that the infectious dose was correctly prepared, the number of CFUs contained in each dose was verified by viable count on a Columbia sheep blood agar plate. For this purpose, $0.1 \mathrm{ml}$ of inoculum per dose was incubated aerobically. Viable counts were determined two times per dose. After $24 \mathrm{~h}$ at $37^{\circ} \mathrm{C}$ the exact number of grown bacteria was counted with a traditional click-counter. The real number of CFUs contained in each infectious dose is shown in Table 2.1. 


\subsubsection{Embryo lethality assay}

According to the previously described methods for AC inoculation of chicken embryos, the ELAs were assayed as follows.

Prior to inoculation, the unfertilized eggs and eggs with dead embryos were removed by candling. Hatching eggs, which had been incubated for 10 days and were in good condition, were inoculated after disinfection of the egg surface with Bacillol AF (Bode Chemie $\mathrm{GmbH}$ ). Each egg was opened carefully on the blunt end of the egg with a punch and inoculated with a disposable and sterile syringe in the AC either with $0.2 \mathrm{ml}$ of bacterial suspension or with $0.2 \mathrm{ml}$ of PBS in the case of the control group. All holes were sealed with wood glue and the embryos returned to incubation at $37.8^{\circ} \mathrm{C}$ for another seven days. The incubated eggs were candled every $24 \mathrm{~h}$ for seven days and embryonic mortalities were daily recorded per group. The number of dead embryos was used to classify the pathogenicity of $E$. faecalis according to the infectious dose.

At the end of each ELA, at 17 days of incubation, all remained embryos were sacrificed by hypothermia. They were stored for $48 \mathrm{~h}$ at $4^{\circ} \mathrm{C}$.

\subsubsection{Macroscopic lesions and re-isolation}

Random selections of the embryos dead by the infection, as well as some surviving embryos at the end of the ELAs, were used for further examinations. After disinfection of the egg surface with Bacillol AF, the eggshell was opened with sterile material. The embryo was carefully separated from its surrounding membranes in order to evaluate macroscopic tissue changes in embryos caused by E. faecalis. In addition, smear samples from the allantoic fluid of some dead and surviving embryos were cultivated in a blood plate for $24 \mathrm{~h}$ at $37^{\circ} \mathrm{C}$ in order to re-isolate the E. faecalis strain. 


\subsubsection{Statistical analysis}

Statistical analyses of mortality data were carried out by applying a linear logistic model for repeated measurements with a binary response variable, which was modelled as a binomial random variable $\left(\mathrm{y}_{\mathrm{i}}\right)$. The dependent variable $\left(\mathrm{y}_{\mathrm{i}}\right)$ can take the value 1 with a probability for embryonic mortality $\pi_{\mathrm{i}}$ or the value 0 with a probability to survive of $1-\pi_{\mathrm{i}}$. The logistic model uses a link function $\mathrm{g}\left(\mu_{\mathrm{i}}\right)$, linking the expected value to the linear predictors $\eta_{\mathrm{i}}$. The logit link function is defined by $\log \left[\pi_{\mathrm{i}} /\left(1-\pi_{\mathrm{i}}\right)\right]=\eta_{\mathrm{i}}$, where $\pi_{\mathrm{i}}$ is the probability of mortality until the end of the research at 17 days of incubation. The data were then analysed with the GLIMMIX procedure (SAS Institute Inc., 2011) using the following generalized linear model (Littell et al., 1999):

$$
\operatorname{Logit}\left(\pi_{\mathrm{ij}}\right)=\eta_{\mathrm{ij}}=\log \left[\pi_{\mathrm{ij}} /\left(1-\pi_{\mathrm{ij}}\right)\right]=\mu+\alpha_{\mathrm{i}}+\beta_{\mathrm{j}},
$$

where $\eta_{\mathrm{ij}}$ denotes the linear predictor, $\pi_{\mathrm{ij}}$ is a binary outcome (i.e., probability of embryonic mortality), $\mu$ is the overall mean effect, $\alpha_{\mathrm{i}}$ is the fixed effect of the infectious dose (from 2.5 to $2500 \mathrm{CFU} / \mathrm{ml}$ ) and $\beta_{\mathrm{j}}$ is the random effect of repeated measurement of ELA. Least squares means (LSMEANS) were estimated on the logit scale and then backtransformed using the inverse link function $\pi=\exp (x \beta) /[1+\exp (x \beta)]$ to the original scale (probability) applying the LSMEANS statement. Significant differences between LSMEANS were tested using a $t$-test procedure by inclusion of the DIFF option in the LSMEANS statement. Differences were considered significant when $P<0.05$.

Different statistical models using different probability distributions, normal, logistic and extreme value distribution, were tested in order to compare its fit statistics for the infectious dose. Underlying normal distribution using the coefficient of determination was found to be the best fit and therefore was applied to estimate the $\mathrm{LD}_{50}$. 
The $\mathrm{LD}_{50}$ was estimated by the SAS PROBIT procedure (SAS Institute Inc., 2011) using the maximum likelihood method of regression parameters. Since the response $\mathrm{Y}$ is binary, the probit equation is:

$\mathrm{p}=\operatorname{Pr}(\mathrm{Y}=0)=\mathrm{C}+(1-\mathrm{C}) \mathrm{F}\left(\mathrm{x}^{\prime} \beta\right)$

where $\mathrm{p}$ is the probability of a response, $\mathrm{C}$ is the natural response rate, $\mathrm{F}$ is the cumulative distribution function, $x^{\prime}$ is the vector of explanatory variables and $\beta$ is the vector of parameter estimates. The response rate was calculated using the INVERSECL statement option by applying the following formula:

$$
\mathrm{x}^{\prime}=1 / \mathrm{b}_{1}\left(\mathrm{~F}^{-1}(\mathrm{p})-\mathrm{x}^{*} \mathrm{~b}^{*}\right)
$$

The course of embryonic survivability over the seven post-inoculation (p.i.) days within each treatment group was illustrated according to the Kaplan-Meier method (survival analysis) by applying the LIFETEST procedure of SAS System 9.3 (SAS Institute Inc., 2011) and using the following model:

$$
\hat{S}(t)=\prod_{j: t_{j} \leq t}\left[1-\frac{d_{j}}{n_{j}}\right] ; \text { for } t_{1} \leq t \leq t_{k}
$$

where $\hat{S}(t)$ is the survivor function and $t$ is the lifetime of a randomly selected experimental unit. For each $\mathrm{j}: \mathrm{t}_{\mathrm{j}} \geq \mathrm{t}$, let $\mathrm{t}_{1}<\mathrm{t}_{2}<\ldots<\mathrm{t}_{\mathrm{k}}$ represent the different event times. $\mathrm{n}_{\mathrm{j}}$ is the number of individuals at risk just prior to $t_{i}$, and $d_{j}$ is the number of individuals that die at time $t_{j}$. 


\subsection{RESULTS}

\subsubsection{Embryo lethality assay}

The ELAs showed a different EMR according to the infectious dose. The infectious dose showed a significant effect $(P<0.0001)$ on the EMR. As shown in Table 2.2., the infectious doses of $250 \mathrm{CFU} / \mathrm{ml}$ and $2500 \mathrm{CFU} / \mathrm{ml}$ used in the ELA I resulted in a high EMR of more than $90 \%$ lethality after seven days p.i. and did not differ significantly from each other. Therefore, neither of these doses were used in the following ELAs in order to avoid a massive embryonic mortality that would not allow the differentiation between the E. faecalis strains. The dose of $25 \mathrm{CFU} / \mathrm{ml}$ produced an average EMR of $63 \%$, which was significantly different than all other used doses. The infectious dose of $5 \mathrm{CFU} / \mathrm{ml}$ was added into ELAs II, III and IV (Table 2.1. and 2.2.) in order to estimate the lethal effect of the low infectious dose and calculate the proper $\mathrm{LD}_{50}$. The average EMR estimated for the doses of $5 \mathrm{CFU} / \mathrm{ml}$ and 2.5 $\mathrm{CFU} / \mathrm{ml}$ was $45 \%$ and $43 \%$, respectively, and did not differ significantly from each other. Moreover, in ELA III a higher EMR was reported with the infectious dose of $2.5 \mathrm{CFU} / \mathrm{ml}$ (64\%) as compared to the infectious dose of $5 \mathrm{CFU} / \mathrm{ml}(51 \%)$.

The average EMR of the control group was $2.5 \%$, with variation from $0 \%$ to $7 \%$. Thus, these low mortalities in the control group confirm the appropriate environment in the incubator during the research, as well as the low negative impact of the injection. Therefore, the mortalities obtained in the different groups can be unequivocally associated to the effect of the infectious doses. The control group differed significantly from all other infectious doses. 
Table 2.2. Percentage of chicken embryo mortality with increasing infectious dose of the $E$. faecalis strain K923/96 following inoculation of $0.2 \mathrm{ml}$ into the AC.

\begin{tabular}{|c|c|c|c|c|c|}
\hline \multirow{2}{*}{$\begin{array}{l}\text { Infectious dose } \\
(\mathrm{CFU} / \mathrm{ml})\end{array}$} & \multicolumn{4}{|c|}{$\mathrm{ELA}^{1}$} & \multirow{2}{*}{ LS-means $^{2}$} \\
\hline & $I_{(460)}$ & $\mathrm{II}_{(927)}$ & $\mathrm{III}_{(1008)}$ & $\mathrm{IV}_{(1048)}$ & \\
\hline 2500 & 92 & - & - & - & $93^{a}$ \\
\hline 250 & 89 & - & - & - & $90^{\mathrm{a}}$ \\
\hline 25 & 71 & 48 & 83 & 56 & $63^{\mathrm{b}}$ \\
\hline 5 & - & 50 & 51 & 38 & $45^{\mathrm{c}}$ \\
\hline 2.5 & 25 & 45 & 64 & 30 & $43^{c}$ \\
\hline Control $^{3}$ & 7 & 0 & 4 & 1 & $2.5^{\mathrm{d}}$ \\
\hline
\end{tabular}

${ }^{1}$ Overall number of infected embryos in each ELA is indicated in brackets.

${ }^{2}$ The effects were estimated using a generalized linear model with binomial error distribution and logit link function. Different letters indicate statistically significant differences between groups.

${ }^{3}$ Embryos of the control group were inoculated in the AC with $0.2 \mathrm{ml}$ of sterile PBS.

\subsubsection{Median lethal dose}

Figure 2.1. shows probit analysis on infectious dose of E. faecalis strain K923/96. The results of the dose level effect on the embryonic mortality (Figure 2.1., left) indicate a mean tolerance for the embryos inoculated with the E. faecalis strain K923/96 of $6.6 \mathrm{CFU} / \mathrm{ml}$, i.e., the dose corresponding to an embryonic mortality probability of $0.5\left(\mathrm{LD}_{50}\right)$ was $6.6 \mathrm{CFU} / \mathrm{ml}$, with a $95 \%$ confidence interval of 3.5 and $11.4 \mathrm{CFU} / \mathrm{ml}$. It can be observed that infectious doses of this strain above $100 \mathrm{CFU} / \mathrm{ml}$ (with a 95\% confidence interval of 45 and 500 $\mathrm{CFU} / \mathrm{ml}$ ) can produce $75 \%$ or greater embryonic mortality.

Figure 2.1. on the right shows the relationship between infectious doses, observed embryonic mortality values, and estimated probability values of the E. faecalis strain K923/96. Embryonic mortality produced with the infectious doses of 2.5 and $250 \mathrm{CFU} / \mathrm{ml}$ was higher than the estimated probability. However, the embryonic mortality observed with the infectious doses of 5 and $2500 \mathrm{CFU} / \mathrm{ml}$ was lower than the estimated probability. The observed and estimated embryonic mortality with the infectious dose of $25 \mathrm{CFU} / \mathrm{ml}$ was the same. 


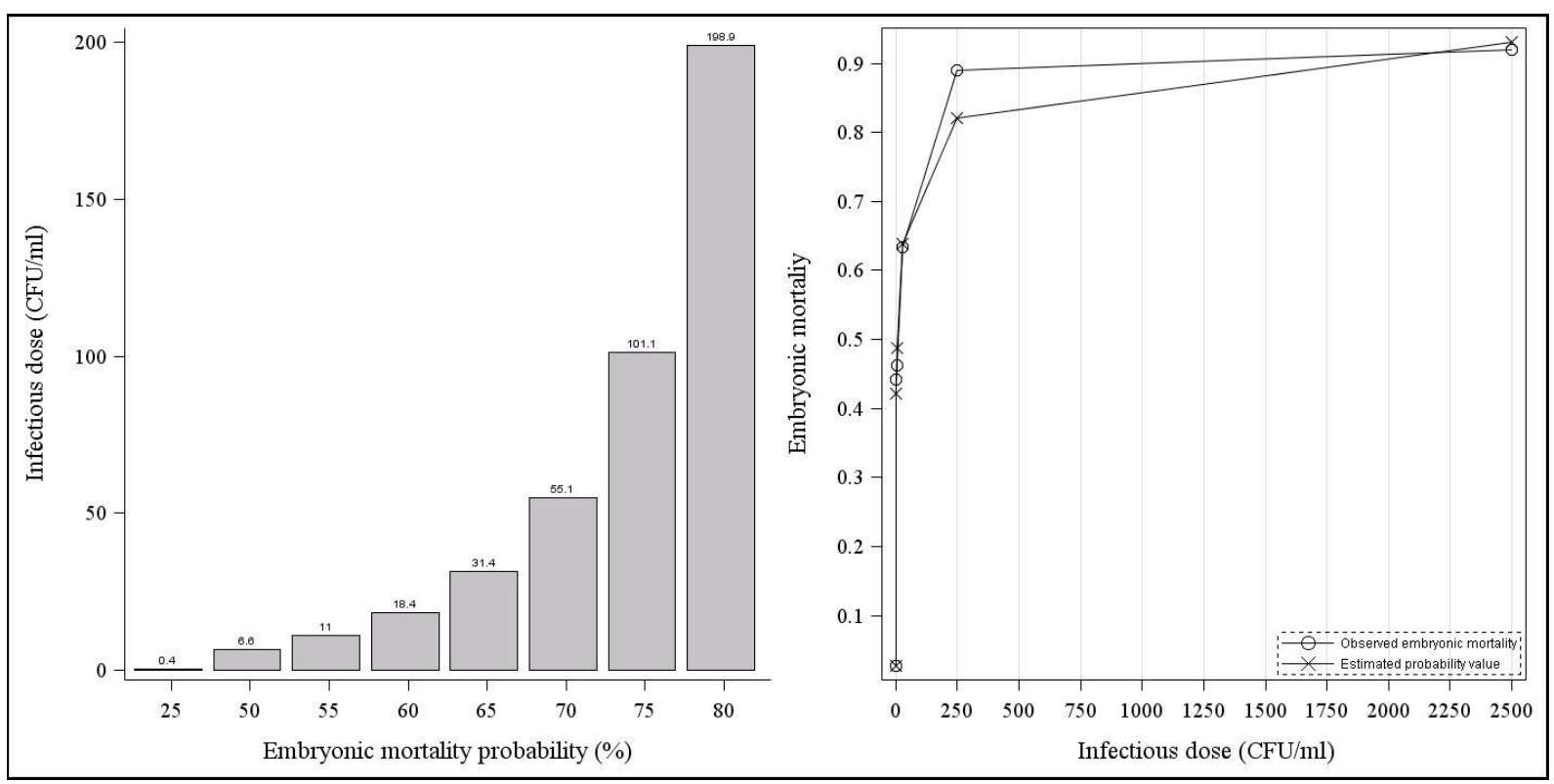

Figure 2.1. Probit analysis on infectious dose of E. faecalis strain K923/96. On the left, the dose level effect on the embryonic mortality and, on the right, the distribution dependent on the dose.

\subsubsection{Embryo survival}

The survival curve for embryos infected with the E. faecalis strain K923/96 is presented in Figure 2.2. Higher infectious doses of this strain were significantly more virulent than the lower doses $(P<0.0001)$. The highest embryonic mortality occurred three and four days p.i. for all doses. As expected, the higher the infectious dose, the lower the embryonic survival time, i.e., the embryos infected with the infectious doses of 250 and $2500 \mathrm{CFU} / \mathrm{ml}$ had less survival probability at day 3 p.i. than the embryos infected with doses of 25,5 and 2.5 CFU/ml. As shown in Figure 2.2., after four day p.i. the embryonic mortality declined substantially. Around $98 \%$ of the embryos in the control group survived until the end of the study duration. 


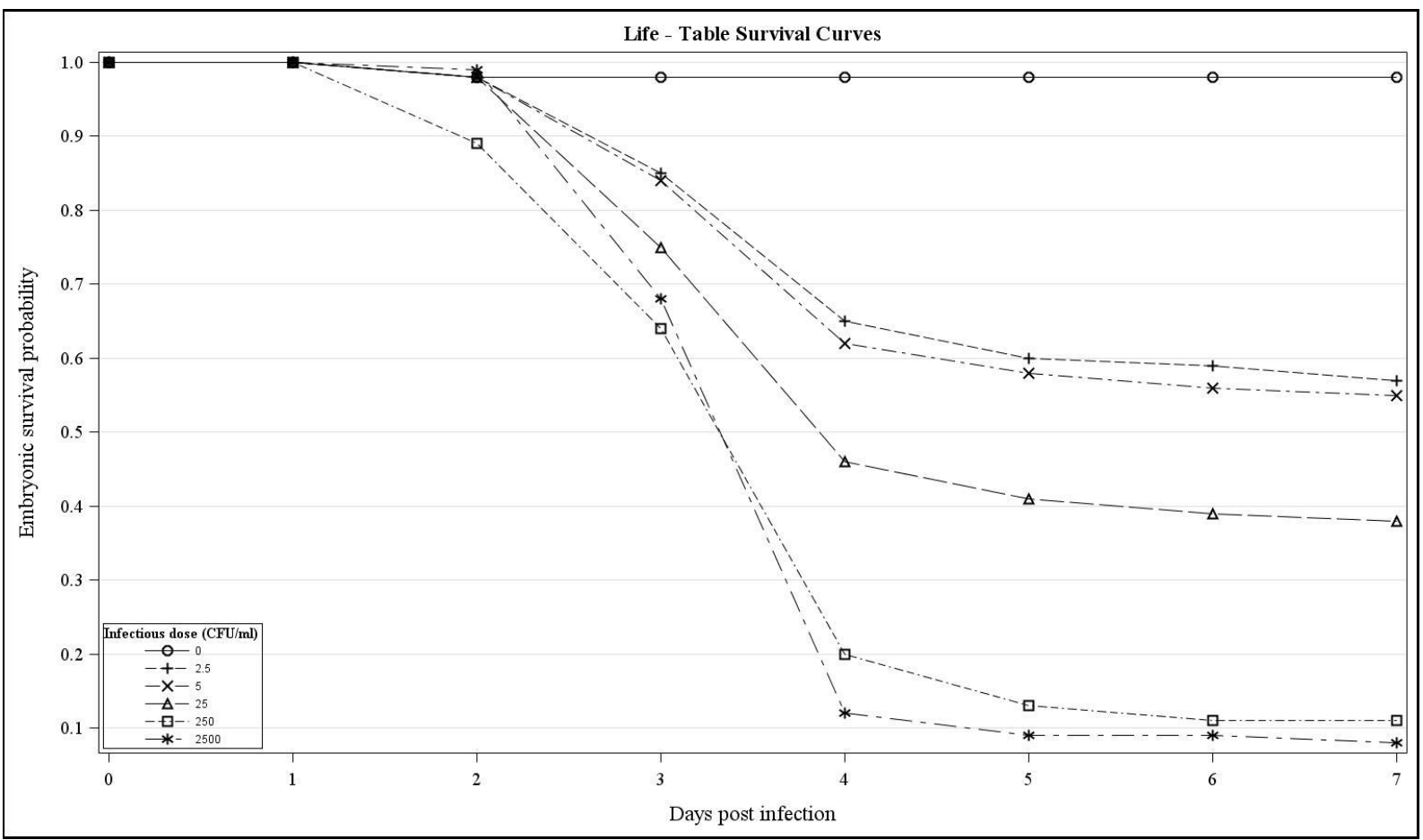

Figure 2.2. Survival curves of 10-day-old chicken embryos inoculated into the AC with different infectious doses of the E. faecalis strain K923/96.

\subsubsection{Macroscopic lesions}

No lesions were observed in the embryos of the control group. However, the embryos infected with E. faecalis succumbed to bacterial infection. Malformed and underdeveloped embryos were observed in all treated groups. Bodies of the analysed infected embryos showed profound subcutaneous oedema, cranial and skin haemorrhages and loss of the plumage regardless of the infectious dose, as shown in Figure 2.3. Therefore, a clear relationship between the embryo lesions and the respective infectious dose was not observed. It should be noted that some dead and surviving infected embryos at the end of the ELAs did not show any visible signs. 

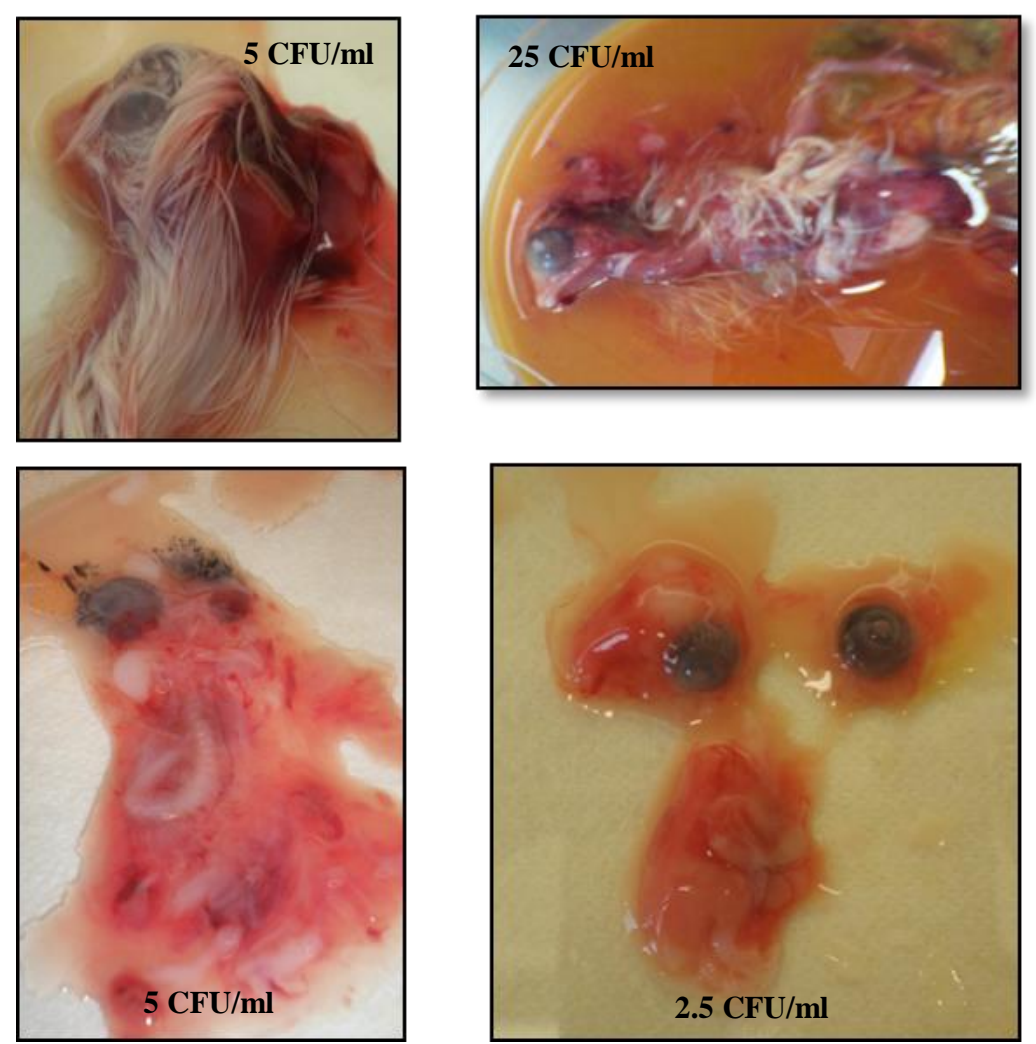

Figure 2.3. Macroscopic lesions of white laying hen embryos infected with different infectious doses of the E. faecalis strain K923/96.

\subsubsection{Re-isolation.}

Smear samples from the allantoic fluid of random analysed dead embryos as well as from surviving embryos were taken in order to re-isolate the E. faecalis strain. The bacterial counts of the infected embryos were always positive and their allantoic fluid contained more $\mathrm{CFU} / \mathrm{ml}$ compared to the infectious doses administered to the embryos (>1000 CFU/ml), although some of them did not show any signs and any abnormalities. In the case of the control group, the bacterial count was negative for all analysis. 


\subsection{DISCUSSION}

Based on the revised literature (Landman et al., 1999b; Wooley et al., 2000; Gibbs et al., 2003; Gibbs \& Wooley, 2003; Rudolph, 2004; Montgomery et al., 2005; Townsend et al., 2008; Stewart-Tull et al., 2009; Jacobsen et al., 2010; Oh et al., 2012; Polakowska et al., 2012; Seo et al., 2013 and Borst et al., 2014) an ELA was carried out as a diagnostic model to establish the pathogenicity of a single E. faecalis strain.

The results on the use of specific pathogen-free (SPF) embryos in the ELA obtained by Borst et al. (2014) with E. cecorum showed that the SPF embryos are as susceptible as normal embryos, suggesting that SPF embryos have no innate resistance to bacterial infection. Therefore, in the present research no SPF embryos were used. Additionally, only embryos of the best quality were used in order to avoid biased results, i.e., to ensure that the inoculation is the only cause of mortality (Wooley et al., 2000).

According to Jacobsen et al. (2010) and Seo et al. (2013), the embryo age at inoculation has an influence on the embryonic lethality rate. The younger the embryos (seven days old), the more susceptible they were the virulent strains compared to embryos at later stage of embryonic development (13 and 15 days old) when they are inoculated with $R$. anatipestifer (Seo et al., 2013) and Aspergillus fumigatus (Jacobsen et al., 2010). However, the greatest differences in EMR between the virulent and avirulent $R$. anatipestifer strains were most evident in 10-day-old chicken embryos (Seo et al., 2013). Therefore, for the present research 10-day-old embryos were used.

The number of inoculated embryos per strains varies among the revised literature. Nix et al. (2006), Townsend et al. (2008) and Stewart-Tull et al. (2009) used less than ten embryos per strain. Wooley et al. (2000), Gibbs et al. (2003), Montgomery et al. (2005), 
Rudolph (2009), Jacobsen et al. (2010), Oh et al. (2012), Polakowska et al. (2012), Seo et al. (2013), Borst et al. (2014) and Jung et al. (2017) inoculated from 10 to 20 embryos per strain. Specifically, Wooley et al. (2000) infected 100 embryos (20 embryos per strain and ELA with five repetitions) and they estimated that at least 11 embryos are necessary to obtain significant differences among the strains of E. coli. However, Gibbs \& Wooley (2003) observed that the overall ELA results seem to be more highly correlated with the results of the adult avian challenge assay when more embryos per ELA are used (100 vs. 44 embryos per strain). Therefore, the largest possible number of embryos was used in the present research, although a minimum of 11 embryos per strain is sufficient (Wooley et al., 2000).

The AC route was chosen as the method of inoculation because other administration routes like yolk sac route and on the egg albumen with E. faecalis (Landman et al., 1999b), as well as the infection on the chorioallantoic membrane with $C$. jejuni (Stewart-Tull et al., 2009) produced a massive embryonic mortality, which would not allow a clear differentiation between the E. faecalis strains or the estimate of the $\mathrm{LD}_{50}$. Landman et al. (1999b) studied the induction of AA and its possible routes of infection through chicken embryo infections with E. faecalis. These authors observed that the dipped fertilised eggs and the inoculation of the air chamber with E. faecalis were ineffective, the inoculation of egg albumen hardly produced any embryonic deaths; on the other hand, yolk sac inoculation resulted in a massive mortality within two days. Additionally, according to the results of Wooley et al. (2000) and Seo et al. (2013), the differentiation among avirulent and virulent strains of avian E. coli and $R$. anatipestifer respectively is possible and more effective through the AC route than into the yolk sac or on the chorioallantoic membrane respectively.

According to Landman (1999) and Ciftci \&Diker (2009), regardless of the route of administration, the infectious dose of E. faecalis in an adult avian challenge assay also plays 
an important role in the development of avian amyloidosis. Landman (1999) reported that the pathological and clinical lesions of AA can be reproduced through inoculation with high doses of E. faecalis. Ciftci \& Diker (2009) observed that arthritis formation in chickens inoculated with E. faecalis depend on the infectious dose independent of the inoculation route. Besides, Nix et al. (2006) reported that inoculated embryos with higher infectious doses of Francisella $(F$.$) tularensis strains (around 2.3 \times 10^{4} \mathrm{CFU}$ ) showed lower survival time and rate than inoculated embryos with lower infectious doses (around $1.3 \times 10^{1} \mathrm{CFU}$ ). Hence, different infectious doses of the E. faecalis strain K923/96 were used in the present research in order to estimate the $\mathrm{LD}_{50}$ of this strain in chicken embryos.

As shown in Table 2.2., the results obtained showed a clear relationship between infectious dose and EMR in accordance with the results obtained by Seo et al. (2013) and Borst et al. (2014), who observed higher EMR with the higher infectious doses than the lower infectious doses. The EMR produced with the infectious dose of $2500 \mathrm{CFU} / \mathrm{ml}$ used in the present research (93\%) is consistent with the values reported by Rudolph (2004), who observed an EMR between $90 \%$ and $100 \%$ with the same strain and infectious dose. This indicates that the ELA results of this research can be considered reliable.

The estimated doses at $\mathrm{LD}_{50}$ for the inoculation of chicken embryos with the $E$. faecalis strain K923/96 was $6.6 \mathrm{CFU} / \mathrm{ml}$ (Figure 2.1.). This result is the first to report the appropriate infectious dose of an E. faecalis strain to inoculate these chicken embryos lines. Borst et al. (2014) reported that the lowest dose of E. cecorum strains able to produce around $50 \%$ embryonic mortality was $10^{3} \mathrm{CFU} / \mathrm{ml}$, and Nix et al. (2006) observed that infectious doses of $F$. tularensis from 30 to $200 \mathrm{CFU}$ produced $100 \%$ embryonic mortality. This observation suggests the importance to determine an appropriate infectious dose according to the type of isolate and probably the strain. 
In addition, Nix et al. (2006) reported that the embryo survival time is usually correlated with the infectious dose; the lower the infectious dose, the greater the survival time of the embryos, which was confirmed in this research (Figure 2.2.).

In accordance with the results obtained by Wooley et al. (2000) and Gibbs et al. (2003), the results obtained showed a fast decrease in survival rate from two to four days p.i., whereas the survival rate decreased more slowly afterwards, as shown in Figure 2.2. The lowest embryonic survival probability was observed at three and four days p.i. in all doses, which confirms the results of Wooley et al. (2000), Gibbs et al. (2003), Gibbs \& Wooley (2003), Stewart-Tull et al. (2009), Seo et al. (2013) and Borst et al. (2014) with other bacterial strains.

Rudolph (2004) confirmed the ELA results with the chicken infection challenge model. Both models have the ability to distinguish among the virulence of different strains, although there are more deaths in the ELA model compared to the chicken challenge study. This author reported that $2500 \mathrm{CFU} / \mathrm{ml}$ of the E. faecalis strain K923/96 (the same strain used in the present research) produced between $90 \%$ and $100 \%$ embryonic mortality in the ELA while no deaths in the chicken model $\left(10^{10} \mathrm{CFU} /\right.$ chicken $)$ were reported, although $66 \%$ of the chickens showed a growth decline and swelling of the joints. These mortality differences may be due to the fact that the embryos succumb to serious bacterial and in part do not withstand the infection while the chickens are able to survive (Gibbs et al., 2003; Gibbs \& Wooley, 2003 and Borst et al., 2014).

The embryos in this research also succumbed to E. faecalis infection. They suffered sepsis, cutaneous haemorrhages and subcutaneous oedema like the infected embryos in the study of the authors mentioned above. Besides, Wooley et al. (2000) observed that avirulent E. coli strains produced fewer lesions than virulent strains, which could not be confirmed in 
this experiment due to the use of only one single strain. All dead infected embryos in the present research showed the same signs regardless of the infectious dose and, therefore, no relationship between the embryo lesions and the infectious doses was observed.

No lesions and no re-isolates were observed in the embryos of the control group, thus indicating that the research was reliable and the embryonic mortality was due to the infection and not due to external effects. On the contrary, the re-isolation of E. faecalis in all analysed infected embryos was always positive, although some of these embryos did not show any visible signs. Besides, an increase in the viable count of the allantoic fluid of dead embryos was observed compared to the initial number of $\mathrm{CFU} / \mathrm{ml}$ contained in each infectious dose, confirming the results obtained by Wooley et al. (2000), Rudolph (2004), Townsend et al. (2008) and Stewart-Tull et al. (2009). Even an increase in the viable count was observed in surviving embryos, which is in accordance with the results obtained by Rudolph (2004) and Townsend et al. (2008). Therefore, the differences in bacterial growth after the inoculation cannot explain the differences in EMR because the number of CFU can fluctuate and no produce clear differences in the lethality, which is consistent with the results of Wooley et al. (2000) with E. coli.

It should be taken into account that the EMR produced in the ELA depends on the dose. It is therefore important to determine an appropriate infectious dose which should not be too high to avoid a massive embryonic mortality that would not allow discrimination between the E. faecalis strains. In this regard, the $\mathrm{LD}_{50}$ can be considered appropriate in order to establish an infection limit of 50\% lethality. In conclusion, the methodology used in the present research, as well as the obtained $\mathrm{LD}_{50}$ of the E. faecalis strain K923/96, can be used as reference in further ELAs on E. faecalis virulence. 


\title{
CHAPTER 3.
}

\section{VIRULENCE CHARACTERIZATION OF AVIAN}

\author{
ENTEROCOCCUS FAECALIS FIELD ISOLATES BY CHICKEN
}

\author{
EMBRYO LETHALITY ASSAY AND ERIC-PCR
}

(EXPERIMENT 2).

\subsection{INTRODUCTION}

Treatment of AA has focused to date on the prevention and treatment of chronic inflammation produced by E. faecalis strains. However, the enterococcal infection treatments are increasingly limited. This, on the one hand, is due to the restrictions on antimicrobial use in animal production emerged since the global health crisis of antimicrobial resistance (World Health Organization, 2012). On the other hand, it is due to the zoonotic potential of the $E$. faecalis strains, its ability to acquire antimicrobial resistance and its capacity to acquire virulence genes by transfer of pathogenicity islands (Coburn et al., 2007). Additionally, little is known about the risk from field avian E. faecalis strains and it is currently difficult to estimate its virulence degree. Therefore, a thorough understanding of the risk from field $E$. faecalis strains is needed in order to develop effective control strategies against bacterial infections to reduce the incidence rate of AA and, consequently, to guarantee the welfare of the birds and improve their economic performance. 
Therefore, the main goal of this research was to characterize different avian E. faecalis field strains through the ELA taking the E. faecalis strain K923/96 and the infectious dose of $5 \mathrm{CFU} / \mathrm{ml}$ reported in the previous Experiment 1 (Chapter 2 of the present dissertation) as reference, and thus corroborates the ELA capacity for distinguishing avian E. faecalis strains. Of particular interest was to characterize the genetic diversity of these strains by ERIC-PCR under the hypothesis that strains with similar DNA banding patterns may be similar also in its infective ability.

\subsection{MATERIAL AND METHODS}

\subsubsection{Bacterial strains}

A total of 69 avian strains of Enterococcus spp. (1 Enterococcus (E.) hirae and 68 E. faecalis strains) were characterized in the present research through 10 ELAs (I to X). As shown in Figure 3.2., most of the known E. faecalis strains were obtained from clinical cases of AA at layers farms in Germany $(\mathrm{n}=31)$, France $(\mathrm{n}=2)$ and Switzerland $(\mathrm{n}=1)$. Only three $E$. faecalis strains (282-4, 513-5 and 515-3) were isolated from apparently healthy birds. Unfortunately, the information on the isolation from 34 strains is unknown. All strains were obtained during 2011 and 2012, except the E. faecalis strain K923/96, which was isolated in 1996 and it has been well-characterized and used in different studies by Rudolph (2004) and Petersen et al. (2009), and the strains 1082-01 and 607-01 isolated in 2004 and characterized by Petersen et al. (2009). Additionally, 49 of the 67 E. faecalis used in the present study were tested before by the laboratory of Lohmann Tierzucht GmbH (Germany) as ST82 by using the Real Time (RT-) PCR method described by Petersen et al. (2010). Besides, the genes ace, 
efaA, cyl, asal (or agg) and gelE were present in all these strains although the genes esp and hyl were not determined.

\subsubsection{ERIC-PCR and phylogenetic analysis}

All Enterococcus spp., except the E. faecalis strain 2323-96, were used to develop the ERIC-PCR method described by Jurkovič et al. (2007). The bacteria, which were preserved in a CRYOBANK ${ }^{\mathrm{TM}}$ tube, were recovered removing the cryobank tube from the freezer. Bacteria were cultured on a Columbia sheep blood agar plate. The agar plate was incubated aerobically for $24 \mathrm{~h}$ at $37^{\circ} \mathrm{C}$. After incubation, colonies were scraped off and a suspension of $400 \mu \mathrm{l}$ was prepared in PBS. DNA was purified using the NucleoSpin Tissue Kit (MachereyNagel, Düren). Afterwards $3 \mu$ of the suspension was used for PCR amplification. Isolates were genotyped by ERIC-PCR. Reactions were carried out in a total volume of $50 \mu 1$ containing $18 \mu \mathrm{l}$ of RNAse free water, $3 \mu \mathrm{l}$ of $\mathrm{MgCl}_{2}, 25 \mu \mathrm{l}$ of dNTPs mix (10 mM of each), 1 $\mu 1$ of ERIC1-R primer (5'-ATGTAAGCTCCTGGGGATTCAC-3') and $3 \mu 1$ of template DNA. The ERIC-PCR was carried out with only one single ERIC 1 primer, which uses the total DNA and, therefore, provides results with good reproducibility. Besides, its discriminatory power is higher than when using both ERIC 1 and ERIC 2 primers (Jurkovič et al., 2007). Amplifications were performed in an Eppendorf thermocycler with a cycling program consisting of an initial denaturing step at $94{ }^{\circ} \mathrm{C}$ for $5 \mathrm{~min}$, then 35 cycles of denaturation at $94^{\circ} \mathrm{C}$ for $1 \mathrm{~min}$, annealing at $48{ }^{\circ} \mathrm{C}$ for $1 \mathrm{~min}$ and elongation at $72{ }^{\circ} \mathrm{C}$ for 2 min and a final extension of $72{ }^{\circ} \mathrm{C}$ for $7 \mathrm{~min}$.

ERIC-PCR results show banding patterns, which can easily be visualized by agarose gel electrophoresis. The genetic diversity of the chromosomal DNA may be explained by differences in the banding patterns among the strains (Odinot et al., 1995). Therefore, all products were analysed by electrophoresis through $1.5 \%$ agarose gels at $70 \mathrm{~V}$ for $70 \mathrm{~min}$ in a 
1x TAE buffer (40mM Tris-acetate, $\mathrm{pH} 8.3)$ and revelled in ethidium bromide $(10 \mathrm{mg} / \mathrm{ml})$. The gels were visualized and photographed under UV trans illuminator.

The phylogenetic analysis was performed based on the banding pattern of the different strains of Enterococcus spp. by using the Phylogenetic Inference Package, PHYLIP-3.68 (Felsenstein, 2005), after ERIC-PCR. The data were calculated by using parsimony. The tree was visualized using the program Archaeopteryx 0.9901 beta (Han \& Zmasek, 2009).

\subsubsection{Embryo lethality assay}

The ELAs were performed on a sample of 9987 eggs of White Leghorn Layers at an age of 29 - 62 weeks. The tested flocks were free from diseases such as Mycoplasma or Salmonella. Only first-quality hatching eggs were used, i.e. soiled eggs as well as eggs with hairline cracks were sorted out. Fertilized eggs were stored at $15^{\circ} \mathrm{C}$ for a maximum of four days prior to incubation and incubated at $37.8{ }^{\circ} \mathrm{C}$ and humidity from $52 \%$ to $56 \%$ with an automatic turning.

Each individual ELA was composed of a subset of eight strains, with the exception of the ELA IX, in which were used seven strains. The known and well-characterized pathogenic avian E. faecalis strain K923/96 (Rudolph, 2004 and Petersen et al., 2009) was included in all ELAs as the positive control (reference strain). Fertilized eggs were inoculated via the AC after 10 days of incubation. In addition to the infected embryos, there was always one negative control group in each ELA, which was inoculated in the AC with $0.2 \mathrm{ml}$ of sterile PBS. In each ELA, 100 eggs per strain and control groups were used, with the exception of two negative control groups (ELA I and II), in which were used 177 and 110 eggs, respectively. 
The inoculum was prepared as described in the Experiment 1 (Chapter 2, section '2.2.3. Inoculum' of the present dissertation) up to an infectious dose of $5 \mathrm{CFU} / \mathrm{ml}$, which corresponds approximately with the $\mathrm{LD}_{50}$ of the reference strain K923/96. By an inoculation volume of $0.2 \mathrm{ml} / \mathrm{egg}$, the number of bacteria used for inoculation was one CFU/egg. The number of CFU contained in each dose was verified by viable count on a Columbia sheep blood agar plate in order to guarantee that the infectious dose was correctly prepared, as shown in Figure 3.1. The number of bacteria inoculated into the embryos ranged from 15 to $120 \mathrm{CFU} / \mathrm{ml}$ (i.e. from 3 to $24 \mathrm{CFU} / \mathrm{egg}$ ), depending on the strain. In the case of the E. hirae strain, the embryos were inoculated with $275 \mathrm{CFU} / \mathrm{ml}$ (55 CFU/egg). The real number of CFU of each strain inoculated into the embryos is shown in Figure 3.3.

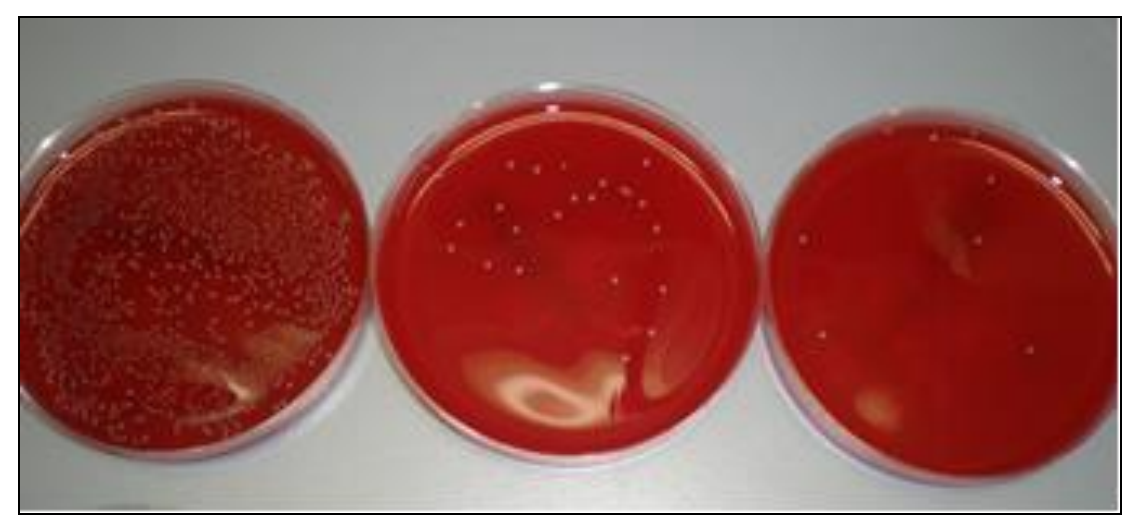

Figure 3.1. Inoculum verification through the incubation of $0.1 \mathrm{ml}$ of inoculum per dose of the E. faecalis strain 2140-5 on Columbia sheep blood agar plates. From left to right, the viable counts for the theoretical doses of 2500, 25 und $5 \mathrm{CFU} / \mathrm{ml}$.

The incubated eggs were candled every $24 \mathrm{~h}$ for seven days after infection, and embryonic mortalities were daily recorded per strain and control groups. The number of dead embryos was used to classify the virulence of the E. faecalis strains. As previously reported by Rudolph (2004), the strains with an EMR below $40 \%$ were considered avirulent strains; 
above $80 \%$ virulent strains and between $40 \%$ and $80 \%$ were classified as strains of moderate virulence. It should be noted that the embryos that died within $24 \mathrm{~h}$ p.i. were removed from the research, since its deaths could be attributed to a lethal trauma during the manipulation (Wooley et al., 2000).

At the end of each ELA, at 17 days of incubation, all surviving embryos were sacrificed by hypothermia. They were stored for $48 \mathrm{~h}$ at $4^{\circ} \mathrm{C}$.

Random selections of the embryos dead by the infection, as well as some surviving embryos at the end of the ELAs, were used to evaluate macroscopic lesions and to re-isolate the strains from the allantoic fluid of the embryos, as described in the Experiment 1 (Chapter 2, section '2.2.5. Macroscopic lesions and re-isolation') of the present dissertation.

\subsubsection{Statistical analysis}

Statistical analyses of mortality data were carried out by applying a linear logistic mixed model with a binary response variable, which was modelled as a binomial random variable $\left(\mathrm{y}_{\mathrm{i}}\right)$. The dependent variable $\left(\mathrm{y}_{\mathrm{i}}\right)$ can take the value 1 with a probability for embryonic mortality $\pi_{\mathrm{i}}$ or the value 0 with a probability to survive of $1-\pi_{\mathrm{i}}$. The data were then analysed with the GLIMMIX procedure (SAS Institute Inc., 2011) using the following generalized linear model (Littell et al., 1999):

$$
\operatorname{Logit}\left(\pi_{\mathrm{ij}}\right)=\eta_{\mathrm{ij}}=\log \left[\pi_{\mathrm{ij}} /\left(1-\pi_{\mathrm{ij}}\right)\right]=\phi+\mathrm{b}\left(\mathrm{x}_{\mathrm{i}}\right)+\alpha_{\mathrm{i}}
$$

where $\eta_{\mathrm{ij}}$ denotes the linear predictor, the logit link function is defined by $\log \left[\pi_{\mathrm{i}} /(1-\right.$ $\left.\left.\pi_{\mathrm{i}}\right)\right]=\eta_{\mathrm{i}}, \pi_{\mathrm{ij}}$ is the probability of mortality until the end of the research at 17 days of incubation, $\phi$ is the overall mean effect, $b$ is the linear regression coefficient of mortality values of the positive control group used in each individual ELA as reference for adjusting the effect of trial $\left(\mathrm{x}_{\mathrm{i}}\right)$ on embryonic mortality ability and $\alpha_{\mathrm{i}}$ is the random effect of the strain. 
The mortality produced by each strain was estimated on the logit scale and then backtransformed using the inverse link function $\pi=\exp (x \beta) /[1+\exp (x \beta)]$ to the original scale (probability).

The development of the embryonic survivability over the seven days p.i. for the different groups of strains classified by its virulence degree quantified by impairment on embryonic mortality ability was illustrated according to the Kaplan-Meier method (survival analysis) by applying the LIFETEST procedure of SAS System 9.3 (SAS Institute Inc., 2011) and using the following model:

$$
\hat{S}(t)=\prod_{j: t_{j} \leq t}\left[1-\frac{d_{j}}{n_{j}}\right] ; \text { for } t_{1} \leq t \leq t_{k}
$$

where $\hat{S}(t)$ is the survivor function and $t$ is the lifetime of a randomly selected experimental unit. For each $\mathrm{j}_{\mathrm{j}}: \mathrm{t}_{\mathrm{j}} \geq \mathrm{t}$, let $\mathrm{t}_{1}<\mathrm{t}_{2}<\ldots<\mathrm{t}_{\mathrm{k}}$ representing the different event times. $\mathrm{n}_{\mathrm{j}}$ is the number of individuals at risk just prior to $t_{i}$, and $d_{j}$ is the number of individuals that die at time $\mathrm{t}_{\mathrm{j}}$.

\subsection{RESULTS}

\subsubsection{ERIC-PCR method and phylogenetic analysis}

Phylogenetic tree of 1 E. hirae and 67 E. faecalis strains based on the banding patterns after ERIC-PCR is shown in Figure 3.2. A visual comparison of the banding patterns revealed DNA fragments ranging in sizes from 236 to 3380 base pairs. ERIC patterns consisted of four to nine DNA fragments. The phylogenetic analysis of banding pattern showed the most distant relationship to the E. hirae strain, which was implemented as an outgroup. This 
indicates that the ERIC-PCR can be considered reliable. E. faecalis strains were clustered into five major groups, and only one strain (E. faecalis 1246-15) was unclustered. All clusters showed a remarkable diversity among the E. faecalis strains since differences among its banding patterns were observed, except the Cluster 2, whose strains showed identical banding patterns although they were classified into different pathogenicity degrees according to the ELA results. All clusters were composed of avirulent, virulent and moderate virulence strains except five avirulent E. faecalis strains clustered in the Cluster 4.

\subsubsection{Embryo lethality assay}

The ELAs showed different EMRs according to the strain. As shown in Figure 3.3., the overall EMR of the infected embryos ranged from $3 \%$ to $89 \%$ depending on the strain. On the basis of virulence classification of Rudolph (2004), 27 strains, including the E. hirae strain, were classified as avirulent with an EMR below 40\%, and five strains were classified as highly virulent with an EMR above $80 \%$. The remaining 37 strains were classified as strains of moderate virulence, whose EMR varied from $40 \%$ to $80 \%$. The average EMR of the negative control group was $1 \%$, and the positive control group (E. faecalis strain K923/96) showed an average of 50\%. The E. hirae strain (strain 580) showed low virulence (31\%) although this strain registered the greatest number of bacteria count (55 CFU/egg) during the verification of the CFU number, as shown in Figure 3.3. 


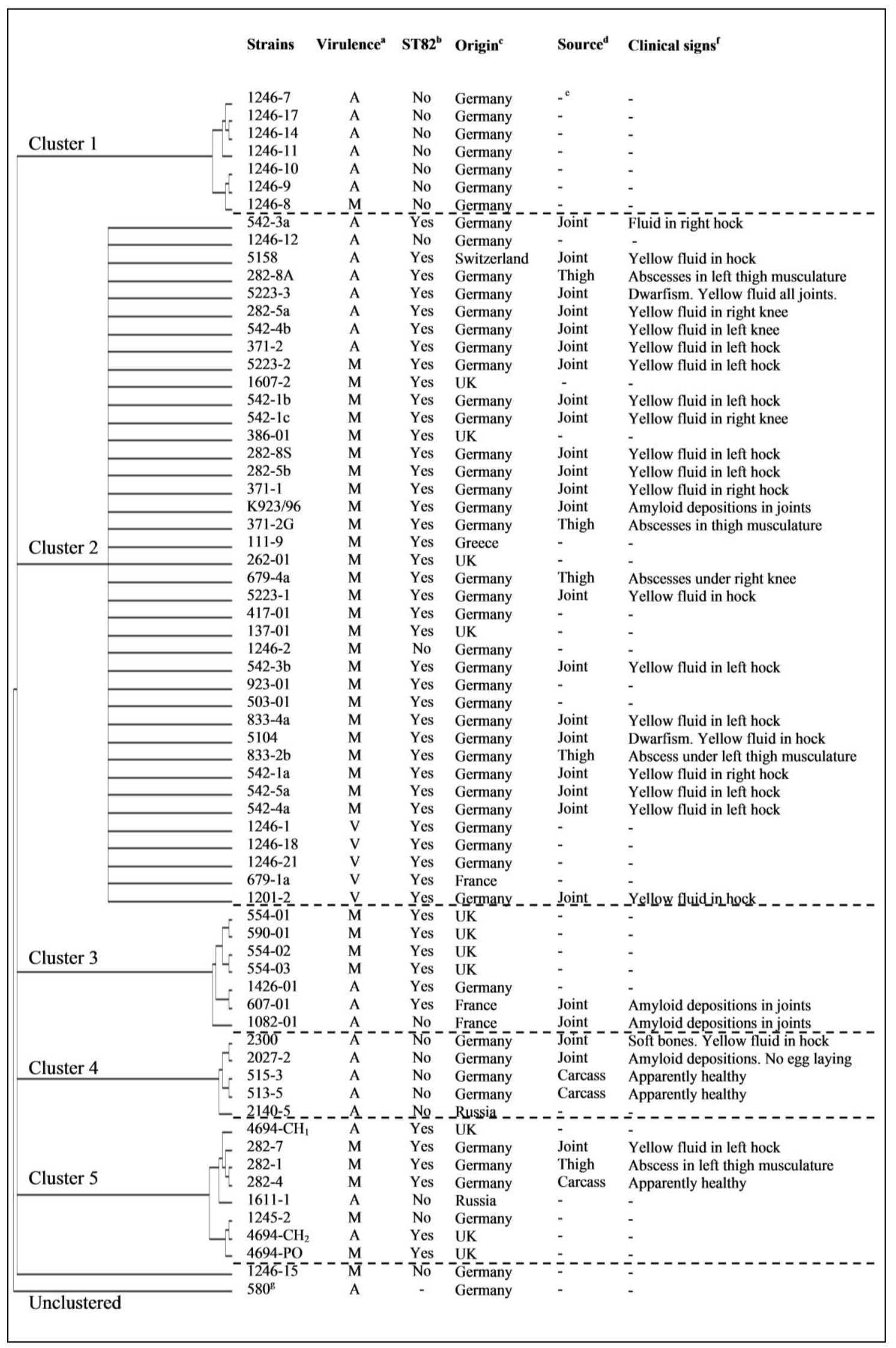


Figure 3.2. Phylogenetic tree (drawn in the rectangular cladogram format) of 1 E. hirae and 67 E. faecalis strains based on the aligned nucleotide sequences after ERIC-PCR.

${ }^{\text {a }}$ Virulence classification of the strains through the ELAs (A=Avirulent, $\mathrm{M}=$ Moderate and $\mathrm{V}=$ Virulent). ${ }^{\mathrm{b}}$ ST82 refers to the sequence type 82 reported by the laboratory of Lohmann Tierzucht GmbH (Germany) by using the RT-PCR. ${ }^{\mathrm{c}}$ Country of origin of the strain. ${ }^{\mathrm{d}}$ Source of isolation. ${ }^{\mathrm{e}}$ This information is unknown. ${ }^{\mathrm{f}}$ Clinical signs observed in the birds. ${ }^{\mathrm{g}}$ E. hirae strain implemented as an outgroup.

The real number of CFU of each strain inoculated into the embryos did not show any clear relationship with the EMR produced. As can be seen in Figure 3.3., some of the strains with the lowest CFU number were able to produce high EMR and, on the contrary, some strains with higher CFU number produced low EMR. For example, 3 CFU/egg of the $E$. faecalis strains 1246-8 and 1246-18 produced an EMR of 78 and 82\%, respectively. However, 20 and $23 \mathrm{CFU} / \mathrm{ml}$ of the E. faecalis strains 1611-1 and 2323-96 produced an EMR of 14 and $18.4 \%$, respectively.

The lack of relationship among the CFU administered to the embryos and the embryonic mortality produced by each strain was also observed in the positive control group used in all ELAs, as shown in Figure 3.4. The number of bacteria inoculated into the embryos of the positive control group varied from 4 to 19 CFU/egg among each individual ELAs and did not shown any relationship with the produced embryonic mortality, which ranged from 24 to $65 \%$. 


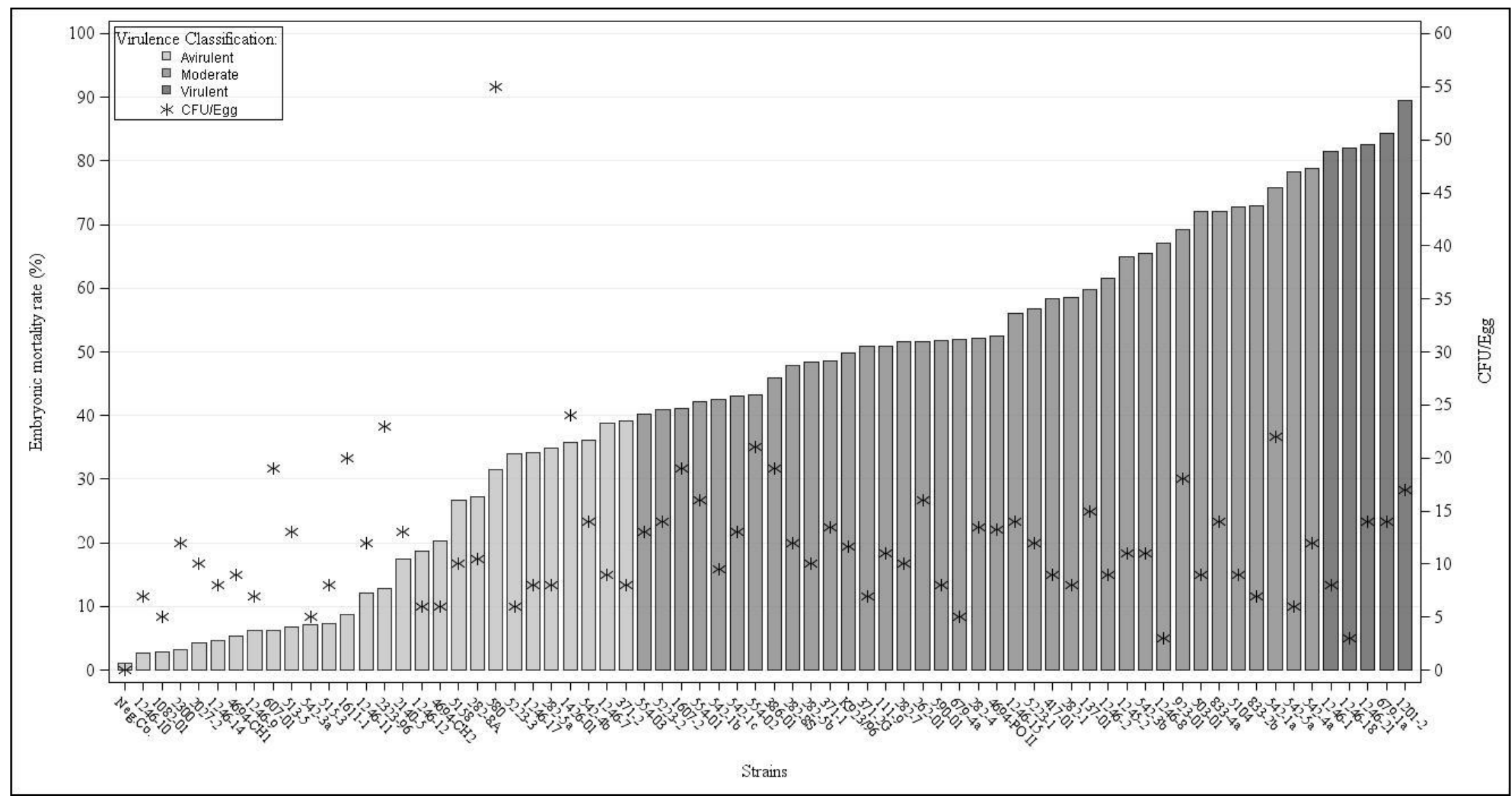

Figure 3.3. Virulence classification of 68 E. faecalis strains, one E. hirae strain (strain 580) and a negative control group (Neg. Co) sorted by the EMR that produce in 10-day-old chicken embryos inoculated into the AC with the represented number of CFU(*). Strains with an EMR below $40 \%(n=27)$ were considered avirulent; from $40 \%$ up to $80 \%$ were classified as strains of moderate virulence ( $n=37)$ and above $80 \%$ virulent strains $(\mathrm{n}=5)$. 


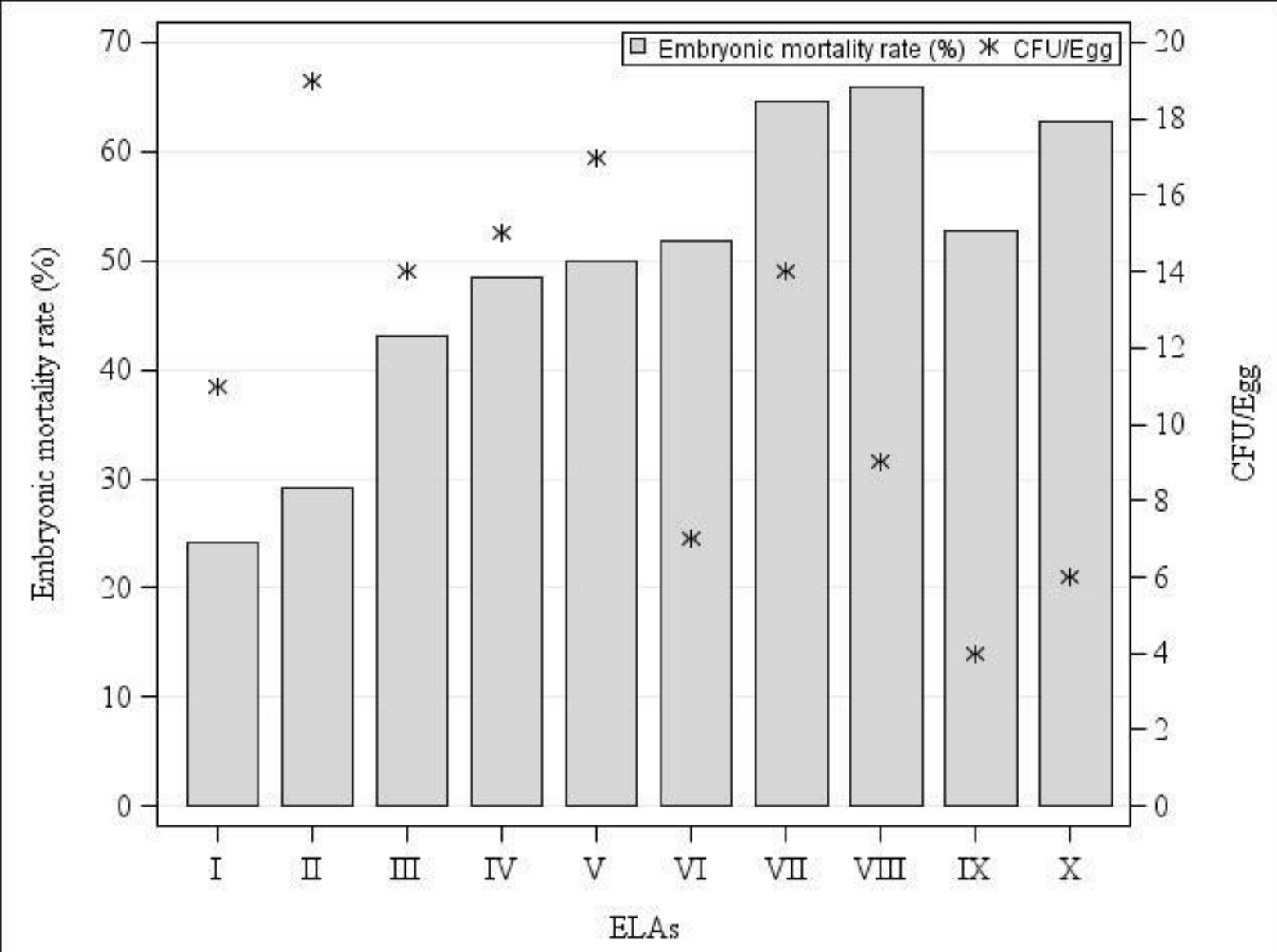

Figure 3.4. Chicken EMR produced by the E. faecalis strain K923/96 used as positive control in 10 individual ELAs when 10-day-old embryos were inoculated into the AC with the represented number of CFU (*).

\subsubsection{Embryo survival}

The survival curve for the embryos infected with three groups of strains classified by its virulence degree is presented in Figure 3.5. Obviously, embryos infected with avirulent strains had more survival probability than the embryos infected with more virulent strains. However, regardless of the virulence degree of the strains, the highest embryonic mortality occurred at three and four days p.i., and after four day p.i. the embryonic mortality declined substantially. 


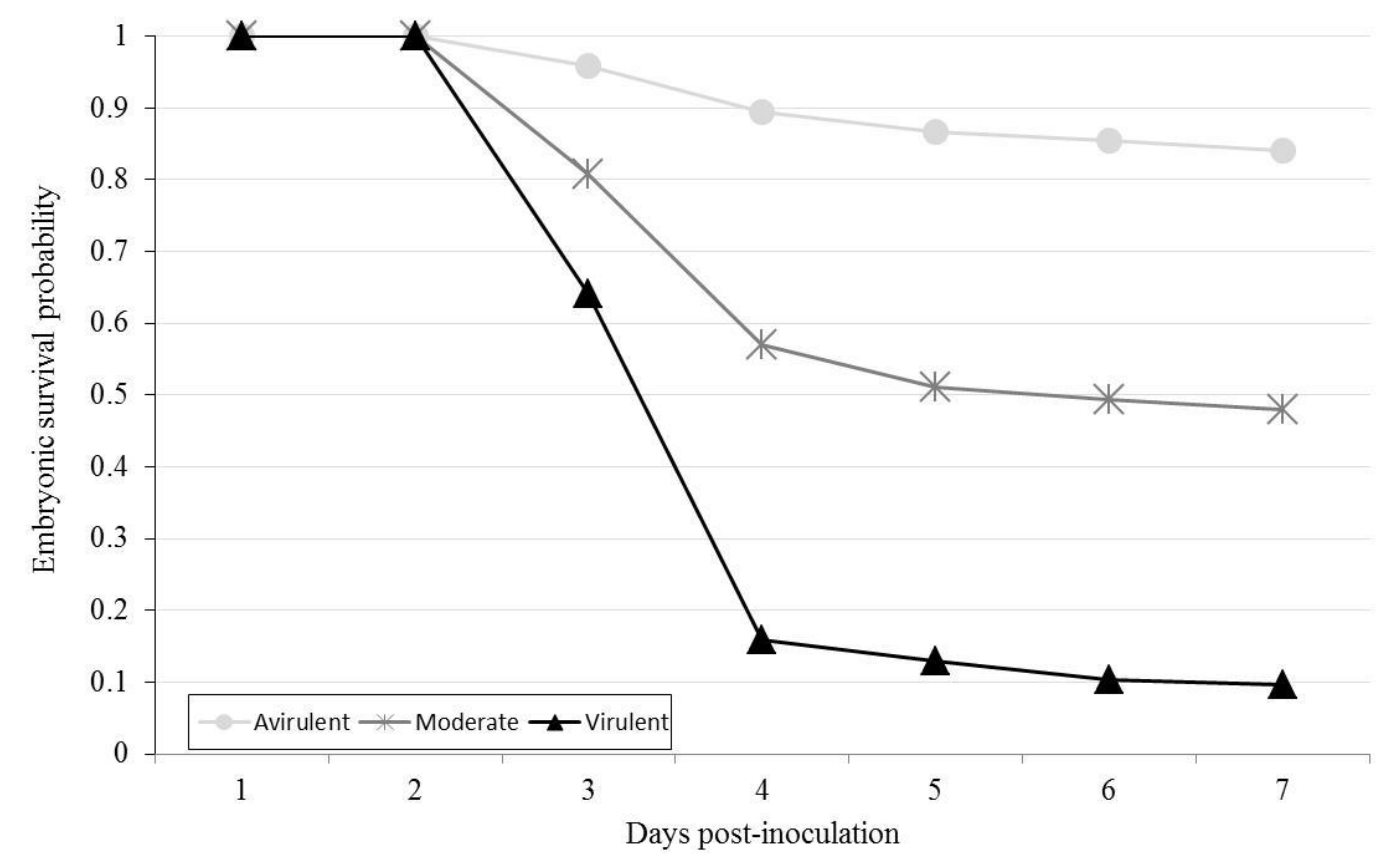

Figure 3.5. Survival curves of 10-day-old chicken embryos inoculated into the AC with $5 \mathrm{CFU} / \mathrm{ml}$ of three groups of different Enterococcus spp. strains classified by its virulence degree.

\subsubsection{Macroscopic lesions}

No lesions were observed in the embryos of the negative control group, which received $0.2 \mathrm{ml}$ of PBS. However, the infected embryos succumbed to the bacterial infection. The most frequent detrimental effects of artificial infection on embryonic organ and tissue were malformations, growth failure, cranial and skin haemorrhages, subcutaneous oedema and loss of the plumage. The detrimental effects resulting by the E. faecalis infection on the chicken embryos showed the same pattern regardless of the degree of virulence of the strains, as shows in Figure 3.6. In addition, most severe lesions were observed at three and four days p.i., and less serious lesions were observed from the fourth day p.i. onwards. Therefore, the most severe lesions were observed when the higher EMR was registered. It should be noted 
that some dead and surviving infected embryos at the end of the ELAs did not show any visible signs.

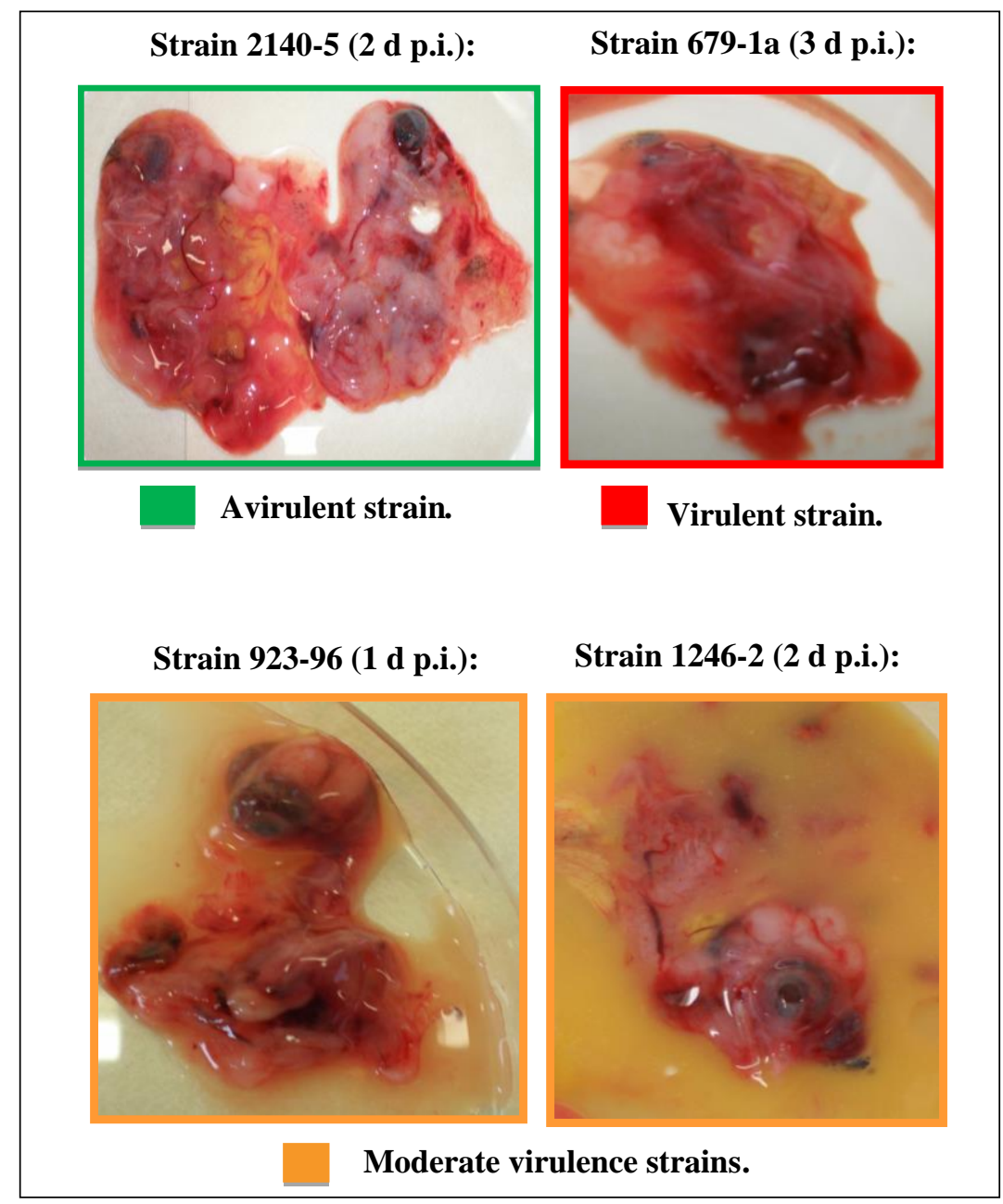

Figure 3.6. Macroscopic lesions of white laying hen embryos infected with different E. faecalis strain with different virulence degree.

\subsubsection{Re-isolation}

Smear samples from the allantoic fluid of random analysed dead embryos as well as from surviving embryos were taken in order to re-isolate the E. faecalis strains. The bacterial counts of the infected embryos were always positive and their allantoic fluid contained more $\mathrm{CFU} / \mathrm{ml}$ compared to the infectious dose administered to the embryos (> $1000 \mathrm{CFU} / \mathrm{ml}$ ), 
although some of them did not show any visible lesions and any abnormalities. The bacterial count of the negative control group was for all analysis negative, confirming that there was no cross-contamination.

\subsection{DISCUSSION}

In order to characterize the genetic diversity of the avian $E$. faecalis strains and under the hypothesis that strains with similar banding patterns might show also similar infective ability, the ERIC-PCR was carried out.

ERIC-PCR has been successfully used in previous studies for genotyping of different bacteria such as E. coli (Leung et al., 2004), Vibrio parahaemolyticus (Zulkifli, et al., 2009) and L. monocytogenes (Moreno et al., 2013). In the case of Enterococcus spp., Jurkovič et al. (2007) reported that the ERIC-PCR produce a high discriminatory power among E. faecium strains isolated from Bryndza cheese in comparison with PFGE and (GTG) $)_{5}$-PCR. Besides, Bachtiar et al. (2015) observed a high genetic diversity among E. faecalis strains from saliva and infected root canal samples by using the ERIC-PCR.

As shown in Figure 3.2., ERIC-PCR in the present research was able to distinguish Enterococcus spp., specifically E. faecalis and E. hirae strains, which is important to ensure the specificity of the test for E. faecalis. ERIC-PCR revealed a considerable genetic diversity among avian E. faecalis strains, which was previously demonstrated in Enterococcus spp. (Jurkovič et al., 2007 and Bachtiar et al., 2015). However, since E. faecalis strains with similar banding patterns did not produce the same EMR through the ELA, ERIC-PCR results did not show a clear relationship to the infection ability of the strains. Similar results were reported by Borst et al. (2014), who observed that an E. cecorum strain with virulent genotype 
by using the PFGE did not have a virulent phenotype through the ELA, suggesting that the ELA may be useful in distinguishing strains with the same genotype but different phenotype. Therefore, the molecular taxonomy of Enterococcus spp. might not be able to distinguish between avirulent and virulent strains, as previously reported by Eaton \& Gasson (2001). Nevertheless, it is possible that the sequencing of the whole genome may lead to different results.

The typing of E. faecalis strains has revealed that several STs are related with different human and avian diseases. Specifically, the ST82 of E. faecalis has been related with AA worldwide (Petersen et al., 2007). In this study, from the 49 E. faecalis strains that contained the ST82 through the RT-PCR, 10\% were classified as virulent strains, $67 \%$ as moderate virulence and $22 \%$ as avirulent strains through the ELA, as shown in Figure 3.2. On the contrary, $78 \%$ from the 18 E. faecalis strains with absence of the ST82 were classified as avirulent strains and $22 \%$ as strains of moderate virulence. The fact that the E. faecalis strain 1082-1, which is not related to the ST82, was isolated from a field case of AA can be explained by the ST172 reported by Petersen et al. (2009), which has been also associated with avian amyloidosis (http://www.mlst.net). In addition, since all used strains presented the same profile of virulence genes and produced however different virulence degree through the ELA, no relationship between the virulence degree of the strains and their virulence genes was observed.

The ELA in the present research has demonstrated its ability to differentiate E. faecalis strains with respect to its virulence (Figure 3.3.), in accordance with the ELA results of several authors with different bacterial strains (Wooley et al., 2000; Gibbs et al., 2003; Gibbs \& Wooley, 2003; Rudolph, 2004; Montgomery et al., 2005; Townsend et al., 2008; Stewart- 
Tull et al., 2009; Jacobsen et al., 2010; Oh et al., 2012; Polakowska et al., 2012; Seo et al., 2013 and Borst et al., 2014).

The average EMR of the negative control group was $1 \%$, which confirms the appropriate environment in the incubator during the ELAs. Therefore, the obtained embryonic mortalities with each strain can be unequivocally associated to its virulence. The average EMR of the embryos inoculated with $5 \mathrm{CFU} / \mathrm{ml}$ of the E. faecalis strain K923/96 used as positive control in each ELA was 50\%, which is in accordance with the results obtained in the previous Experiment 1 (Chapter 2) of the present dissertation; an EMR of $45 \%$ with the same strain and infectious dose. Therefore, although the E. faecalis strain K923/96 showed variability between the individual ELAs, as shown in Figure 3.4., its relative virulence provides accurate results, which is in accordance with the results reported by Gibbs et al. (2003) and Montgomery et al. (2005) with E. coli strains. Hence, these authors suggest the need to be careful when determining the absolute virulence of a strain based on a single ELA.

The EMR which was produced by each strain cannot be explained by the number of CFU administered to the embryos, as shown in Figure 3.3. This observation is consistent with the results obtained by Gibbs et al. (2003) with E. coli strains, who reported that the ability of a strain to colonize the embryo was not related to its capacity to invade the embryo and cause disease or death. This explains the fact that the number of CFU/egg of the E. faecalis strain K923/96 used as positive control did not show a clear relationship with the EMR in each individual ELA (Figure 3.4.). However, Seo et al. (2013) reported that virulent and avirulent $R$. anatipestifer strains showed different capacity to replicate in ovo after the inoculation. They observed that the maximum number of $\mathrm{CFU} / \mathrm{ml}$ of a virulent strain was about 1000 times higher than those of an avirulent strain for four days, suggesting that the ability of replication of the strains into embryonic tissues is related to systemic infection of the embryo 
and death. The E. hirae strain 580, which was inoculated into the embryos with the same infectious dose like the E. faecalis strains, showed the greatest number of bacterial count administered to the embryos (55 CFU/egg); however, it produced low embryonic mortality (31\%). Therefore, the number of CFU able to produce embryonic mortality seems to depend not only on the strain but also on the specie. More researches with different species of Enterococcus are required in order to corroborate this theory.

In accordance with the results reported by Wooley et al. (2000), Gibbs et al., (2003), Gibbs \& Wooley (2003), Stewart-Tull et al. (2009), Seo et al. (2013) and Borst et al. (2014), regardless of the strain virulence, the survival rate of the embryos decreased faster from two to four days p.i., whereas the survival rate decreased slower afterwards, as shown in Figure 3.5. Therefore, the ELA with E. faecalis strains might be optimized by reducing the time of study until four days p.i. as Wooley et al. (2000) and Montgomery et al. (2005) have previously reported with E. coli strains. Additionally, Wooley et al. (2000) reported that the survival rate and lesions of the embryos infected with $E$. coli strains showed a relationship with the strain virulence degree. The results obtained in the present research also showed a relationship between the embryonic survival rate and the strain virulence degree since more virulent strains produced a faster decrease in embryonic survival rate from two to four days p.i. than avirulent strains (Figure 3.5.). However, all infected embryos showed the same lesions regardless of the virulence of the strains, in contrast with the results of Wooley et al. (2000) and Borst et al. (2014). The observed macroscopic lesions were similar than those in the broiler embryos infected with E. cecorum by Borst et al. (2014) (Figure 3.6.).

No lesions and no re-isolations were observed in the embryos of the negative control group, thus indicating that the embryonic mortality was due to the infection and not due to external effects and, therefore, the research was reliable. On the contrary, the recovered 
bacterial counts from the allantoic fluid of all analysed infected embryos with E. faecalis strains were always positive, although some of these embryos did not show any visible signs. Besides, an increase in the viable count of the allantoic fluid of dead embryos was observed compared to the initial number of $\mathrm{CFU} / \mathrm{ml}$ contained in the infectious dose. This ability of the bacteria to replicate and invade the embryos after the inoculation, even without killing them, has been previously reported by Wooley et al. (2000), Rudolph (2004), Montgomery et al. (2005), Townsend et al. (2008), Stewart-Tull et al. (2009) and Seo et al. (2013).

In conclusion, the results obtained in this research suggest that the ELA can be considered a reliable and useful tool to evaluate the virulence of avian E. faecalis strains by using the EMR. Although the clustering based on the ERIC-PCR did not show a clear relationship with the virulence assessment obtained by the ELA in this research, it can be applied successfully and be useful to obtain the genetic distribution and epidemiology of these bacteria. The results obtained in the present research can be used as a basis for future researches on the E. faecalis virulence, and high pathogenic isolates tested in the present experiment might be good candidates for autogenous vaccines. 
- 92 - 


\section{CHAPTER 4.}

\section{GENETIC APPROACH TO SELECT MORE RESISTANT \\ LAYING HENS FOR ENTEROCOCCUS FAECALIS \\ INFECTION (EXPERIMENT 3).}

\subsection{INTRODUCTION}

It is estimated that over 25,000 people die each year in Europe from infections caused by antibiotic-resistant bacteria according to the World Health Organization (2011). Therefore, it is expected that the use of antibiotics substantially decrease in the future, specifically in animal production, in order to satisfy the regulations and consumer demands. However, avian infectious diseases cause important production losses in the poultry industry, which is not only an economic problem but also it compromises the welfare of the birds and raise humane concerns worldwide. Consequently, there is high requirement for control strategies against bacterial infections. Different general strategies could be applied in the fight against bacterial infections such as the development of vaccines and breeding for more resistant birds, in addition to hygienic measures and biosecurity.

The development of AA in chickens is associated with chronic inflammation and infection, which appears to be induced by arthropathic and amyloidogenic E. faecalis strains. AA is considered an irreversible disease (Landman et al., 1998a) since the amyloid fibrils have low solubility and a relative resistance to proteolytic digestion under physiological 
conditions. Therefore, the treatment of AA has focused to date on treating the underlying inflammatory disease caused by E. faecalis and thus prevent the occurrence of fibrillogenesis.

Antibiotics such as penicillin, erythromycin, novobiocin, nitrofurans, oxytetracycline, chlortetracycline and tetracycline are used in poultry to treat enterococcal infections (Stephan et al., 2008). However, E. faecalis have a natural intrinsic resistance towards erythromycin and tetracycline (McBride et al., 2007), which difficult its treatment and it can lead to resistant infections, issue that is becoming increasingly important. Consequently, control strategies against $E$. faecalis infections are required.

It has been demonstrated that selection for increased resistance of Marek's disease, avian leukosis viruses, salmonellosis, colibacillosis among other diseases can be effective (Kuhnlein et al., 2003). Genetic selection to reduce susceptibility to diseases requires first the presence of genetic variation in susceptibility among individuals. The selection response can then be predicted from estimating heritability.

Genetic variation in susceptibility to AA between brown and white breed layers have been reported both in field and induced cases of AA, as previously mentioned in the introduction of the present dissertation (Chapter 1, section '1.1.5.1. Breed susceptibility'). The greater susceptibility to AA of chicken breeds may be associated with immunological response pattern since brown and white layers show a different immune reaction when they are infected with amyloidogenic E. faecalis strains (Zekarias et al. 2000). According to Ovelgönne et al. (2001), although the differences in susceptibility to AA among individuals could have a genetic basis, it cannot be explained by the SAA genes because its amino acid sequences in both chicken breeds are identical. 
Therefore, the aim of the present study was to investigate the possibility to breed for higher resistance against E. faecalis infection through the ELA, which is proposed as an alternative model to replace the adult avian challenge assays.

\subsection{MATERIAL AND METHODS}

\subsubsection{Embryo lethality assay}

All ELAs carried out in the present research were developed as the ELAs previously described in the Experiment 1 and 2 (Chapter 2 and 3, respectively) of the present dissertation, but the experiment duration of these ELAs was four days. The embryos were inoculated via the AC after 10 days of incubation with the reference E. faecalis strain K923/96 and $0.2 \mathrm{ml}$ of different infectious doses (5 and/or $2.5 \mathrm{CFU} / \mathrm{ml}$ ) prepared as previously described in the Experiment 1 (Chapter 2, section '2.2.3. Inoculum') of the present dissertation.

The incubated eggs were candled every $24 \mathrm{~h}$ for four days and embryonic mortalities were daily recorded per group. It should be noted that the embryos that died within $24 \mathrm{~h}$ p.i. were removed from the experiment, since its deaths could be attributed to a lethal trauma during the manipulation rather than due to the infection (Wooley et al., 2000). At the end of each ELA, at 14 days of incubation, all surviving embryos were sacrificed by hypothermia. They were stored for $48 \mathrm{~h}$ at $4^{\circ} \mathrm{C}$.

Random selections of the embryos dead by the infection, as well as some surviving embryos at the end of the ELAs, were used to evaluate of macroscopic lesions and to recover the bacteria from the allantoic fluid of the embryos p.i., as reported in the Experiment 1 (Chapter 2, section '2.2.5. Macroscopic lesions and re-isolation') of the present dissertation. 


\subsubsection{Preliminary study}

Since AA has never been reported in field cases in white layers and they are less susceptible to induced AA than brown layers (Ovelgönne et al., 2001) and, therefore, the genetic selection to reduce susceptibility to E. faecalis infection would make sense for brown layer chickens, it could be expected that chicken embryos of brown layers would be less resistant to E. faecalis infection compared with embryos of white layers when they are infected with the same E. faecalis strain and infectious dose.

A total of 2711 embryos of Lohmann Brown Layers at an age of 35 - 55 weeks were inoculated in six individual ELAs (I to VI), as shown in Table 4.1. The embryos were inoculated with a single avian E. faecalis strain K923/96 (reference strain) and $0.2 \mathrm{ml}$ of two infectious doses of 2.5 and $5 \mathrm{CFU} / \mathrm{ml}$. Both infectious doses were used in all these ELAs, with the exception of two ELAs (IV and V), in which was only used the infectious dose of 5 $\mathrm{CFU} / \mathrm{ml}$. In addition to the infected embryos, there was always one control group in each ELA, which was inoculated in the AC with $0.2 \mathrm{ml}$ of sterile PBS.

Table 4.1. Accumulated embryo mortality in six individual ELAs during the preliminary study.

\begin{tabular}{|c|c|c|c|c|c|c|c|}
\hline \multirow{2}{*}{$\begin{array}{c}\text { Infectious } \\
\text { Dose }\end{array}$} & \multicolumn{6}{|c|}{ ELAs } & \multirow{2}{*}{ LS-means $^{3}$} \\
\hline & I & II & III & IV & V & VI & \\
\hline Control $^{1}$ & $39 / 93^{2}$ & $2 / 95$ & $3 / 95$ & $7 / 132$ & $4 / 125$ & $3 / 187$ & $3^{a}$ \\
\hline $5 \mathrm{CFU} / \mathrm{ml}$ & $81 / 84$ & $85 / 94$ & $70 / 93$ & $352 / 424$ & $356 / 425$ & $148 / 194$ & $83^{\mathrm{b}}$ \\
\hline $2.5 \mathrm{CFU} / \mathrm{ml}$ & $87 / 93$ & $75 / 89$ & $69 / 92$ & - & - & 92/191 & $69^{c}$ \\
\hline
\end{tabular}

${ }^{1}$ Embryos of the control group were inoculated in the AC with $0.2 \mathrm{ml}$ of sterile PBS.

${ }^{2}$ These embryos were accidentally contaminated with $E$. faecalis and the ELA I was therefore considered invalid.

${ }^{3}$ The effects were estimated using a generalized linear model with binomial error distribution and logit link function. Different letters indicate statistically significant differences between groups. 
As shown in Table 4.1., the EMR of the control group in the ELA I was surprisingly high $(42 \%)$. We realized that the embryos were accidentally contaminated with E. faecalis after cultivating smear samples from the allantoic fluid of some of them and, therefore, this ELA was considered invalid and remove.

\subsubsection{Main study}

Once the appropriate dose for brown embryos was determined, three more ELAs (VIIIX) were carried out. These three ELAs were performed on a sample of 7563 embryos of 500 Brown Layers families at an age of 54 - 56 weeks from a commercial breeding program of Lohmann Tierzucht GmbH. As shown in Table 4.2., the number of embryos and families used were 2656 and 463 in the ELA VII, 2478 and 454 in the ELA VIII, and 2429 and 452 in the ELA IX, respectively. For each family and trial, an average of 5.5 embryos (ranging from one to eight) was inoculated with $0.2 \mathrm{ml}$ of $2.5 \mathrm{CFU} / \mathrm{ml}$ of the E. faecalis strain K923/96.

Table 4.2. Characteristics of the ELAs VII-IX carried out in the main study.

\begin{tabular}{llll}
\hline ELA & VII & VIII & IX \\
\hline $\mathrm{N}^{\circ}$ Embryos & 2656 & 2478 & 2429 \\
$\mathrm{~N}^{\circ}$ Families & 463 & 454 & 452 \\
EMR $(\%)$ & 54 & 30 & 74 \\
\hline
\end{tabular}

\subsubsection{Traits of economic importance}

In order to investigate the possibility to breed for higher resistance against $E$. faecalis infection, the influence of this selection for other traits of economic importance in the poultry industry was assessed. Laying performance was recorded and estimated based on the average of measurement in three periods; period 1 (start of lay) between 20 and 23 weeks of age, period 2 (peak of lay) between 24 and 51 weeks of age, and period 3 (end of lay) between 56 
and 71 weeks of age. The egg weight (EW) was estimated based on the mean of the three measurements at 28, 35 and 45 weeks of age. The body weight (BW) was recorded at 32 weeks of age. Additionally, two traits related with the shell stability were recorded. The egg shell breaking strength (BS) captures the maximum load that can be withstood by an egg and provides information about the strength required to crack the eggshell (Bain, 2005). This trait was recorded and estimated based on the average of measurement at 28, 35 and 45 weeks of age (Period 1) and at 60 and 65 weeks of age (Period 2). Dynamic stiffness $\left(\mathrm{K}_{\mathrm{dyn}}\right)$ is based on acoustic resonance test and offers information about the uniformity and eggshell strength as well as the probability of cracking (Bain et al., 2006), which was recorded at 40 weeks of age.

\subsubsection{Statistical analysis}

\subsubsection{Preliminary study}

Statistical analyses of mortality data were carried out by applying a linear logistic model for repeated measurements with a binary response variable, which was modelled as a binomial random variable $\left(\mathrm{y}_{\mathrm{i}}\right)$. The dependent variable $\left(\mathrm{y}_{\mathrm{i}}\right)$ can take the value 1 with a probability for embryonic mortality $\pi_{\mathrm{i}}$ or the value 0 with a probability to survive of $1-\pi_{\mathrm{i}}$. The logistic model uses a link function $g\left(\mu_{\mathrm{i}}\right)$, linking the expected value to the linear predictors $\eta_{\mathrm{i}}$. The logit link function is defined by $\log \left[\pi_{\mathrm{i}} /\left(1-\pi_{\mathrm{i}}\right)\right]=\eta_{\mathrm{i}}$, where $\pi_{\mathrm{i}}$ is the probability of mortality until the end of the experiment at 17 days of incubation. The data were then analysed with the GLIMMIX procedure (SAS Institute Inc., 2011) using the following generalized linear model (Littell et al. 1999):

$$
\operatorname{Logit}\left(\pi_{\mathrm{ij}}\right)=\eta_{\mathrm{ij}}=\log \left[\pi_{\mathrm{ij}} /\left(1-\pi_{\mathrm{ij}}\right)\right]=\mu+\alpha_{\mathrm{i}}+\beta_{\mathrm{j}},
$$

where $\eta_{\mathrm{ij}}$ denotes the linear predictor, $\pi_{\mathrm{ij}}$ is a binary outcome (i.e., probability of embryonic mortality), $\mu$ is the overall mean effect, $\alpha_{\mathrm{i}}$ is the fixed effect of the infectious dose 
and $\beta_{\mathrm{j}}$ is the fixed effect of repeated measurement of the ELA. LSMEANS were estimated on the logit scale and then back-transformed using the inverse link function $\pi=\exp (x \beta) /[1+$ $\exp (x \beta)]$ to the original scale (probability) applying the LSMEANS statement. Significant differences between LSMEANS were tested using a $t$-test procedure by inclusion of the DIFF option in the LSMEANS statement. Differences were considered significant when $P<0.05$.

\subsubsection{Main study}

For the estimation of genetic parameters, the egg traits and the full pedigree information of all tested animals from four generations were used. For the estimation of the heritability of embryonic survivability to E. faecalis infection, the mean value of the three ELAs was calculated for each family. Heritability and repeatability were calculated using univariate animal model with the variance of the logit and probit link functions by applying the package ASREML (Gilmour et al., 1998). The variance of the logit link function implies a correction of the residual variance by factor $\pi^{2} / 3$ presented as follows:

$$
h^{2}=\frac{\sigma_{A}^{2}}{\sigma_{A}^{2}+\sigma_{E P}^{2}+\pi^{2} / 3}
$$

where $\sigma_{\mathrm{A}}^{2}$ is the additive genetic variance and $\sigma_{\mathrm{EP}}^{2}$ is the variance of permanent environment. Estimates of random effects of animal were calculated in a univariate model on the logit scale and then back-transformed to the original scale using the inverse link function $\pi=\exp (\mathrm{x} \beta /[1+\exp (\mathrm{x} \beta)]$.

Genetic correlations between embryonic survivability and egg traits were estimated using bivariate animal model analysis. Fixed effects for the bivariate model were the same as the univariate analysis. Genetic correlations between binomially distribute traits were also estimated via ASREML (Gilmour et al., 1998) using the probit link function. 
The course of embryonic survivability over the four post-inoculation days within each treatment group was illustrated according to the life table method (survival analysis) by applying the LIFETEST procedure of SAS System 9.3 (SAS Institute Inc., 2011) and using the following model:

$$
\hat{S}(t)=\prod_{j: t_{j} \leq t}\left[1-\frac{d_{j}}{n_{j}}\right] ; \text { for } t_{1} \leq t \leq t_{k}
$$

where $\hat{S}(t)$ is the survivor function and $t$ is the lifetime of a randomly selected experimental unit. For each $\mathrm{j}_{\mathrm{j}}: \mathrm{t}_{\mathrm{j}} \geq \mathrm{t}$, let $\mathrm{t}_{1}<\mathrm{t}_{2}<\ldots<\mathrm{t}_{\mathrm{k}}$ represent the different event times. $\mathrm{n}_{\mathrm{j}}$ is the number of individuals at risk just prior to $t_{i}$, and $d_{j}$ is the number of individuals that die at time $t_{j}$.

\subsection{RESULTS}

\subsubsection{Preliminary study}

The ELAs I to VI showed different EMR according to the infectious dose. The infectious dose showed a significant effect $(P<0.0001)$ on the EMR. As shown in Table 4.1, both infectious doses resulted in more than $60 \%$ lethality after four days p.i. The average EMR for the infectious dose of $5 \mathrm{CFU} / \mathrm{ml}$ was $83 \%$ and for the infectious dose of $2.5 \mathrm{CFU} / \mathrm{ml}$ was $69 \%$. They differed significantly from each other. The highest EMR was recorded after three days p.i. with both doses. Malformed and underdeveloped embryos were observed in both treated groups regardless of the infectious dose. Additionally, the bacterial counts from the allantoic fluid of random analysed dead embryos, as well as from surviving embryos, were always positive. 
In the case of the control group, with the exception of the control group of the ELA I, the bacterial count was always negative and no lesion were observed indicating that there was no cross-contamination and, therefore, the contamination of the control group of the ELA I had to be only caused by the accidental contamination of the bottle of sterile PBS. The average EMR of the control group was 3\%, indicating the appropriated environment in the incubator during the study and the low negative impact of the injection. Besides, the control group differed significantly from each other infectious doses.

On the basis of these results, the embryos in the main study were infected with a single infectious dose of $2.5 \mathrm{CFU} / \mathrm{ml}$ in order to avoid a massive embryonic mortality that would not allow the differentiation between the susceptibility of the families.

\subsubsection{Main study}

\subsubsection{Embryo lethality assay}

The average EMR was $54 \%$ in the ELA VII, $30 \%$ in the ELA VIII and $74 \%$ in the ELA IX, as shown in Table 4.2. Thirty four from 500 families were discarded because they did not present embryos in any ELA. The average EMR in the three ELAs varied among the families from $0 \%$ to $100 \%$, with a standard deviation of $23 \%$, as shown in Figure 4.1. All embryos from 14 families survived the infection and 12 families showed an average EMR lower than $10 \%$ during the three ELAs. On the contrary, all embryos from seven families died during the three ELAs and two families suffered an average EMR of more than 95\%. The embryos from 84 families suffered an average EMR between $50 \%$ and $60 \%$. 


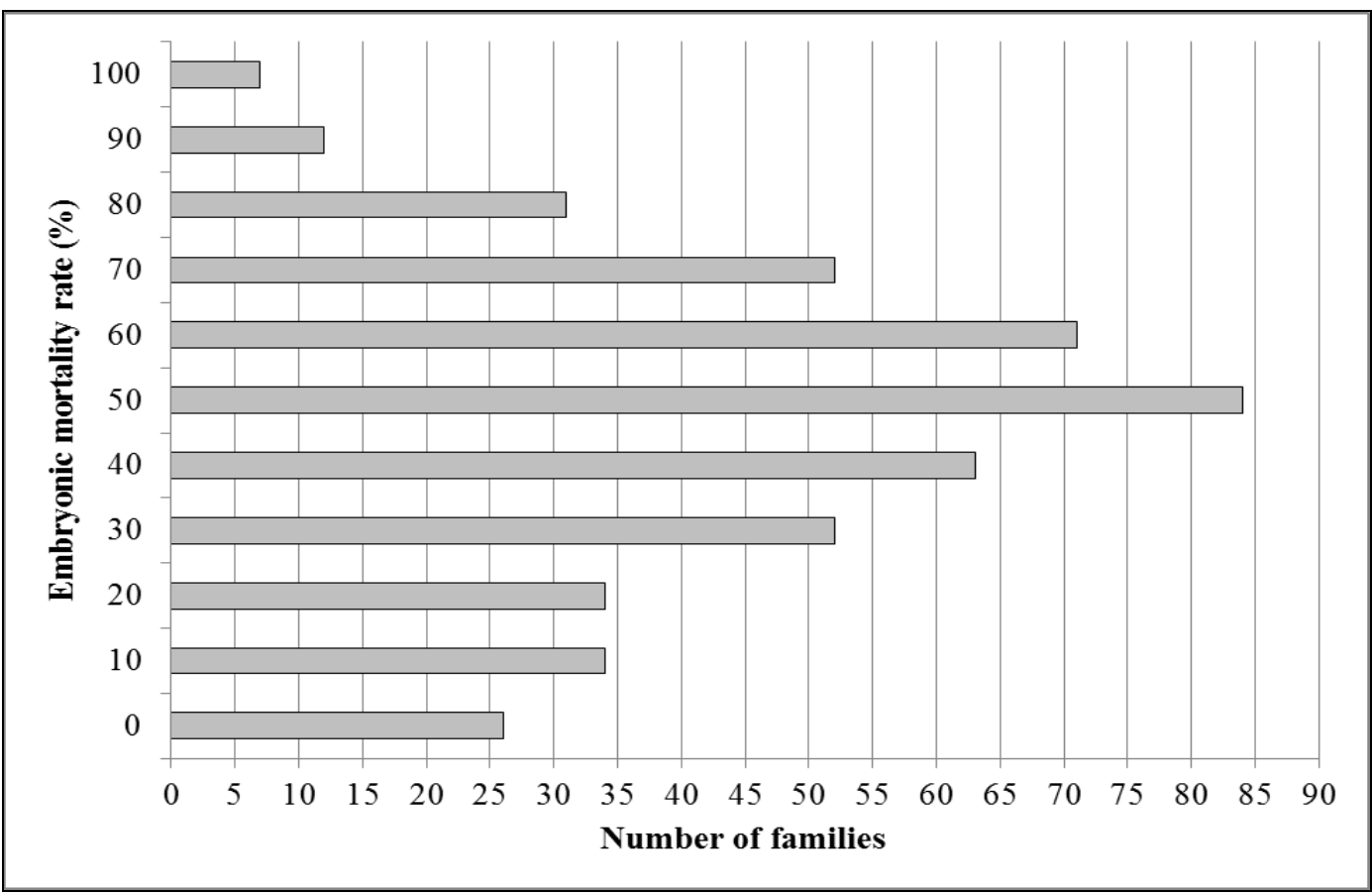

Figure 4.1. Average EMR of 10-day-old embryos from 466 families during three ELAs when they were inoculated into the AC with $2.5 \mathrm{CFU} / \mathrm{ml}$ of the E. faecalis strain K923/96.

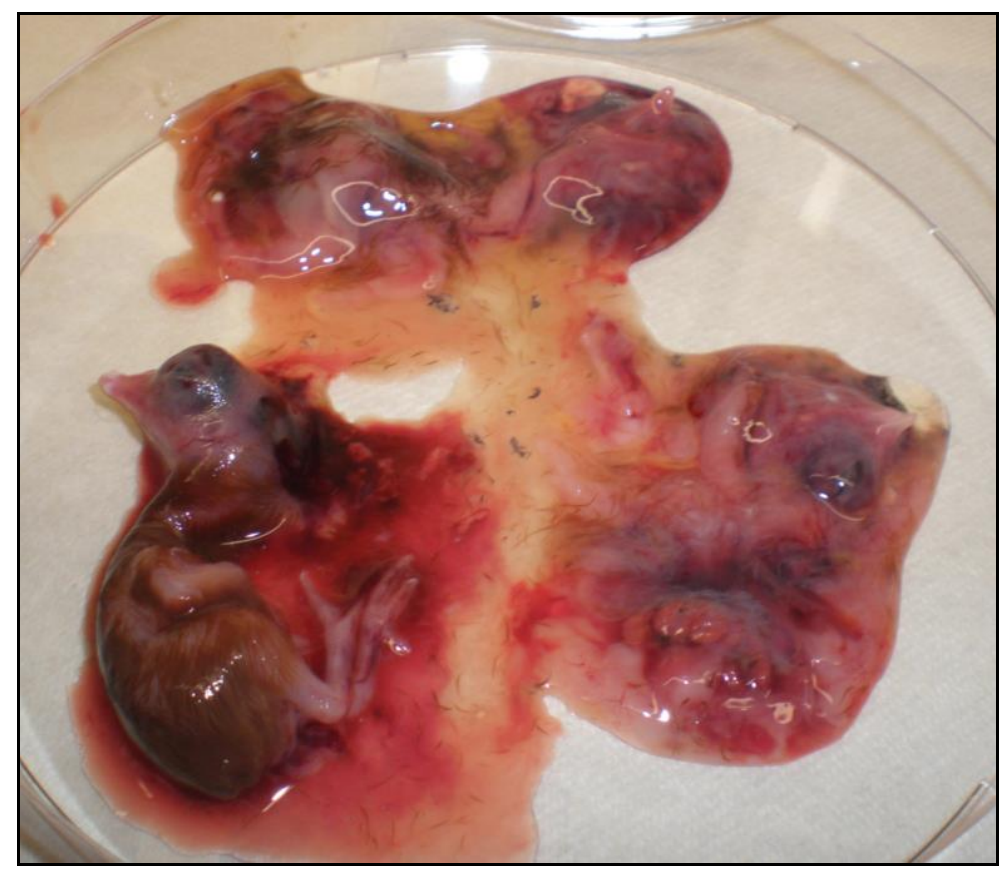

Figure 4.2. Macroscopic lesions of brown embryos infected with the E. faecalis strain K923/96. 
The infected embryos succumbed to bacterial infection and their bodies showed malformations, underdevelopment, cranial and skin haemorrhages, loss of plumage and subcutaneous oedema, as shown in Figure 4.2.

The survival curve for the embryos infected during the three ELAs is presented in Figure 4.3. Obviously, the infected embryos in ELA VIII, whose EMR was lower, had more survival probability than the embryos infected in the ELAs VII and IX, respectively. Regardless of the ELA, the highest embryonic mortality occurred three and four days p.i..

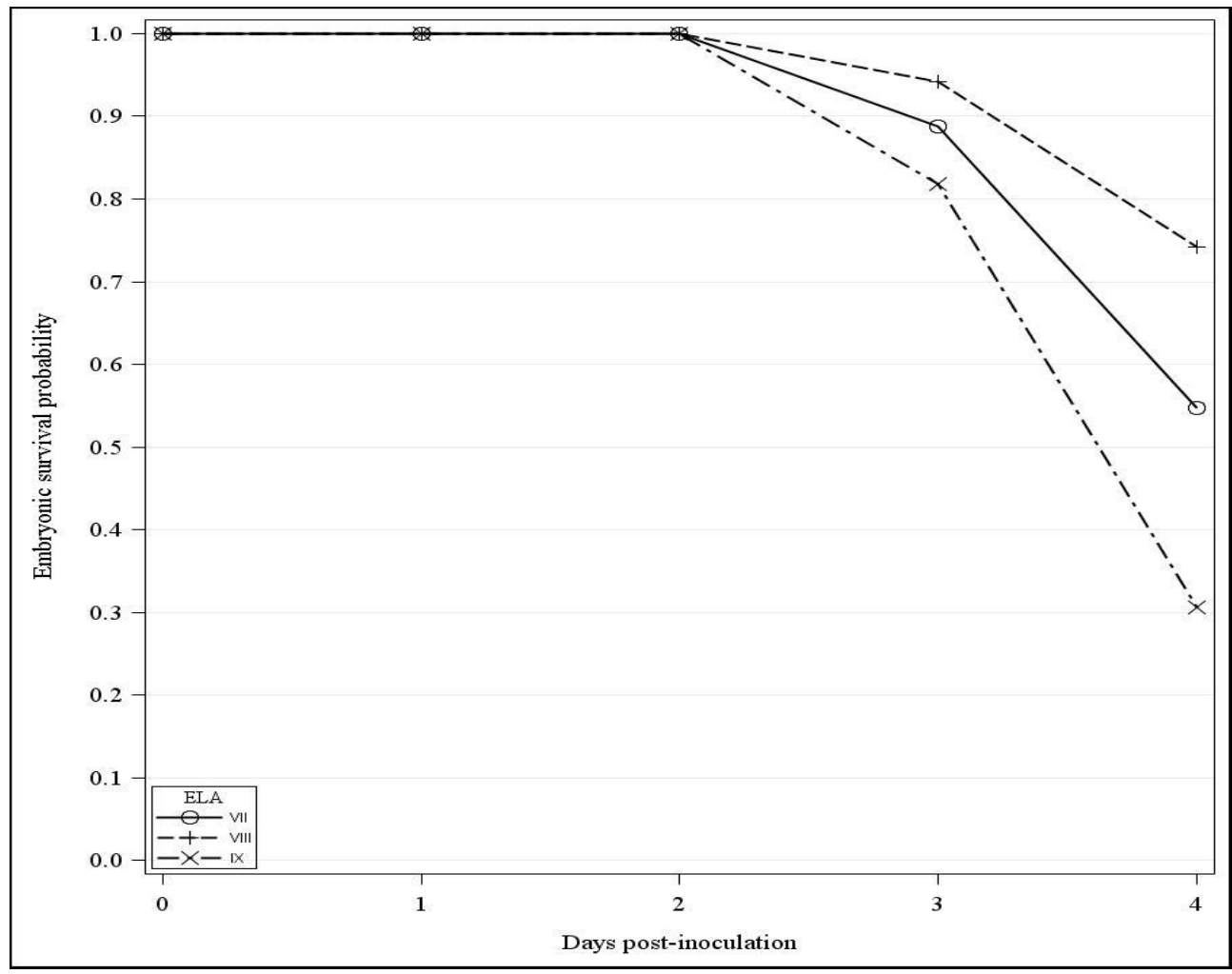

Figure 4.3. Survival curves of 10-days old chicken embryos inoculated into the AC with the E. faecalis strain K923/96 in three ELAs. 


\subsubsection{Descriptive statistics}

The Table 4.3. shows the descriptive statistics for the embryonic survival and each analysed traits including mean values and standard deviations. The average embryonic survivability estimated during the three ELAs was 50\%. The average laying performance varied from $74 \%$ to $94 \%$ among the periods. The average EW estimated based on the mean of three measurements at 28, 35 and 45 weeks of age was $63.6 \mathrm{~g}$. BW measured at 32 week of age ranged from 1.4 to $2.5 \mathrm{~kg}$ among the birds, with an average of $1.9 \mathrm{~kg}$. Regarding to the traits related with shell stability, the average BS in the period 1 was $4.5 \mathrm{~N}$ higher than in the period 2, and the average $K_{\text {dyn }}$ at 40 weeks of age was 163 .

Table 4.3. Means, SD, as well as minimum (Min) and maximum (Max) values for the embryonic survivability and traits of economic importance.

\begin{tabular}{llccccc}
\hline \multicolumn{1}{c}{ Trait $^{1}$} & & $\mathrm{n}$ & Mean & SD & Min & Max \\
\hline Embryonic survivability & & 454 & 0.50 & 0.34 & 0 & 1 \\
& Period 1 & 453 & 74.0 & 16.2 & 11.0 & 100 \\
Laying performance $(\%)^{2}$ & Period 2 & 454 & 94.0 & 6.3 & 44.0 & 100 \\
& Period 3 & 383 & 86.0 & 12.1 & 33.0 & 100 \\
EW (g) & & 454 & 63.6 & 4.6 & 52.1 & 81.8 \\
$\mathrm{BW}(\mathrm{kg})$ & & 454 & 1.9 & 0.2 & 1.4 & 2.5 \\
$\mathrm{BS}(\mathrm{N})^{3}$ & Period 1 & 454 & 42.7 & 6.6 & 24.1 & 62.0 \\
$\mathrm{~K}_{\text {dyn }}$ & Period 2 & 369 & 38.2 & 9.0 & 15.7 & 66.0 \\
\hline
\end{tabular}

Trait: $\mathrm{EW}=$ egg weight; $\mathrm{BS}=$ breaking strength; $\mathrm{K}_{\mathrm{dyn}}=$ dynamic stiffness; $\mathrm{BW}=$ body weight.

${ }^{2}$ Period 1 (start of lay): average of measurement at 20 and 23 weeks of age, period 2 (peak of lay): at 24 and 51 weeks of age, and period 3 (end of production): at 56 and 71 week of age.

${ }^{3}$ Period 1: average measurement at 28, 35 and 45 weeks of age and period 2: at 60 and 65 weeks of age. 


\subsubsection{Heritabilities and genetic correlations}

Estimated genetic parameters for embryonic survivability are presented in Table 4.4. The estimated heritability for embryonic survivability was on a moderate level in general. The estimated heritability was $\mathrm{h}^{2}=0.17$ calculated with the logistic link function and $\mathrm{h}^{2}=0.20$ calculated with the probit link function.

Table 4.4. Estimation of heritability and repeatability for embryonic survivability using univariate repeatability animal model with logit and probit link functions.

\begin{tabular}{lllll}
\hline & Var (a) & Var $(\mathrm{pe})$ & Heritability & Repeatability \\
\hline Logistic & $0.74 \pm 0.23$ & $0.29 \pm 0.18$ & $0.17 \pm 0.05$ & $0.07 \pm 0.04$ \\
Probit & $0.27 \pm 0.08$ & $0.10 \pm 0.06$ & $0.20 \pm 0.05$ & $0.07 \pm 0.05$ \\
\hline
\end{tabular}

The estimated genetic correlations between the embryonic survivability and the analysed traits are shown in Table 4.5. The correlations were negative and higher in the two last periods $\left(r_{g}=-0.69\right.$ in the period 2 and $r_{g}=-0.55$ in the period 3$)$ compared with the first period of production, where the correlation was positive $\left(r_{g}=+0.31\right)$. A positive correlation was also found between EW and the embryonic survivability $\left(r_{g}=+0.16\right)$. No genetic correlation between BW and the embryonic survivability $\left(r_{g}=-0.04\right)$ was found. The genetic correlation between BS and the embryonic survivability was $r_{g}=-0.30$ in the period 1 and $r_{g}=$ -0.48 in the period 2. However, there was no correlation between $K_{d y n}$ and the embryonic survivability $\left(\mathrm{r}_{\mathrm{g}}=-0.05\right)$. 
Table 4.5. Genetic correlations between the embryonic survivability and the analysed traits.

\begin{tabular}{lcc}
\hline Trait $^{1}$ & \multicolumn{1}{c}{$\mathrm{r}_{\mathrm{g}}$} \\
\hline${\text { Laying performance }(\%)^{2}}^{2}$ & Period 1 & $+0.31 \pm 0.12$ \\
& Period 2 & $-0.69 \pm 0.73$ \\
& Period 3 & $-0.55 \pm 0.24$ \\
$\mathrm{EW}(\mathrm{g})$ & & $+0.16 \pm 0.13$ \\
$\mathrm{BW}(\mathrm{kg})$ & & $-0.04 \pm 0.14$ \\
$\mathrm{BS}(\mathrm{N})^{3}$ & Period 1 & $-0.30 \pm 0.16$ \\
$\mathrm{~K}_{\mathrm{dyn}}$ & Period 2 & $-0.48 \pm 0.22$ \\
\hline
\end{tabular}

1 Trait: EW = egg weight; $\mathrm{BS}=$ breaking strength; $\mathrm{K}_{\text {dyn }}=$ dynamic stiffness; $\mathrm{BW}=$ body weight.

${ }^{2}$ Period 1 (start of lay): average of measurement at 20 and 23 weeks of age, period 2 (peak of lay): at 24 and 51 weeks of age, and period 3 (end of production): at 56 and 71 week of age.

${ }^{3}$ Period 1: average measurement at 28,35 and 45 weeks of age and period 2: at 60 and 65 weeks of age.

The relationships between embryonic survivability and analysed traits are plotted in Figure 4.4. The graphs A, B and C show the relationship between embryonic survivability and laying performance at the beginning of the lay (period 1), at peak of lay (period 2) and at the end of the lay (period 3), respectively. A clear lineal negative effect on the laying performance in the periods 2 and 3 can be distinguished. The negative relationship between embryonic survivability and the traits related with shell stability are shown in graphs D and E for BS in the periods 1 and 2, respectively and in graph $\mathrm{F}$ for $\mathrm{K}_{\mathrm{dyn}}$. The positive relationship between EW and embryonic survivability is plotted in the graph G. The graph $\mathrm{H}$ shows the weak relationship between BW and embryonic survivability. 


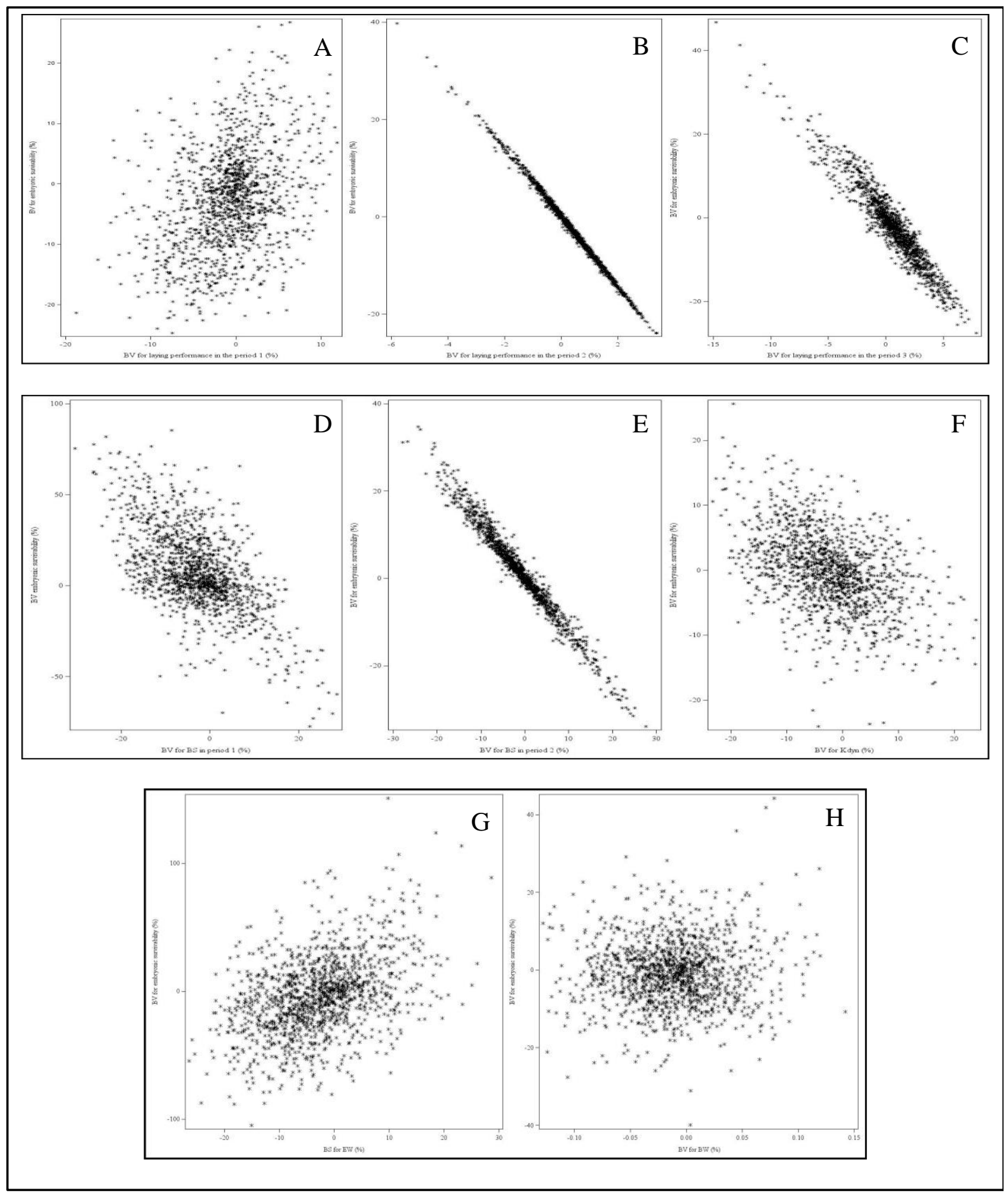

Figure 4.4. Breeding values for embryonic survivability plotted against breeding values for laying performance $(A, B, C)^{\mathrm{a}}$, BS $(\mathrm{D}, \mathrm{E})^{\mathrm{b}}, \mathrm{K}_{\mathrm{dyn}}(\mathrm{F}), \mathrm{EW}(\mathrm{G})$ and $\mathrm{BW}(\mathrm{H})$.

${ }^{\mathrm{a}}$ A for period 1 (start of lay), B for period 2 (peak of lay) and C for period 3 (end of lay).

${ }^{\mathrm{b}} \mathrm{D}$ for period 1 and $\mathrm{E}$ for period 2 . 


\subsection{DISCUSSION}

Breeding for increased disease resistance have been one of the challenges of many breeders and geneticists. However, breeding for resistance to diseases is difficult because the estimated heritabilities for resistance against a particular pathogen are generally low, although the heritabilities for the trait resistance to one specific disease is normally higher than for mortality in general. It should be taken into account that, although the genetic improvements are perhaps small for each generation, they are permanent and cumulative (Lamont, 1998). Additionally, breeding for resistance involves exposure of the animals to pathogenic agents, which raises ethical questions from an animal welfare standpoint. Consequently, in the present study the ELA was proposed as an alternative to adult avian challenge assays.

Heritability for resistance to diseases reported in the literature by applying different statistical methods is usually low. Berthelot et al. (1998) reported heritabilities for resistance to the cecal carrier state of $S$. Enteritidis from $h^{2}=0.08$ to $h^{2}=0.09$. Janss \& Bolder $(2000)$ estimated heritability for mortality to $S$. Enteritidis of $h^{2}=0.12$. Different studies have reported direct heritabilities estimates for ascites syndrome from $\mathrm{h}^{2}=0.12$ to $\mathrm{h}^{2}=0.44$ (Ahmadpanah et al., 2017) and Cavero et al. (2009) reported heritability for resistance to E. coli of $\mathrm{h}^{2}=0.17$. According to the usual range of the heritabilities for resistance to diseases, the heritability for resistance to $E$. faecalis infection estimated in the present dissertation ranged from $\mathrm{h}^{2}=0.17$, calculated with the logistic link function, to $\mathrm{h}^{2}=0.20$, calculated with the probit link function, i.e, that $17-20 \%$ of the total variability of the resistance to the E. faeaclis infection is explained by additive genetic reasons. Traits with similar or even lower heritability are successfully included in the breeding programs. Therefore, it might be feasible to include this trait in the breeding programs taking into account all traits and their genetic correlations to achieve a balanced genetic progress. 
Genetic correlation among traits allows carrying out an indirect selection through a correlated response, i.e., a favourable correlation allows making simultaneous improvement in the traits. On the contrary, an unfavourable correlation results in selection for one trait worsening another. Genetic correlations in the present study are in accordance with the results obtained by Cavero et al. (2009), who observed that laying hens more resistant against E. coli infection have a better initial laying performance and lower feed intake while susceptible laying hens to colibacillosis showed better BS and EW, although these differences between resistant and susceptible laying hens were not large and, therefore, the selection for E. coli resistance could be added into a commercial selection program without penalizing the improvement of the analysed traits.

As shown in Table 4.5., the estimated correlation between EW and embryonic survivability in this research was positive $\left(r_{g}=+0.16\right)$, which imply a favourable genetic relation. However, the genetic correlation between embryonic survivability and the traits related with shell stability indicate that $\mathrm{BS}$ and $\mathrm{K}_{\mathrm{dyn}}$ are not favoured by a lower mortality, which it is not desired from a breeding point of view. Due to the fact that the negative genetic correlation between BS and embryonic survivability $\left(r_{g}=-0.30\right.$ to -0.48$)$ was much higher than for embryonic survivability and $\mathrm{K}_{\mathrm{dyn}}\left(\mathrm{r}_{\mathrm{g}}=-0.05\right)$, it would be advantageous to use $\mathrm{K}_{\mathrm{dyn}}$ as a selection trail measurement to achieve an optimal combination of embryonic survivability and adequate shell strength.

On the other side, from the results obtained it can be concluded that the use of the ELA offers great benefits. Only 4 days are required to provide proper outcomes and it is an easy assay to carry out. Besides, the ELA does not require that the hens are exposed to pathogens saving labour and cost. This fact allows the selection on the pedigree population without the need of a challenge test with a large number of birds. Therefore, the ELA might 
be feasible for implementation in selection programs. However, it would be important to establish if selection against $E$. faecalis infection alters susceptibility against other pathogens because the economic importance of bacterial diseases as a whole is much higher than that of one bacterium alone. Besides, the present study was carried out with a single pathogenic $E$. faecalis strain and, therefore, a very specific disease selection program might protect the current birds and however provide little protection for years to come.

In summary, the heritabilities estimated in the present study show that the selection for increased resistance to E. faecalis infection is feasible. However, negative correlations between embryonic survivability and some economically important traits were observed. Special care should therefore be taken to monitor and to take all traits and their correlations into account to achieve a balanced genetic progress. Thanks to the ELA, the labour and cost associated to the challenge is reduced and the ethical and animal welfare reasons are minimised. Whether selection against $E$. faecalis alters susceptibility against other pathogens is unknown, which is essential in the treatment of bacterial diseases as a whole that of $E$. faecalis alone. This research shows a new perspective for the implementation of genetic selection for E. faecalis susceptibility in laying hens. 


\section{CHAPTER 5.}

\section{GENERAL DISCUSSION AND FINAL CONCLUSIONS.}

\subsection{GENERAL DISCUSSION}

In this final Chapter, the main findings of this dissertation will be evaluated and discussed. Finally, the conclusion and suggestions for further researches will be presented.

\subsubsection{Amyloid arthropathy}

The first Chapter of the present dissertation summarises the knowledge collected in the literature about AA in chickens during the last twenty years. Highlight concerning the different hypotheses and theories about pathogenesis and transmission of this disease, as well as the differences in susceptibility to AA between brown and white layers.

Since E. faecalis is the most frequently isolated bacterium in field outbreaks of AA and its specific association with this disease has been extensively confirmed, it has been deemed important to underline in this first Chapter the main features of E. faecalis and its role in AA pathogenesis as well as its possible routes of transmission.

The Chapter 1 of the present dissertation highlights the need of expanding and deepening more the knowledge about this disease. The pathology of AA in chickens is widely recognised and it is characterized by deposits of orange-coloured amyloid materials in the joints. Nevertheless, there are also cases in which amyloid depositions have not been reported and hence the real question is whether all field cases reported in poultry are AA or if there are 
other hidden problems. Although there are substances and anti-inflammatory agents such as methylprednisolone and pentoxifylline which inhibit the amyloid deposition in birds, more investigations are required to determine the effects of different agents on the treatment of AA and clarify if the amyloid deposits are really irreversible.

Although there are various investigations about the pathogenesis of AA in layers, it still cannot be fully explained. The inflammatory cytokines play an important role in the pathogenesis of amyloidosis. Besides, some pro-inflammatory cytokines are produced by peripheral blood monocytes and tissue macrophages, which are likely to start an acute phase response after a stimulus. Furthermore, the differences in susceptibility to AA among individuals could be due to the differences in the immune system. Therefore, the role of these cytokines in the pathogenesis and in the susceptibility of AA could be studied together.

In most cases of AA, E. faecalis is the bacterium which has been isolated. To date, it is still not known whether the STs, which were found both in E. faecalis isolates from poultry and human isolates, are normal inhabitants of the gastro-intestinal tract or represent a genuine zoonosis. This fact shows the lack of knowledge about this bacterium. In addition, traditional management strategies such as preventive use of, or therapeutic treatment with, antibiotics are insufficient in preventing E. faecalis infections because of its ability to acquire antimicrobial resistance and its capacity to transfer virulence genes. In addition, antibiotic use in animal production is expected to substantially decrease in the future, which shows the necessity of a thorough understanding of the risk from field E. faecalis strains in order to develop effective control strategies against AA. 


\subsubsection{Embryo lethality assay}

According to the Seventh Report on the Statistics on the Number of Animals used for Experimental and other Scientific Purposes in the Member States of the European Commission (2013), rodents and rabbits represented more than $80 \%$ of the total number of animal used in experiments in the European Union in 2011. The third largest group of animals used was birds with a $6 \%$ of the total use. The birds were mainly used for studies on animal diseases on avian influenza, Gumboro disease and bronchitis including studies on quality and safety of vaccines.

The adult avian challenge assay is the most commonly used method for determining the virulence of different microbial pathogens to date, as well as to study the pathogenesis of different avian infections and the selection for disease resistance. However, this method requires exposure of the birds to disease agents in a controlled manner, usually by chicken inoculation, which leads two main difficulties. On the one hand, such assay is complicate to carry out in diagnostic laboratories in order to characterize the avian strains or to study the pathogenesis of infections. On the other hand, it cannot normally be done in the pedigreed population under selection, due to the risk of killing excessive numbers of breeders and reducing effective selection for other traits. Additionally, the adult avian challenge assay is limited by relatively high costs, labour intensive and ethical animal welfare considerations. Consequently, the ELA has emerged as an alternative method to characterize the virulence of different fungi (Jacobsen et al., 2010) and bacteria isolated (Wooley et al., 2000; Gibbs et al., 2003; Gibbs \& Wooley, 2003; Rudolph 2004; Montgomery et al., 2005; Oh et al., 2012; Nix et al., 2006; Townsend et al., 2008; Stewart-Tull et al., 2009; Polakowska et al., 2012; Seo et al., 2013; Borst et al., 2014, Andersson et al., 2015 and Jung et al., 2017). Comparison of adult avian challenge assay and ELA has been reported by some authors. Gibbs \& Wooley 
(2003) compared the EMR produced by E. coli strains through the adult avian challenge assay and the ELA. A high positive correlation $(r=0.823, P<0.0001)$ was reported and the correlation was even higher between the ELA and the combined mortality/morbidity of the adult avian challenge assay $(r=0.861, P<0.0001)$ since the ELA results in more deaths compared to the chicken challenge. These results were confirmed by Rudolph (2004) with $E$. faecalis strains and by Seo et al. (2013) with $R$. anatipestifer, who reported that both assays have therefore the ability to distinguish among the virulence of different strains. These authors agree that the ELA is faster, more sensitive, less expensive, more specific and less labor intensive than the adult avian challenge assay. In addition, Gibbs \& Wooley (2003) reported that the correlation between the ELA and the adult avian challenge assay is higher when more embryos per challenge are used, although Wolley et al. (2000) reported that 11 embryos per strain are sufficient to observe significant differences between strains versus the 30 chickens per strain required for the adult avian challenge assay.

Specifically, an ELA with two avian E. faecalis strains was already published by Rudolph (2004). However, this author used a single infectious dose (2500 CFU/ml) of the avian E. faecalis strain K923/96, which produced a high EMR from $90 \%$ to 100\% that would not allow a clear differentiation among the E. faecalis strains. Additionally, since the EMR produced during an ELA is influenced by several factors as previously mentioned in Chapter 2, the first step was to establish a generic methodology of the ELA for avian E. faecalis field strains and thus identify any details needed to be addressed before the main data collection goes ahead.

The virulence and the $\mathrm{LD}_{50}$ of the well-known pathogenic avian E. faecalis strain K923/96 were estimated in the present dissertation in order to use it as reference strain in further analyses. The results of the Experiment 1 (Chapter 2) showed that the EMR depends 
on the infectious dose; the higher the infectious dose, the greater the EMR, thus indicating the importance to determine an appropriate infectious dose which should not be too high to avoid a massive embryonic mortality. In this regard, the $\mathrm{LD}_{50}$ can be considered appropriate in order to establish an infection limit of $50 \%$ lethality. The estimated doses at $\mathrm{LD}_{50}$ for the inoculation of these chicken embryos lines with the E. faecalis strain K923/96 was 6.6 $\mathrm{CFU} / \mathrm{ml}$ (Figure 2.1.). To my knowledge, this is the first time that the $\mathrm{LD}_{50}$ of an E. faecalis strain to inoculate chicken embryos is estimated. Noteworthy is that the $\mathrm{LD}_{50}$ estimated is relatively low compared to the infectious dose of E. cecorum $\left(10^{3} \mathrm{CFU} / \mathrm{ml}\right)$ strains able to produce around 50\% embryonic mortality (Borst et al., 2014). This might be explained by the differences in virulence among the bacterial species. However, this estimation was reliable since similar results were obtained after develop several ELAs with the same strain and infection dose in the present dissertation. In accordance with Gibbs et al. (2003) and Montgomery et al. (2005), it is important to interpret the results of an ELA with caution because it is possible to observe variability between individual ELAs, although the relative virulence provides accurate results. As it has been shown in the different experiments even with the same infectious doses, there is still a variation among the ELAs. Therefore, it is a good practice to do some repetitions of the experiments to obtain more reliable results.

In regard to the embryo survival, regardless of the infection dose and the strain virulence, all ELAs conducted in this dissertation showed a fast decrease in survival rate from two to four days p.i., whereas the survival rate decreased more slowly afterwards in accordance with the results of several authors (Wooley et al., 2000; Gibbs et al., 2003; Gibbs \& Wooley, 2003; Stewart-Tull et al., 2009; Seo et al., 2013 and Borst et al., 2014). Therefore, the experiment duration can be reduced to four days p.i. as was done in the Experiment 3 (Chapter 4) of the present dissertation in order to optimise the ELAs. 
The results obtained showed that the embryo survival depends on the infectious dose; the higher the infectious dose, the lower the embryo survival time (Figure 2.2.), which confirms the results obtained by Nix et al. (2006). As shown in Figure 3.5., the embryonic survival probability also decrease significantly when the embryos are infected with more virulent than avirulent $E$. faecalis strains in accordance with the results of Wooley et al. (2000) with E. coli strains. These authors observed a relationship between the virulence degree of the strains and the lesions of the embryos infected in contrast with the results obtained in the present dissertation. As shown in Figure 3.6., all infected embryos in the Experiment 2 (Chapter 3) showed similar lesions regardless of the virulence degree of the strains, which were also similar than the embryos infected with E. cecorum strains by Borst $e t$ al. (2014). Most severe lesions were observed at three and four days p.i. when the higher EMR was registered, which could be explained by the capacity of the strains to replicate in ovo after the inoculation as previously reported by several authors (Wooley et al., 2000; Rudolph, 2004; Montgomery et al., 2005; Townsend et al., 2008; Stewart-Tull et al., 2009 and Seo et al., 2013) with different bacteria. Unfortunately, the capacity of the strains to replicate in ovo after the inoculation could not be confirmed in this study due to the fast growth rate of the E. faecalis strains in the allantoic fluid. The viable count of the allantoic fluid of the infected dead and surviving embryos was usually much higher (> $1000 \mathrm{CFU}$ ) than the initial number of $\mathrm{CFU} / \mathrm{ml}$ contained in the infectious dose. Additionally, as shown in Figures 3.3. and 3.4., the real number of CFU administered to the embryos cannot explain the EMR produced by each strain since the number of CFU for a same infectious dose varied among the strains and no showed relationship with the EMR in accordance with the results of Gibbs et al. (2003). Therefore, the results obtained suggest that for a same infectious dose, the ability of the strain to produce embryonic disease or death is not related with the number of CFU administered to the embryos, but with their capacity to replicate in ovo after the 
inoculation. Researches on the growth rate of different species of Enterococcus during the ELAs are required in order to corroborate this theory.

In summary, the ELA can be considered a good method to achieve the principle of the “Three Rs" (3Rs) for more ethical use of animals in research:

- Replacement: the ELA replaces adult avian challenge assays with embryos.

- Reduction: the ELA enables researchers to obtain comparable information from 11 embryos (Wooley et al., 2000) versus the 30 chickens required by the adult avian challenge assay (Gibbs \& Wolley, 2003). Besides, the use of the chicks in further research concerning epidemiology and pathogenesis of E. faecalis associated diseases after the hatch might be possible.

- Refinement: the ELA minimizes potential pain, suffering or distress until 4 days p.i.

\subsubsection{Virulence characterization of avian $E$. faecalis field strains}

As described in Experiment 2 (Chapter 3) of the present dissertation, the ELAs showed different EMRs according to the strains. The virulence classification of the E. faecalis strains used in the present dissertation was the classification previously reported by Rudolph (2004), i.e., the strains with an EMR below $40 \%$ were considered avirulent, above $80 \%$ virulent strains and between $40 \%$ and $80 \%$ were classified as strains of moderate virulence (Figure 3.3.). However, Wooley et al. (2000) classified the E. coli strains with an EMR below $10 \%$ as avirulent, above $29 \%$ as virulent strains and between $10 \%$ and $29 \%$ as strains of moderate virulence according to the clinical cases of colibacillosis, and reported that commensal E. coli strains produced lower EMR. Seo et al. (2013) used this same classification to sort $R$. anatipestifer strains. However, these authors observed that some strains isolated from clinically normal ducks were classified through the ELA as moderate 
virulence strains and, therefore, suggest the evaluation of these strains by the duck lethality assay. Similar finding were obtained in the present dissertation. As shown in Figure 3.2., no clear relationship was observed among the clinical signs observed in the chickens and the virulence obtained through the ELA, which could be partially explained by the infectious dose used. The $\mathrm{LD}_{50}$ of the E. faecalis strain K923/96 was used to evaluate the virulence degree of all other strains, which does not mean that this infectious dose is able to kill half of the embryos with another E. faecalis strain. Therefore, although the $\mathrm{LD}_{50}$ of each strain was not assayed, it might be different for each one. The $\mathrm{LD}_{50}$ estimated in the present dissertation should be considered as an infectious dose of reference.

As shown in Figure 3.5., the embryos infected with avirulent strains had less probability of dying than the embryos infected with more virulent strains. Jung et al. (2017) also observed that virulent E. cecorum strains of different animal species isolated from clinical signs and/or pathological changes produced significantly higher EMR than avirulent strains. However, these authors did not observed differences among the avirulent and virulent strains identified through the Matrix-Assisted Linear Desorption/Ionization Time-Of-Flight Mass Spectrometry (MALDI-TOF MS), neither by using 16S-rRNA-gene sequencing and either by the detection of the fatty acid composition by gas chromatography. As shown in Figure 3.2., E. faecalis strains with different pathogenic degree estimated in the present dissertation through the ELA were also not clearly clustered by the ERIC-PCR in accordance with Eaton \& Gasson (2001), who reported that the molecular taxonomy of Enterococcus spp. might not lead to a differentiation between avirulent and virulent strains. Nevertheless, ERICPCR revealed a considerable genetic diversity among avian E. faecalis strains in accordance with the results of Jurkovič et al. (2007) and Bachtiar et al. (2015), and, therefore, it can be applied successfully and be useful to obtain the genetic distribution and epidemiology of $E$. faecalis strains. 
Virulence of the Enteroccoci still cannot be fully explained because they are considered commensals pathogen of the endogenous intestinal microflora of humans and birds and, as such, have subtle virulence traits that are not easily identified. As revised by Eaton \& Gasson (2001), this bacterium possesses virulence traits such as adherence and invasion of tissues and abscess formation, modulation of host inflammatory responses, and secretion of toxic products. The molecular typing methods have identified several STs within the $E$. faecalis population associated with different human and avian diseases. Although different STs have been related with AA in poultry, the ST82 has been specifically related with this disease worldwide (Petersen et al., 2007). As shown in Figure 3.2, the results obtained did not show a clear relationship between the ST 82 and the virulence degree since $22 \%$ and $67 \%$ of the E. faecalis strain classified as avirulent and moderate virulence, respectively, were ST82. Although all virulent strains were ST82, they only represent the $10 \%$ of all strains that contained the ST82. On the contrary, $78 \%$ from the 18 E. faecalis strains with absence of ST82 were classified as avirulent and $22 \%$ as strains of moderate virulence. However, it seems that the ERIC-PCR tended to cluster the strains regarding the ST82, as shown in Figure 3.2.

Additionally, Eaton \& Gasson (2001) reported that there is a risk that an avirulent strain of Enterococci that lacks of virulence genes could acquire them by conjugation since some virulence genes are associated with highly transmissible plasmids. Skyberg et al. (2003) reported that there seems to be a relationship between the virulence of E. coli strains for embryos and the number of genes present in the strains, which is in contrast with the results obtained by Jung et al. (2017), who did not find significantly more virulence genes in the virulent E. cecorum strains than avirulent strains. The results obtained in the present dissertation neither show a clear relationship between the pathogenicity of the strains and their virulence genes since all strains used in the present dissertation showed the same profile of 
virulence genes and produced however different virulence degree through the ELA. These findings suggest that the virulence genes are not the only cause of virulence and more investigations are therefore required to determine the role of the virulence genes and STs in the virulence of the E. faecalis strains. It is possible that a thorough analysis of a representative number of avirulent and virulent strains using the whole genome sequencing shows significant differences and maybe also new putative virulence factors.

\subsubsection{Genetic variation in susceptibility to $E$. faecalis infection}

The ELA with avian E. faecalis field strains was first carried out on white fertilized eggs because the candle is pretty easier and requires less labour intensive to see the embryos in white eggs than in brown eggs. However, AA has never been reported in field cases in white layer breeds and they are more resistant to induced AA than brown layers according to Ovelgönne et al. (2001). Therefore, the genetic selection to reduce susceptibility to E. faecalis would make sense for brown layer chickens. In this regard, a preliminary study with brown fertilized embryos was carried out under the hypothesis that chicken embryos of brown layers would be less resistant to E. faecalis infection compared with embryos of white layers when they are infected with the same strain and infectious dose.

The results obtained in the preliminary study of the Experiment 3 (Chapter 4) support this hypothesis. In accordance with the results of the Experiment 1 (Chapter 2) (Table 2.2.), the infectious dose in brown embryos used in the preliminary study of the Experiment 3 (Chapter 4) also showed a significant effect on the EMR (Table 4.1.). However, the infectious doses of 5 and $2.5 \mathrm{CFU} / \mathrm{ml}$ differed significantly from each other in contrast with the results of the Experiment 1 (Chapter 2) with white layers. The EMR of the brown embryos was higher than of the white embryos, even when the experiment duration was shorter. The EMR of the brown embryos was $83 \%$ with the infectious dose of $5 \mathrm{CFU} / \mathrm{ml}$ and $69 \%$ with 2.5 
$\mathrm{CFU} / \mathrm{ml}$ while the EMR of the white embryos was $45 \%$ with the infectious dose of $5 \mathrm{CFU} / \mathrm{ml}$ and $43 \%$ with $2.5 \mathrm{CFU} / \mathrm{ml}$. These results prove genetic variation in susceptibility to $E$. faecalis infection between brown and white breed layers.

\subsubsection{Genetic selection against susceptibility to $E$. faecalis infection}

Breeding for disease resistance in poultry such as Marek's disease, avian leukosis viruses, salmonellosis and colibacillosis has been researched. However, to my knowledge, this is the first time that breeding for resistance to E. faecalis infection has been assessed. In accordance with the estimated heritabilities for resistance to different diseases, the estimated heritability for embryonic survivability in the present dissertation $\left(\mathrm{h}^{2}=0.17-0.20\right.$, depending on the model used) shows that selection for more resistant laying hens against E. faecalis infection is feasible (Table 4.4.). Besides, the average EMR obtained per family during the three ELAs showed a standard deviation of 23\%, as shown in Figure 4.1. Genetic selection for resistance to E. faecalis infection will contribute to the reduction of the incidence of AA, the disease-related costs, decrease the consumption of antibiotics, and will improve the welfare of the future layers produced. However, it should be taken into account the estimated correlations between embryonic survivability and other economical important traits because it allows prediction of the extent to which selection for increased resistance will reduce the gain in the other criteria.

As shown in Table 4.5., favourable genetic correlations were found between embryonic survivability and EW $\left(r_{\mathrm{g}}=+0.16\right)$, as well as with the egg production at the beginning of the lay $\left(r_{g}=+0.31\right)$, but not with BS $\left(r_{g}=-0.48\right.$ to -0.30$)$, the egg production at peak of lay $\left(r_{g}=-0.69\right)$ and at the end of the egg production $\left(r_{g}=-0.55\right)$. Besides, no genetic correlation with BW $\left(r_{g}=-0.04\right)$ and $K_{d y n}\left(r_{g}=-0.05\right)$ was found. 
Selection for disease resistance based on adult avian challenge assays may not be feasible by the need of test an excessive number of breeders on the pedigree population. Therefore, marker gene(s) of resistance or gene itself has been proposed as the most promising research area, which could be assessed from a blood sample by molecular analysis. Cavero et al. (2009) reported that information on genetic markers will avoid the inconvenience of experimental challenges and it could be done before production traits are measured, even in pure-line pedigree stocks. However, very little is known to date about the effects of the genes involved in resistance to poultry diseases and genetic resistance to the majority of poultry diseases is usually controlled by many genes as well as influenced by environmental conditions (Beaumont et al., 2003), which makes it difficult for practical implementation. In this regard, the results obtained from the ELA could be used to try to find markers related to resistance to E. faecalis. Besides, embryos of pure-line pedigree stocks could be tested and selected without subjecting breeding stock to disease conditions.

It should be noted that the Experiment 3 (Chapter 4) was done with a single virulent $E$. faecalis strain. However, many other different strains of E. faecalis have been isolated from AA field outbreaks, as shown in Figure 3.2. Therefore, the lower susceptibility to one strain does not automatically mean a general improvement in immune response against all strains, but rather to a limited range of them. Besides, the economic importance of bacterial diseases as whole is much higher than of E. faecalis infection alone and, therefore, it would be important to know whether selection against E. faecalis infection alters susceptibility against other pathogens.

In summary, it has been demonstrated that it is possible to breed for E. faecalis infection resistance through the ELA although the relationship between E. faecalis resistance and some economically important traits should be take into account to achieve a balanced 
genetic progress. The implementation of selection against susceptibility to E. faecalis infection in practice will require that breeding company is convinced that AA is of significant economic importance, which depends on disease incidence, production costs and losses associated with sick and/or dead chicks, in addition to welfare and food safety concerns of consumers. 
- 124 - 


\subsection{FINAL CONCLUSIONS}

The general conclusions of the present dissertation are summarized as follow:

- Virulence characterization of avian E. faecalis field isolates allows us to know the risk that the strains represent and provide valuable information, which can be important for the selection of isolated for the production of vaccines. The ERIC-PCR can be applied successfully to obtain the genetic distribution and epidemiology of E. faecalis strains.

- The estimated heritability for susceptibility to the infection by E. faecalis was $\mathrm{h}^{2}=0.17$ 0.20, depending on the model used, indicating that the selection for increased resistance to E. faecalis infection is feasible.

- The ELA can be considered a reliable and useful tool to evaluate the virulence of avian $E$. faecalis strains by using the EMR as well as to select more resistant laying hens against $E$. faecalis infection, which can be used as alternative model to replace the adult avian challenge assays. It is important to determine an appropriate infectious dose which should not be too high to avoid a massive embryonic mortality. The obtained $\mathrm{LD}_{50}$ of the $E$. faecalis strain K923/96 can be used as reference in further ELAs on E. faecalis virulence and the ELA can be optimized by reducing the time of study until four days p.i. 
- 126 - 


\subsection{SUGGESTIONS FOR FURTHER RESEARCHES}

Although major progress in the understanding of AA has been gained in the last twenty years, the present dissertation revealed the lack of knowledge about it and the pathogenesis of E. faecalis associated disease. Besides, based on the results of the current dissertation and given the economic importance of AA, as well the animal welfare concerns, I would like to suggest some ideas for further research:

- Evaluate the effects of different agents on the treatment of AA and clarify if the amyloid deposits are really irreversible.

- Investigate the role of different agents involved in the pathogenesis of AA, such as the cytokines or ILs.

- Quantitative studies of the extrahepatic production of SAA, which may act as nidus of amyloid fibrils, to investigate the possibility that the synoviocytes of brown layers might proliferate more strongly than the synoviocytes of white layers.

- Study the grow rate of different species of Enterococcus during the ELAs in order to known if the ability of the strain to produce embryonic disease or death is related with their capacity to replicate in ovo after the inoculation.

- Determine the role of the virulence genes and STs in the virulence of the avian E. faecalis field strains as well as to clarify whether the STs are normal inhabitants of the gastrointestinal tract or represent a genuine zoonosis.

- Develop autogenous vaccines from proven high pathogenic avian E. faecalis strains.

- Investigate whether selection against $E$. faecalis infection alters susceptibility against other pathogens. 
- 128 - 


\section{ETHICAL STATEMENT}

Avian embryos are currently not regulated by legislation as animal experiments in Germany (https://www.gesetze-im-internet.de/tierschg/BJNR012770972.html) and, therefore, an approval from an ethics committee was not required for this thesis. Besides, all ELAs developed in the present dissertation were finished four and seven days prior to hatching, on developmental day 17 and 14, respectively. 
- 130 - 


\section{BIBLIOGRAPHY}

ABBAS, A. K. (2005). Diseases of immunity. Robbins and Cotran Pathologic Basis of Disease, 7: 205-218.

AHMADPANAH, J., GHAVI HOSSEIN-ZADEH, N., SHADPARVAR, A. A. \& PAKDEL, A. (2017). Genetic parameters of body weight and ascites in broilers: effect of different incidence rates of ascites syndrome. British Poultry Science, 58(1): $32-39$.

ANDERSSON, C., GRIPENLAND, J. \& JOHANSSON, J. (2015). Using the chicken embryo to assess virulence of Listeria monocytogenes and to model other microbial infections. Nature Protocols, 10(8): 1155-1164.

ARTHUR, J. A., \& ALBERS, G. A. (2003). Industrial perspective on problems and issues associated with poultry breeding. Poultry Genetics, Breeding and Biotechnology, 1-12.

BACHTIAR, E. W., BACHTIAR, B. M., DEWIYANI, S., AKBAR, S. \& SURONO AKBAR, S. M. (2015). Enterococcus faecalis with capsule polysaccharides type 2 and biofilm-forming capacity in Indonesians requiring endodontic treatment. Journal of Investigative and Clinical Dentistry, 6(3): 197-205.

BAIN, M. M. (2005). Recent advances in the assessment of eggshell quality and their future application. World's Poultry Science Journal, 61(2):268-277.

BAIN, M. M., DUNN, I. C., WILSON, P. W., JOSEPH, N., DE KETELAERE, B., DE BAERDEMAEKER, J. \& WADDINGTON, D. (2006). Probability of an egg cracking during packing can be predicted using a simple nondestructive acoustic test. British Poultry Science, 47(4):462-469. 
BAUTISTA JIMENEZ, V., VAN ECK, J.H., TOOTEN, P.C. \& UPRAGARIN, N. (2009). A case study: Amyloid arthropathy in silver chickens. USM R\&D Journal, 17(1): $1-7$.

BEAUMONT, C., DAMBRINe, G., CHAUSSÉ, A. M. \& FLOCK, D. (2003). Selection for disease resistance: conventional breeding for resistance to bacteria and viruses. Poultry Genetics, Breeding and Biotechnology, 357-384.

BERNDT, A. \& METHNER, U. (2001). Gamma/delta T cell response of chickens after oral administration of attenuated and non-attenuated Salmonella typhimurium strains. Veterinary Immunology and Immunopathology, 78(2): 143-161.

BERTHELOT, F., BEAUMONT, C., MOMPART, F., GIRARD-SANTOSUOSSO, O., PARDON, P. \& DUCHET-SUCHAUX, M. (1998). Estimated heritability of the resistance to cecal carrier state of Salmonella enteritidis in chickens. Poultry Science, 77(6): 797-801.

BORST, L. B., SUYEMOTO, M. M., KEELARA, S., DUNNINGAN, S. E., GUY, J. S. \& BARNES, H. J. (2014). A Chicken Embryo Lethality Assay for Pathogenic Enterococcus cecorum. Avian Diseases, 58(2): 244-248.

CAVERO, D., SCHMUTZ, M., PHILIPP, H. C. \& PREISINGER, R. (2009). Breeding to reduce susceptibility to Escherichia coli in layers. Poultry Science, 88(10): 2063-2068.

CHADField, M. S., CHRISTEnSEN, J. P., CHRISTENSEN, H. \& BISGAARD, M. (2004). Characterization of streptococci and enterococci associated with septicaemia in broiler parents with a high prevalence of endocarditis. Avian Pathology, 33(6): 610617. 
CIFTCI, A. \& DIKER K.S. (2009). The role of enterococcal virulence factors on experimental amyloid arthropathy in chickens. Kafkas Üniversitesi Veteriner Fakültesi Dergisi, 15(6): 903-908.

COBURN, P. S., BAghdAYAN, A. S., DOLAN, G. T. \& SHANKAR, N. (2007). Horizontal transfer of virulence genes encoded on the Enterococcus faecalis pathogenicity island. Molecular Microbiology, 63(2): 530-544.

DEMBER L.M. (2005). Emerging treatment approaches for the systemic amyloidosis. Kidney International, 68(3): 1377-1390.

DEMBER, L. M. (2006). Amyloidosis-associated kidney disease. Journal of the American Society of Nephrology, 17(12): 3458-3471.

EATON, T. J. \& GASSON, M. J. (2001). Molecular Screening of Enterococcus Virulence Determinants and Potential for Genetic Exchange between Food and Medical Isolates. Applied and Environmental Microbiology, 67(4): 1628-1635.

EUROPEAN COMMISSION (EC). (2013). Seventh Report on the Statistics on the Number of Animals used for Experimental and other Scientific Purposes in the Member States of the European Union $\operatorname{COM(2013)~} 859$ final. Brussels. Report from the Commission to the Council and the European Parliament. (EC).

FAO (2003). World agriculture: towards 2015/2030: an FAO perspective. Bruinsma, J. (Ed.). Earthscan.

FELSENSTEIN J. (2005) PHYLIP (Phylogeny Inference Package) Version 3.695 Distributed by the author. Department of Genome Sciences, University of Washington. Seattle. 
FERTNER, M., OLSEN, R., BISGAARD M. \& CHRISTENSEN, H. (2011). Transmission and genetic diversity of Enterococcus faecalis among layer chickens during hatch. Acta Veterinaria Scandinavica, 53(1):56.

FISHER, K. \& PHILLIPS, C. (2009). The ecology, epidemiology and virulence of Enterococcus. Microbiology, 155(6): 1749-1757.

Freitas, A. R., NOVAIS, C., RUIZ-GARBAJOSA, P., COQUE, T. M. \& PEIXE, L. (2009). Clonal expansion within clonal complex 2 and spread of vancomycin-resistant plasmids among different genetic lineages of Enterococcus faecalis from Portugal. Journal of Antimicrobial Chemotherapy, 63(6): 1104-1111.

GAVORA, J. S., SPENCER, J. L., GRUNDER, A. A., ROBERTSON, A., \& SPECKMANN, G. W. (1974). Genetic resistance to Marek's disease (MD): response of strains and inbred lines to challenge with JM-V tumor cells or the BC-1 isolate of MD virus. In 15th World's Poultry Congress. New Orleans, La., Proc. and Abstr (pp. 255-257).

GIBBS, P. S., MAURER, J. J., NOLAN, L. K. \& WOOLEY, R. E. (2003). Prediction of chicken embryo lethality with the avian Escherichia coli traits complement resistance, colicin $\mathrm{V}$ production, and presence of the increased serum survival gene cluster (iss). Avian Diseases, 47(2): 370-379.

GIBBS, P. S. \& WOOLEY, R. E. (2003). Comparison of the intravenous chicken challenge method with the embryo lethality assay for studies in avian colibacillosis. Avian Diseases, 47(3): 672-680.

GILMOUR, A. R., GOGEL, B. J.. CULLIS, B. R., WELHAM, S. J. \& THOMPSON, R. (1998). ASReml User Guide Release .1.0. NSW Agriculture, Orange, Australia. 
GREEF, K. H., GERRITSEN, C. L. M. \& OLDENBROEK, J. K. (1998). Within and between line variation in ascites related traits in broilers. In Proceedings of the 6th World Congress on Genetics Applied to Livestock Production (Vol. 24, pp. 267-270).

GregerSen, R.H., PETERSEN, A., CHRISTENSEN H. \& BISGAARD, M. (2010). Multilocus sequence typing of Enterococcus faecalis isolates demonstrating different lesion types in broiler breeders. Avian Pathology, 39(6): 435-440.

GRUYS, E., TOUSSAINT, M. J. M., NIEWOLD, T. A. \& KOOPMANS, S. J. (2005). Review: Acute phase reaction and acute phase proteins. Journal of Zhejiang University. Science, 6(11): 1045.

HAN, M. V. \& ZMASEK, C. M. (2009). PhyloXML: XML for evolutionary biology and comparative genomics. BMC Bioinformatics, 10(1): 356.

HAN, P. F. S., \& SMYTH JR, J. R. (1972). The influence of growth rate on the development of Marek's disease in chickens. Poultry Science, 51(3): 975-985.

HAWKEN, R. J., BEATTIE, C. W. \& SCHOOK, L. B. (1998). Resolving the genetics of resistance to infectious diseases. Revue cientifique et Technique (Office International des Epizooties), 17(1): 17-25.

HAYeS, J. R., ENGliSh, L. L., CARTER, P. J., PROESCHOLDT, T., LEE, K. Y., WAGNER, D. D. \& WHITE, D. G. (2003). Prevalence and antimicrobial resistance of Enterococcus species isolated from retail meats. Applied and Environmental Microbiology, 69(12): 7153-7160. 
JACOBSEN, I. D., GROßE, K., SLESIONA, S., HUBE, B., BERNDT, A. \& BROCK, M. (2010). Embryonated eggs as an alternative infection model to investigate Aspergillus fumigatus virulence. Infection and Immunity, 78(7): 2995-3006.

JANSS, L. L. \& BOLDER, N. M. (2000). Heritabilities of and genetic relationships between Salmonella resistance traits in broilers. Journal of Animal Science, 78(9): 2287-2291.

JIE, H., \& LIU, Y. P. (2011). Breeding for disease resistance in poultry: opportunities with challenges. World's Poultry Science Journal, 67(4): 687-696.

JUNG, A., METZNER, M. \& RYLL, M. (2017). Comparison of pathogenic and nonpathogenic Enterococcus cecorum strains from different animal species. BMC microbiology, 17(1): 33 .

JURKOVIČ, D., KRIŽKOVÁ, L., SOJKA, M., TAKÁČOVÁ, M., DUŠINSKÝ, R., KRAJČOVIČ, J., VANDAMME, P. \& VANCANNEYT, M. (2007). Genetic diversity of Enterococcus faecium isolated from Bryndza cheese. International Journal of Food Microbiology, 116(1): 82-87.

KANATA, I. B. I., MURAKAMI, T., GODA, W. M., KOBAYASHI, N., ISHIGURO, N. \& YANAI, T. (2015). Prevalence of amyloid deposition in mature healthy chickens in the flock that previously had outbreaks of vaccine-associated amyloidosis. Journal of Veterinary Medical Science, 77(10): 1241-1245.

KISILEVSKY, R. \& MANLEY, P.N. (2012). Acute-phase serum amyloid A: perspectives on its physiological and pathological roles. Amyloid, 19(1): 5-14. 
KUHNLEIN, U., AGGREY, S.E. \& ZADWORNY, D. (2003). Progress and prospects in resistance to Disease. Pages 283-292 in Poultry Genetics, Breeding, and Biotechnology. Muir, W. M., \& Aggrey, S. E. (Eds.). CABI.

LAMONT, S. J. (1998). Impact of genetics on disease resistance. Poultry Science, 77(8): 1111-1118.

LANDMAN, W. J. M., GRAYS, E. \& DWARS, R. M. (1994). A syndrome associated with growth depression and amyloid arthropathy in layers: a preliminary report. Avian Pathology, 23(3): 461-470.

LANDMAN, W. J. M., PEPERKAMP, N. H., KOCH, C. A., TOOTEN, P. C. P., CRAUWELS, A. \& GRUYS, E. (1997). Induction of amyloid arthropathy in chickens. Amyloid, 4(2): 87-97.

LANDMAN, W. J. M., GRUYS, E. \& GIELKENS, A. L. J. (1998a). Avian amyloidosis. Avian Pathology, 27(5): 437-449.

LANDMAN, W. J. M., VAN DEN BOGAARD, A. E. J. M., DOONENBAL, P., TOOTEN, P. C. J., ELBERS, A. R. W. \& GRUYS, E. (1998b). The role of various agents in chicken amyloid arthropathy. Amyloid: The International Journal of Experimental and Clinical Investigation, 5(4): 266-278.

LANDMAN, W. J. M. (1999). Amyloid arthropathy in chickens: (Summary of thesis, Utrecht University, faculty of veterinary medicine, 1998). Veterinary Quarterly, 21(3): 78-82. 
LANDMAN, W. J. M., MEKKES, D. R., CHAMANZA, R., DOORNENBAL, P. \& GRUYS, E. (1999a). Arthropathic and amyloidogenic Enterococcus faecalis infections in brown layers: a study on infection routes. Avian Pathology, 28(6): 545557.

LANDMAN, W. J. M., FEBERWEE, A., MEKKES, D. R., VELDMAN, K. T. \& MEVIUS, D. J. (1999b). A study on the vertical transmission of arthropathic and amyloidogenic Enterococcus faecalis. Avian Pathology, 28(6): 559-566.

LANDMAN, W. J. M., VELDMAN, K. T., MEVIUS, D. J. \& DOORNENBAL, P. (2000). Contamination of Marek's disease vaccine suspensions with Enterococcus faecalis and its possible role in amyloid arthropathy. Avian Pathology, 29(1): 21-25.

LANDMAN, W. J. M., FEBERWEE, A., VELDMAN, K. T. \& MEVIUS, D. J. (2001). Epidemiology: Study on the vertical transmission of arthropathic and amyloidogenic Enterococcus faecalis in a flock of brown layer chickens. Veterinary Quarterly, 23(2): 88-91.

LANDMAN, W. J. M. \& FEBERWEE, A. (2001). Field studies on the association between amyloid arthropathy and Mycoplasma synoviae infection, and experimental reproduction of the condition in brown layers. Avian Pathology, 30(6): 629-639.

LANDMAN, W. J. M, VELDMAN, K. T., MEVIUS, D. J. \& VAN ECK, J. H. H. (2003). Investigations of Enterococcus faecalis-induced bacteraemia in brown layer pullets through different inoculation routes in relation to the production of arthritis. Avian Pathology, 32(5): 463-471. 
LEUNG, K. T., MACKERETH, R., TIEN, Y. \& TOPP, E. (2004). A comparison of AFLP and ERIC-PCR analyses for discriminating Escherichia coli from cattle, pig and human sources. FEMS Microbiology Ecology, 47(1):111-119.

LILLEHOJ, H. S. (1994). Analysis of Eimeria acervulina-induced changes in the intestinal T lymphocyte subpopulations in two chicken strains showing different levels of susceptibility to coccidiosis. Research in Veterinary Science, 56(1): 1-7.

LITTELL, R., MILLIKEN, G., STROUP, W. \& WOLFINGER, R. (1999). SAS System for Mixed Models. Raleigh, NC: SAS Institute.

MCBRIDE, S. M., FISCHETTI, V. A., LEBLANC, D. J., MOELLERING JR, R. C. \& GILMORE, M. S. (2007). Genetic diversity among Enterococcus faecalis. PloS one, 2(7): e582.

MOGHADAM, H. K., MCMILLAN, I., CHAMBERS, J. R. \& JULIAN, R. J. (2001). Estimation of genetic parameters for ascites syndrome in broiler chickens. Poultry Science, 80(7): 844-848.

MONTGOMERY, R. D., JONES, L. S., BOYLE, C. R., LUO, Y. \& BOYLE, J. A. (2005). The embryo lethality of Escherichia coli isolates and its relationship to various in vitro attributes. Avian Diseases, 49(1): 63-69.

MORENO, A. M., PAIXÃO, R., MORENO, L. Z., DE GOBBI, D. D. S., RAIMUNDO, D. C., FERREIRA, T. S. P., HOFER, E., MATTE, M. H. \& MORENO, M. (2013). Molecular epidemiology of Listeria monocytogenes isolated from different sources in Brazil. Brazilian Journal of Veterinary Research and Animal Science, 50(2): 136-144. 
MULTI LOCUS SEQUENCE TYPING WEBSITE (http://www.mlst.net) at Imperial College, London, United Kingdom, developed by Man-Suen Chan and David Aanensen and funded by the Wellcome Trust.

NIX, E. B., CHEUNG, K. K., WANG, D., ZHANG, N., BURKE, R. D. \& NANO, F. E. (2006). Virulence of Francisella spp. in chicken embryos. Infection and Immunity, 74(8): 4809-4816.

ODINOT, P. T., MEIS, J. F. G. M., VAN DEN HURK, P. J. J. C., HOOGKAMPKORSTANJE, J. A. A. \& MELCHERS, W. J. G. (1995). PCR-based characterization of Yersinia enterocolitica: comparison with biotyping and serotyping. Epidemiology and Infection, 115(2): 269-277.

OH, J. Y., KANG, M. S., YOON, H., CHOI, H. W., AN, B. K., SHIN, E. G., KIM, Y. J. KWON, J. H. \& KWON, Y. K. (2012). The embryo lethality of Escherichia coli isolates and its relationship to the presence of virulence-associated genes. Poultry Science, 91(2): 370-375.

OLSEN, R. H., SCHØNHEYDER, H. C., CHRISTENSEN, H. \& BISGAARD, M. (2012a). Enterococcus faecalis of human and poultry origin share virulence genes supporting the zoonotic potential of E. faecalis. Zoonoses and Public Health, 59(4): 256-263.

OlSEN, R. H., FRANTzen, C., CHRISTEnSEN, H. \& BISGAARD, M. (2012b). An investigation on first-week mortality in layers. Avian Diseases, 56(1): 51-57.

OLSEN, R.H., CHRISTENSEN, H. \& BISGAARD, M. (2012c). Transmission and genetic diversity of Enterococcus faecalis during hatch of broiler chicks. Veterinary Microbiology, 160(1): 214-221. 
OVELGÖNNE, J. H., LANDMAN, W. J. M., GRUYS, E., GIELKENS, A. L. J. \& PEETERS, B. P. H. (2001). Identical amyloid precursor proteins in two breeds of chickens which differ in susceptibility to develop amyloid arthropathy. Amyloid, 8(1): $41-51$

PEPERKAMP, N. H. M. T., LANDMAN, W. J. M., TOOTEN, P. C. J., ULTEE, A., VOORHOUT, W. F. \& GRUYS, E. (1997). Light microscopic, immunohistochemical, and electron microscopic features of amyloid arthropathy in chickens. Veterinary Pathology Online, 34(4): 271-278.

PETERSEN, A., CHRISTENSEN, H. \& BISGAARD M. (2007). Investigations on the existence of a global clone of Enterococcus faecalis associated with amyloid arthropathy in chickens. In: The Congress and Exhibition of the World Veterinary Poultry Association, Beijing, China.

Petersen, A., CHADfield, M. S., Christensen, J. P., CHRistensen, H. \& BISGAARD, M. (2008). Characterization of small-colony variants of Enterococcus faecalis isolated from chickens with amyloid arthropathy. Journal of Clinical Microbiology, 46(8): 2686-2691.

Petersen, A., CHRistensen, H., PHILIPP, H. C. \& BISGAARD, M. (2009). Clonality of Enterococcus faecalis associated with amyloid arthropathy in chickens evaluated by multilocus sequence typing (MLST). Veterinary Microbiology, 134(3): 392-395.

PETERSEN, A., BISGAARD M. \& CHRISTENSEN, H. (2010). Real-time PCR detection of Enterococcus faecalis associated with amyloid arthropathy. Letters in Applied Microbiology, 51(1): 61-64. 
PICKEN, M. M. (2007). New insights into systemic amyloidosis: the importance of diagnosis of specific type. Current Opinion in Nephrology and Hypertension, 16(3): 196-203.

POLAKOWSKA, K., LIS, M. W., HELBIN, W. M., DUBIN, G., DUBIN, A., NIEDZIOLKA, J. W., MIEDZOBRODZKI, J. \& WLADYKA, B. (2012). The virulence of Staphylococcus aureus correlates with strain genotype in a chicken embryo model but not a nematode model. Microbes and Infection, 14(14): 1352-1362.

RUDOLPH, B. (2004). Variations Investigations to Enterococcus faecalis as possible factor for etiology of amyloid arthropathy of brown layers. PhD Thesis. Journal-Nr. 2846. Freie Universität, Berlin, Germany.

SAS INSTITUTE INC. (2011). SAS/STAT 9.3 User's Guide. Cary, NC. SAS Institute Inc..

SAVA, I. G., HEIKENS, E. \& HUEBNER, J. (2010). Pathogenesis and immunity in enterococcal infections. Clinical Microbiology and Infection, 16(6): 533-540.

SEO, H. S., CHA, S. Y., KANG, M. \& JANG, H. K. (2013). Chicken embryo lethality assay for determining the virulence of Riemerella anatipestifer isolates. Avian Pathology, 42(4): 387-392.

SEVIMLI, A., MISIRLIOĞLU, D., POLAT, Ü., YALÇIN, M., AKKOÇ, A. \& UGUZ, C. (2005). The effects of vitamin A, pentoxyfylline and methylprednisolone on experimentally induced amyloid arthropathy in brown layer chicks. Avian Pathology, 34(2): 143-149. 
SEVIMLI, A., MISIRLIOĞLU, D., YALÇIN, M., BÜLBÜL, A., YILMAZTEPE, A. \& ALTUNBAS, K. (2008). The role of chicken IL-1 $\beta$, IL-6 and TNF- $\alpha$ in the occurrence of amyloid arthropathy. Veterinary Research Communications, 32(7): 499-508.

SEVIMLI, A., BÜBÜL, T., BULÜBÜL, A. \& YAĞCI, A. (2013). Chicken amyloid arthropathy: serum amyloid A, interleukin-1 $\beta$, interleukin- 6 , tumour necrosis factor- $\alpha$ and nitric oxide profile in acute phase (12th hour). Polish Journal of Veterinary Sciences, 16(2): 241-247.

SHTRASBURG, S., PRAS, M., RABINOVICH, E., GAL, R., LIVNEH, A. \& LIDAR, M. (2012). Attempts at suppression of amyloidogenesis in a mouse model by a variety of anti-inflammatory agents. Autoimmunity Reviews, 12(1): 18-21.

SIPE, J. D., BENSON, M. D., BUXBAUM, J. N., IKEDA, S. I., MERLINI, G., SARAIVA, M. J. \& WESTERMARK, P. (2014). Nomenclature 2014: amyloid fibril proteins and clinical classification of the amyloidosis. Amyloid, 21(4): 221-224.

SKYBERG, J. A., HORNE, S. M., GIDDINGS, C. W., WOOLEY, R. E., GIBBS, P. S. \& NOLAN, L. K. (2003). Characterizing avian Escherichia coli isolates with multiplex polymerase chain reaction. Avian Diseases, 47(4): 1441-1447.

SNYDER, P. W. (2007). "Diseases of immunity: amyloidosis." In: Pathologic Basis of Veterinary Diseases, $4^{\text {th }}$ Edit. Mosby, St. Louis 246-251.

SPENCER, J. L., GAVORA, J. S., \& GOWE, R. S. (1979). Effect of selection for high egg production in chickens on shedding of lymphoid leukosis virus and gs antigen into eggs. Poultry Science, 58(2): 279-284 
STEENTJES, A., VELDMAN, K. T., MEVIUS, D. J. \& LANDMAN, W. J. M. (2002). Molecular epidemiology of unilateral amyloid arthropathy in broiler breeders associated with Enterococcus faecalis. Avian Pathology, 31(1): 31-39.

STEPHAN G. THAYER, W., WALTMAN, D. \& WAGES, D. P. (2008). Streptococcus and Enterococcus. Pages 900 - 908 in Diseases of Poultry. Saif, F., Glisson, M., Nolan, L. K., \& David, E. S. Ed. 12th Edition. Blackwell Publishing Professional.

STEWART-TUlL, D. E. S., COOTE, J. G., THOMPSON, D. H., CANDLISH, D., WARDLAW, A. C. \& CANDLISH, A. (2009). Virulence spectra of typed strains of Campylobacter jejuni from different sources: a blinded in vivo study. Journal of Medical Microbiology, 58(5): 546-553.

TANKSON, J. D., THAXTON, J. P. \& VIZZIER-THAXTON, Y. (2001). Pulmonary hypertension syndrome in broilers caused by Enterococcus faecalis. Infection and Immunity, 69(10): 6318-6322.

TOWNSEND, M. K., CARR, N. J., IYER, J. G., HORNE, S. M., GIBBS, P. S. \& PRÜß, B. M. (2008). Pleiotropic phenotypes of a Yersinia enterocolitica flhD mutant include reduced lethality in a chicken embryo model. BMC microbiology, 8(1): 1-12.

UPRAGARIN, N., LANDMAN, W. J. M., GAASTRA, W. \& GRUYS, E. (2005). Extrahepatic production of acute phase serum amyloid A. Histology and Histopathology, 20(4): 1295-1307.

WARNER, C. M., MEEKER, D. L., \& ROTHSCHILD, M. F. (1987). Genetic control of immune responsiveness: a review of its use as a tool for selection for disease resistance. Journal of Animal Science, 64(2): 394-406. 
WESTERMARK, P. (2005). Aspects on human amyloid forms and their fibril polypeptides. Febs Journal, 272(23): 5942-5949.

WOLDEMESKEL, M. (2012). A concise review of amyloidosis in animals. Veterinary medicine international.

WOOLEY, R., GIBBS, P., BROWN, T. \& MAURER, J. (2000). Chicken embryo lethality assay for determing the virulence status of avian Escherischia coli isolates. Avian Diseases, 44(2): 318-324.

WORLD HEALTH ORGANIZATION. (2011). Tackling antibiotic resistance from a food safety perspective in Europe. World Health Organization, 2011. Rome, Italy.

WORLD HEALTH ORGANIZATION. (2012). The evolving threat of antimicrobial resistance: options for action. World Health Organization, 2012. Geneva, Switzerland.

ZEKARIAS, B., LANDMAN, W. J. M., TOOTEN, P. C. \& GRUYS, E. (2000). Leukocyte responses in two breeds of layer chicken that differ in susceptibility to induced amyloid arthropathy. Veterinary Immunology and Immunopathology, 77(1): 55-69.

ZEKARIAS, B., TER HUURNE, A. A., LANDMAN, W. J., REBEL, J. M., POL, J. M. \& GRUYS, E. (2002). Immunological basis of differences in disease resistance in the chicken. Veterinary Research, 33(2): 109-125.

ZULKIFLI, Y., ALITHEEN, N. B., SON, R., RAHA, A. R., SAMUEL, L., YEAP, S. K. \& NISHIBUCHI, M. (2009). Random amplified polymorphic DNA-PCR and ERIC PCR analysis on Vibrio parahaemolyticus isolated from cockles in Padang, Indonesia. International Food Research Journal, 16(2), 141-150. 
- 146 - 